\title{
CONSIDERATIONS FOR REPRODUCTIVE MANAGEMENT OF BOS INDICUS-INFLUENCED BEEF HEIFERS
}

\author{
A Thesis Presented to \\ the Faculty of the Graduate School \\ at the University of Missouri
}

In Partial Fulfillment

of the Requirements for the

Degree Master of Science

by

JAMES WILLIAM CAMERON LOCKE

Dr. David J. Patterson, Thesis Advisor

DECEMBER 2017 


\section{DEDICATION}

This work is dedicated to my family, who, many times didn't know what state I was in or when I'd be home, but knew I was doing something I enjoyed. 


\section{ACKNOWLEDGEMENTS}

While contemplating being a nutritionist-DVM, I was reluctant to listen to my would-be major professor's future for me as a reproductive physiologist. To this day, Dr. Patterson would tell you he still struggles convincing me on a variety of fronts, although I have agreed it was a wise life choice to become a physiologist instead of a nutritionist. I owe a lot of credit for choosing this path to Dr. Dallas Wilson, the trailblazer for us Patterson lab DVM students. When I asked his opinion of a degree with Dr. Patterson, he replied, "Best thing I ever did." That was it. That's all he offered up to say, but that's all it took for me to be convinced this was the right way to go.

I can't express enough appreciation for members of my committee. First, Dr. Patterson thank you for pushing me to join your group and let me become part of a long history of respected research. We are lucky to be able to work with you as closely as we do, knowing that your door is most always open. Dr. Smith, as for countless other students, you reinforced my interest in reproduction and inspired my continued education in the discipline. I can only hope to be a continual learner as you are, and always have the desire to improve my knowledge and skills for not only my benefit, but also for the benefit of my clients. Dr. Ellersieck, thank you for the hours spent with me figuring out how to run a statistical analysis on my project. I know just enough about statistical analysis software to be dangerous and really screw up an analysis, so I am thankful that you were willing to code my programs and share stories of the adventures of your past. Dr. Poock, I cannot thank you enough for everything you have done throughout my academic career. You are far too humble to acknowledge the contribution you have made 
on the success of many young veterinarians. Early mornings at the dairy palpating ovaries, ultrasounding heifers in Florida, and rolling around milk parlors to scan thousands of tiny dairy cows have been the experiences that will help shape my career.

A number of my peers have played crucial roles in this degree. Lauren Ciernia, you could tell I dislike lab work with a passion, but I need to thank you for your time spent in the lab and for being patient with me as I took my borderline-reckless approach and learned the fine art of radioimmunoassay. To my fellow future veterinarians Brianne Bishop and Jill Abel, thank you for your guidance and advice throughout vet school and the MS degree. I am confident you will both find great success in the near future. To future veterinary colleagues Emma Knickmeyer and Rachael Bonacker, graduate school is a great opportunity to really influence your skills and become a better veterinarian. Take every opportunity you can to get out of the office, meet new people and palpate new cows. Lastly, I cannot adequately thank the almost Dr. Jordan Thomas for his role as my unofficial coadvisor. I have interrupted your train of thought countless times by barging into your office to ask questions and made you read drafts of my writing, but I sincerely could not have done any of this without you.

A final thank you goes to the producers that provided me the opportunity to gain experience and hone my skills on their operations: Darrin Plank, Eugene and the rest of the crew in Florida, Travis Lybbert of Deseret Ranch, Jon Schreffler and crew at the Thompson Research Center, and Dr. John Barnhart and Frank Barnitz. Finally, I cannot thank the Mason, Knox, and Ogren families enough for opening their homes and herds for weeks at a time to allow us to do research. Thank you for letting us become part of your families. 
TABLE OF CONTENTS

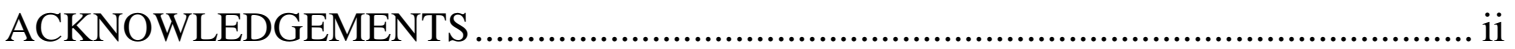

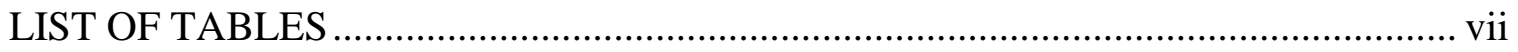

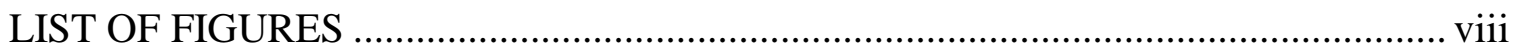

LIST OF ABBREVIATIONS ......................................................................... ix

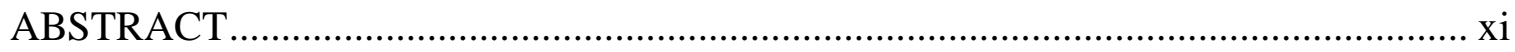

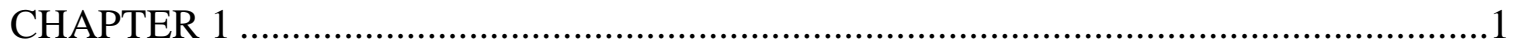

REVIEW OF LITERATURE......................................................................

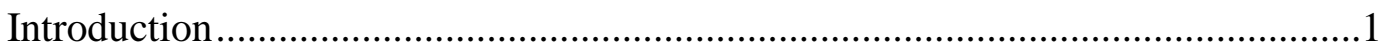

Review of the bovine estrous cycle ...................................................................

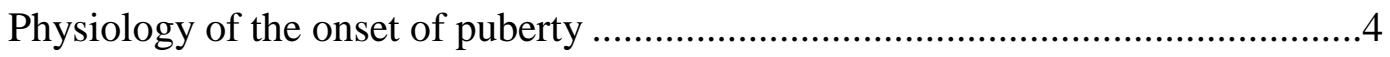

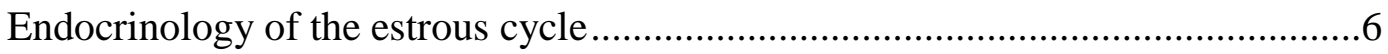

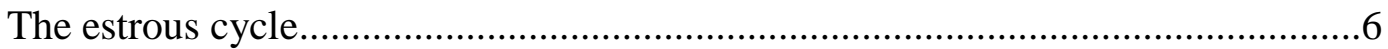

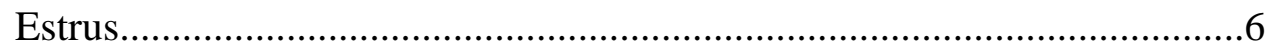

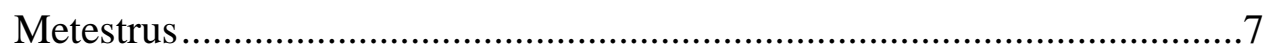

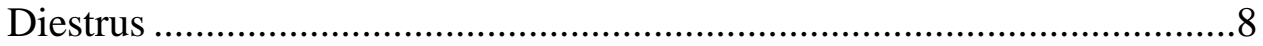

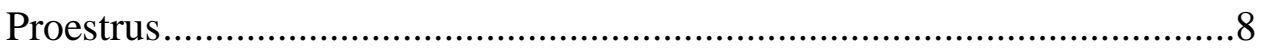

Ovarian dynamics .................................................................... 10

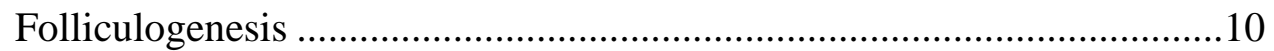

Recruitment ................................................................................ 10

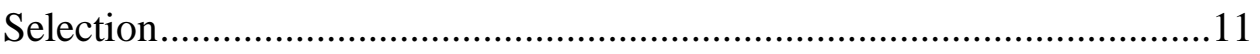

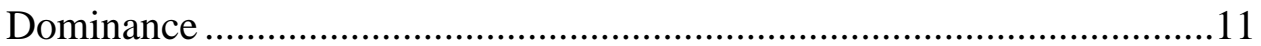

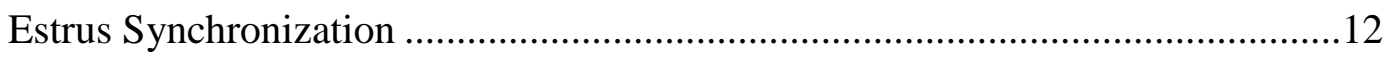

Use of Progestins in Estrus Synchronization Systems ...........................12

Induction of Puberty with Progestins........................................13

Melengestrol Acetate ........................................................ 14

Controlled Internal Drug Release Inserts.................................16

Development of Long-term Progestin-based Methods

to Synchronize Estrus in Beef Heifers ..................................................18

Development of MGA-PG .................................................. 18 
Development of MGA Select................................................19

Development of CIDR Select ................................................20

Development of CIDR-PG ................................................20

CIDR vs MGA as a Progestin Source.......................................21

CIDR-PG vs MGA-PG for

Fixed-Time Artificial Insemination ......................................22

Use of Prebreeding Exams to Time Estrus Synchronization Programs.................23

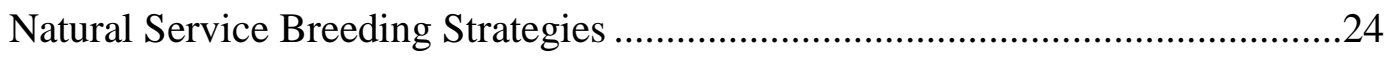

Induction of puberty with bull introduction.......................................25

Bull-to-female ratio.....................................................................26

Natural service with estrus-synchronized females ...............................26

Considerations for Reproductive Management of

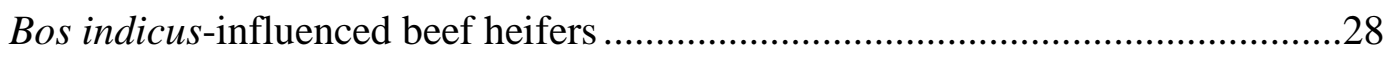

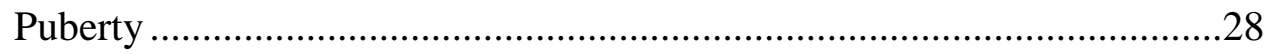

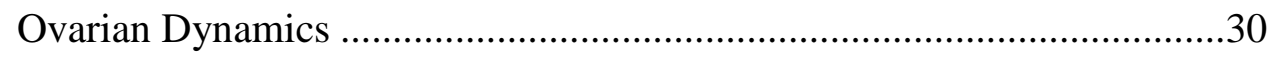

Estrous Behavior .......................................................................... 30

Sensitivity to pharmaceuticals ....................................................... 31

Transrectal ovarian palpation........................................................32

Response to physiological stress ...................................................33

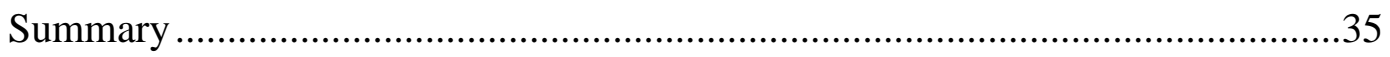

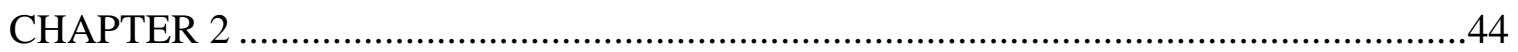

COMPARISON OF LONG-TERM PROGESTIN-BASED PROTOCOLS

TO SYNCHRONIZE ESTRUS PRIOR TO FIXED-TIME ARTIFICIAL

INSEMINATION OR NATURAL SERVICE IN BOS INDICUS- 


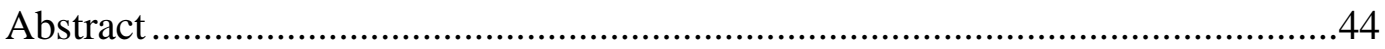

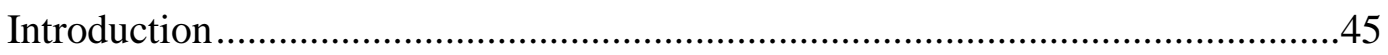

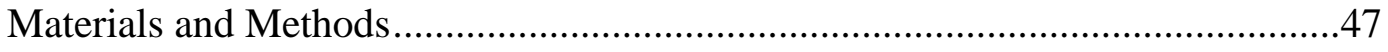

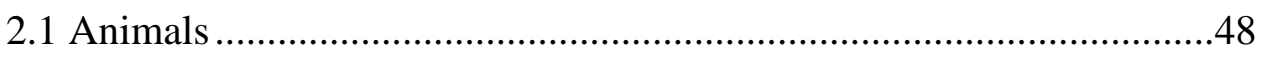

2.2 Experimental Treatments ..................................................................

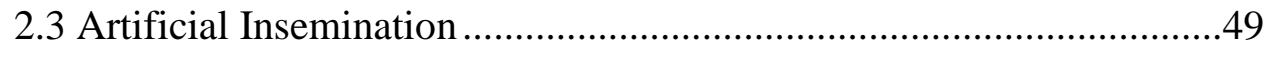

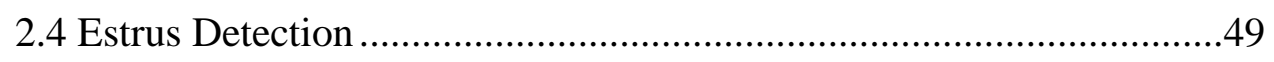

2.5 Blood Collection and RIA …………………………....................50

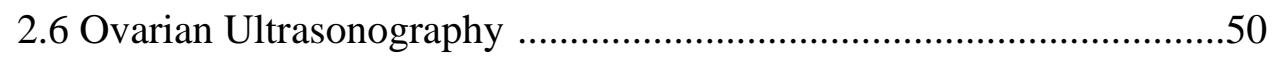

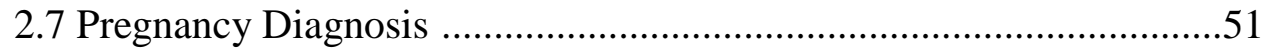

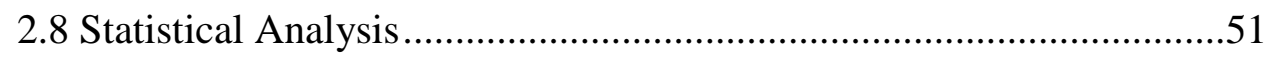

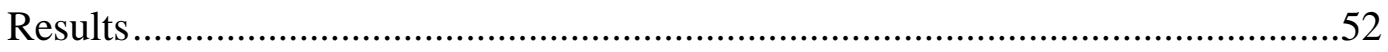

3.1 Pregnancy Rates........................................................................52

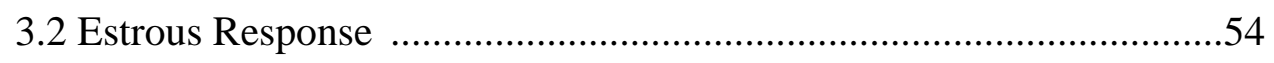

3.3 Endocrinology and Follicular Dynamics ..........................................54

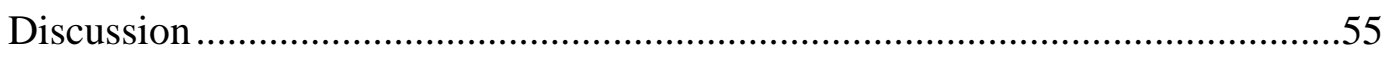

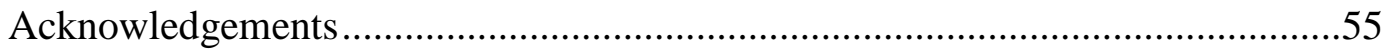

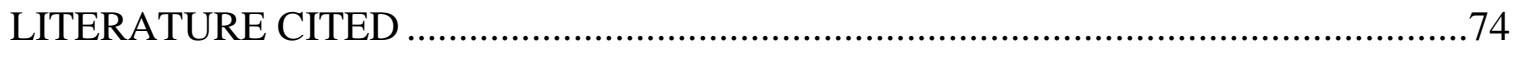

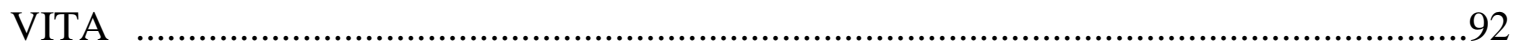




\section{LIST OF TABLES}

Table

Page

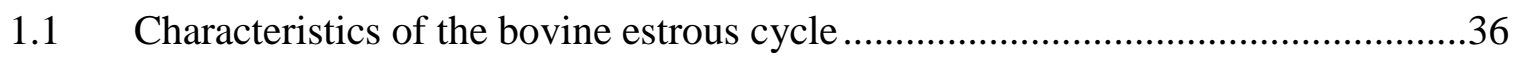

1.2 Characteristics associated with the reproductive tract scoring system ................40

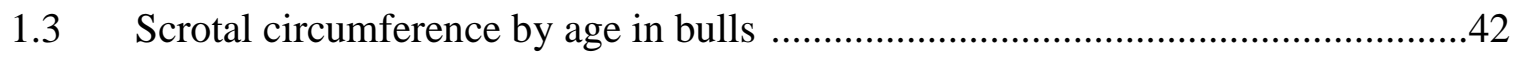

2.1 Number of heifers, mean weight (Wt), and reproductive tract score (RTS) by treatment

2.2 Pregnancy rates of heifers within treatment based on pubertal status and day(s) of the breeding season

2.3 Pregnancy rate of heifers based on progestin and service type ..........................70

2.4 Estrous response rates after PG and FTAI pregnancy rates among heifers assigned to FTAI treatments based on treatment and pretreatment pubertal status

2.5 Steroid concentrations of heifers assigned to FTAI treatments based on estrous response and pregnancy status

2.6 Diameter of the largest follicle (LFD) and estradiol concentration $\left(\mathrm{E}_{2}\right)$ at FTAI based on treatment and estrous response 


\section{LIST OF FIGURES}

Figure

1.1 Chemical structures of progesterone $\left(\mathrm{P}_{4}\right)$, medroxyprogesterone acetate (MAP), and melengestrol acetate (MGA)

1.2 Treatment schedules for MGA Select, CIDR Select, MGA-PG and CIDR-PG

1.3 Treatment schedules for MGA-PG and CIDR-PG utilizing

a FTAI approach

1.4 A conceptual model for endocrine and ovarian changes associated with onset of puberty in heifers

1.5 Treatment schedule for "BEE Synch" or PG 5-d CO-SYNCH + CIDR utilizing a FTAI approach

2.1 Treatment schedules for NS, MGA + NS, CIDR + NS, MGA-PG + FTAI, and CIDR-PG + FTAI 


\title{
LIST OF ABBREVIATIONS
}

\author{
AI Artificial Insemination \\ BFR Bull-to-female ratio \\ CL Corpus luteum/corpra lutea \\ CIDR Controlled Internal Drug Release \\ d $\quad \operatorname{Day}(\mathrm{s})$ \\ $\mathrm{E}_{2} \quad$ Estradiol-17 $\beta$ \\ FSH Follicle stimulating hormone \\ FTAI Fixed-time artificial insemination \\ GnRH Gonadotropin-releasing hormone \\ h $\quad \operatorname{Hour}(\mathrm{s})$ \\ i.m. Intramuscular \\ kg Kilogram(s) \\ LH Luteinizing hormone \\ MAP Medroxyprogesterone acetate \\ MGA Melengestrol acetate \\ mg Milligram(s) \\ $\mathrm{mL} \quad$ Milliliter(s) \\ $\mathrm{mm} \quad$ Millimeter(s) \\ mo Month(s) \\ ng Nanogram(s) \\ $\mathrm{P}_{4} \quad$ Progesterone
}




$\begin{array}{ll}\text { pg } & \text { Picogram(s) } \\ \text { PG } & \text { Prostaglandin } \mathrm{F}_{2 \alpha} \\ \text { RIA } & \text { Radioimmunoassay } \\ \text { RTS } & \text { Reproductive tract score } \\ \text { SAS } & \text { Statistical Analsis System } \\ \text { Mg } & \text { Microgram(s) } \\ \text { US } & \text { United States } \\ \text { wk } & \text { Week(s) } \\ \text { yr } & \text { Year(s) }\end{array}$




\title{
CONSIDERATIONS FOR REPRODUCTIVE MANAGEMENT OF BOS INDICUS-INFLUENCED BEEF HEIFERS
}

\author{
James William Cameron Locke \\ Dr. David J. Patterson, Thesis Advisor
}

\begin{abstract}
The Bos indicus species of beef cattle presents a number of unique reproductive challenges, especially with regard to those that influence reproductive efficiency including timely attainment of puberty, response to certain pharmaceutical drugs used to control estrus and ovulation, and response to physiological stressors. Cattle of this biological type comprise a substantial percentage of the beef cattle population in southern regions of the United States because of their ability to withstand high ambient temperatures and relative humidity. Additionally, Bos indicus cattle are regarded to exhibit increased parasite and disease resistance, resulting in improved production in subtropical climates as compared to Bos taurus cattle in those same regions. Research utilizing composite breeds of Bos taurus and Bos indicus beef heifers has been limited in the United States, and adoption of reproductive technologies such as artificial insemination and estrus synchronization has been sluggish compared to Bos taurus cattle in other regions of the country.
\end{abstract}

To help answer a number of questions about this biological type, an experiment was designed to evaluate reproductive performance of Bos indicus-influenced heifers ( $\mathrm{n}=$ 1,456). Weights and reproductive tract scores (RTS; Scale 1-5) were obtained for heifers 
prior to assignment of one of five treatments: Non-synchronized + natural service (NS); melengestrol acetate + natural service $\left(\mathrm{MGA}+\mathrm{NS} ; 0.5 \mathrm{mg} \cdot \mathrm{animal}^{-1} \cdot \mathrm{d}^{-1}\right) ; 14-\mathrm{d}$ controlled internal drug release + natural service (CIDR + NS; 1.38g progesterone); 14-d MGA-PG + fixed-time AI (FTAI); and 14-d CIDR-PG + FTAI. Heifers in the three NS treatments were exposed to fertile bulls for $65 \mathrm{~d}$, beginning $10 \mathrm{~d}$ after progestin removal for CIDR + $\mathrm{NS}$ and MGA + NS groups. Heifers in FTAI treatments were administered $\mathrm{PGF}_{2 \alpha}(\mathrm{PG} ; 25$ mg, IM) 16 or $19 \mathrm{~d}$ following CIDR or MGA removal. Fixed-time AI was performed 66 and $72 \mathrm{~h}$ after PG for CIDR-PG and MGA-PG treatments, respectively. Gonadotropin-

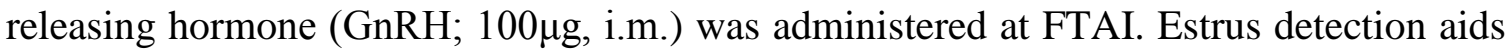
were applied at PG for heifers in FTAI treatments and evaluated at AI. Heifers in FTAI treatments were exposed to fertile bulls $12 \mathrm{~d}$ following FTAI. Blood samples were collected and ovarian ultrasounds performed at PG administration and FTAI to compare serum concentrations of estradiol and progesterone and to evaluate follicular dynamics among a subset of heifers assigned to FTAI treatments. Pregnancy status was determined at the end of a 65-d breeding period. Data were analyzed using PROC FREQ and GLIMMIX procedures of SAS. Mean concentrations of estradiol at AI differed between MGA- versus CIDR-treated heifers $(\mathrm{P}=0.04 ; 8.2$ versus $6.6 \mathrm{pg} / \mathrm{ml})$, however estrous response after PG (52\% versus 53\%) and pregnancy rates after FTAI (40\%) did not differ between MGA- and CIDR-PG treatments, respectively. Across all treatments, pregnancy rates were compared on 21, 30 and $60 \mathrm{~d}$ of the breeding period based on pubertal status (prepubertal RTS $=1$ and 2; peripubertal RTS $=3$; pubertal RTS $=4$ and 5). Pregnancy rates differed at each time point based on pretreatment pubertal status $(\mathrm{P} \leq 0.02)$ and weight $(\mathrm{P} \leq 0.05)$. No differences were apparent with regard to progestin type at any time 
point, although higher pregnancy rates $(\mathrm{P} \leq 0.004)$ were observed among NS treatments than FTAI followed by NS exposure at Days 30 and 60.

This experiment is the largest comprehensive field trial conducted in the United States and reported in the literature involving Bos indicus-influenced beef heifers utilizing estrus synchronization prior to natural service or FTAI. This study reinforced results from previous studies, however raises a number of questions yet to be answered for heifers of this biological type. These data should be used as a basis for improvements in reproductive management of Bos indicus-influenced beef heifers prior to their first breeding season, and creates a number of possibilities for future research trials that build upon results reported in this thesis. Selection, management, and post-weaning to prebreeding development of Bos indicus-influenced replacement beef heifers should involve the cooperative efforts of beef producers, veterinarians, and research scientists to further investigate methods to improve reproductive efficiency and genetic merit of these herds. 


\section{CHAPTER 1}

\section{REVIEW OF LITERATURE}

\section{INTRODUCTION}

Reproduction is the single most important economic trait in a cow/calf operation. Beef heifers must conceive by 15 months of age and calve by 24 months in order to maximize lifetime performance measured by pounds of calf weaned. Consequentially, heifers that calve early in their first calving season are more productive than those that calve late (Lesmeister et al., 1973; Perry and Cushman, 2013). Calves that are born late in the calving season are usually lighter in weight by weaning, which typically occurs at a fixed time when calves of various weights and ages are weaned as a group (Lesmeister et al., 1973; Patterson and Decker et al., 2015). Further, cows that calve late in the calving season tend to calve late or even fail to calve the following year (Burris and Priode, 1958).

To abate these inherent production concerns, current best management practices recommend that heifers be bred to calve prior to mature cows, which allows for increased labor at calving, and the opportunity to provide more time for younger age cows to resume estrous cyclicity following calving. Cows that calve early experience longer postpartum intervals before rebreeding, which tends to increase first service conception rates in primiparous cows (Wiltbank, 1970). 
Early attainment of puberty is essential in order to meet the 15 month benchmark. As such, prebreeding exams can be used to assess the reproductive status of heifers prior to the first breeding season. Estrus synchronization programs that include a progestin are an effective means of accelerating age at puberty of pre- and peri-pubertal beef heifers, thereby increasing the proportion of females that become pregnant early in the breeding season. Estrus synchronization offers the potential to shorten the breeding and calving seasons, resulting in more uniform calf crops (Dziuk and Bellows, 1983; Patterson et al., 2017a).

Over the last 10 years, the beef industry has seen a gradual increase in the number of heifers that receive at least one AI service (USDA NAHMS, 2007; Patterson et al., 2017). This resulted from development of protocols that effectively synchronize estrus and ovulation and facilitate fixed-time artificial insemination (FTAI). Fixed-time AI concentrates time and labor for herd managers which historically was a major factor hindering the adoption of reproductive technologies in the beef industry (USDA NAHMS, 2007). Most of this growth, however, has occurred within the Bos taurus population of beef cattle in the US. This is due in part to the larger body of research involving taurine females. Limited research has examined the use of protocols designed to facilitate FTAI in Bos indicus-influenced beef heifers with pharmaceuticals approved by the US Food and Drug Administration (FDA).

Widespread adoption of AI within the beef industry requires that protocols designed to synchronize estrus are cost effective, easy to administer, minimize cattle handling, and yield consistent and acceptable pregnancy rates, all while fitting within an operation's management goals and labor resources (Yelich and Bridges, 2012). Protocols 
designed to effectively synchronize estrus and ovulation result in a large proportion of females exhibiting estrus over a narrow window of time which eliminates time and labor required for detection of estrus, increases conception rate to AI, and produces older, heavier calves at weaning (Patterson et al., 2017a). The development of protocols that achieve these goals in Bos taurus females progressed rapidly and should now be expanded to include Bos indicus-influenced breeds to improve herds nationwide.

Beef producers in the southern and southeastern United States benefit from incorporating Bos indicus genetics into their herds where these cattle are better adapted to tropical and subtropical environmental conditions. These benefits include improved heat tolerance, increased parasite and disease resistance, and subsequent improved production in subtropical climates (Sartori et al., 2010; Yelich and Bridges, 2012). Bos indicusinfluenced females are unique from Bos taurus females based on their distinct reproductive physiology (Saldarriaga et al., 2007). Bos indicus-influenced heifers reach puberty at later ages than Bos taurus females (Chenoweth, 1994), exhibit differences in timing of ovarian events including follicular wave emergence and preovulatory follicle diameters (Bó et al., 2003), and exhibit differences in sensitivity to pharmaceuticals utilized in estrus synchronization (Sartori et al., 2010).

Limited research has been conducted to evaluate controlled breeding strategies in Bos indicus-influenced beef heifers, including use of long-term progestin-based estrus synchronization protocols followed by exposure for natural service or FTAI. This review of the literature provides an overview of the physiology and endocrinology of the bovine estrous cycle, factors involved with timing of puberty onset in replacement beef heifers, 
and special consideration of the unique differences in reproductive physiology comparing Bos indicus and Bos taurus breeds and biological types of cattle.

\section{REVIEW OF THE BOVINE ESTROUS CYCLE}

\section{Physiology of the onset of puberty}

Senger (2012) defines puberty as 1) age at first estrus 2) age at first ovulation, or 3) age at which a female can support pregnancy without deleterious effects. While it is easy to determine behavioral estrus, the first ovulation is generally not accompanied by expression of estrus (Parish et al., 2010, Senger, 2012). Therefore, the age at first estrus may not accurately represent actual attainment of puberty. Alternatively, observing first ovulation requires a much more intensive and less practical study via transrectal palpation or ovarian ultrasonography to determine precisely when ovulation occurred.

The regulation of ovarian function and the onset of puberty are primarily influenced by the hypothalamus. Reproductive maturity, in part, begins at the level of the hypothalamus, as the number and distribution of GnRH neurons within the hypothalamus and GnRH receptors within the pituitary increase (Day et al., 1987). The prepubertal heifer is able to respond to the predominant reproductive hormones $\left(\mathrm{LH}, \mathrm{FSH}, \mathrm{E}_{2}\right.$, and $\mathrm{P}_{4}$ ) months prior to the first ovulation. By 5 to 6 months of age, heifers are able to develop follicles as a result of LH and FSH treatment, produce an LH surge, and ovulate (Seidel et al., 1971; Schillo et al., 1983; McLeod et al., 1985).

The prepubertal hypothalamus is highly sensitive to the negative feedback effect of estradiol on GnRH release, even in the face of low concentrations of estradiol 
produced by small ovarian follicles. This sensitivity is reduced as the heifer matures due to a decrease in the number of $E_{2}$ receptors in the hypothalamus. Decreased sensitivity to estradiol negative feedback results in a sufficient release of LH and FSH to cause an increase in pulse amplitude, frequency, and regularity of LH pulses (Day et al., 1987; Smith et al., 2007).

Prepubertal heifers have yet to develop a normal pattern of LH release from the anterior pituitary, as increased LH pulse frequency is the determining factor for sexual maturity in heifers (Day et al., 1987). Gonadotropin-releasing hormone (GnRH) from the hypothalamus controls the release of LH in a pulsatile fashion until the preovulatory $\mathrm{LH}$ surge, and frequency and amplitude of LH pulses determines the growth or decline of follicles. In pubertal heifers, LH and FSH release is affected by feedback of circulating concentrations of estradiol, progesterone, and inhibin; however, in prepubertal heifers, estradiol is the primary hormone responsible for inhibiting GnRH release and subsequent control of LH and FSH secretion (Kiser et al., 1981; Day et al., 1984).

Although a heifer is capable of ovulating at 5 to 6 months of age in response to LH and FSH treatment (Seidel et al., 1971; Schillo et al., 1983; McLeod et al., 1985), the limiting factor in determining whether a heifer will assume normal estrous cyclicity, is dependent upon her ability to form and maintain a corpus luteum of normal lifespan (Smith et al., 2007). Furthermore, Byerley et al. (1987) noted that heifers often reach maximum fertility on their third versus first estrus. Treatment of prepubertal heifers with progestins was shown to be effective in advancing age to puberty, thereby increasing the number of estrous cycles expressed by heifers prior to breeding (Gonzalez-Padilla et al., 
1975; Patterson et al., 1990; Anderson et al., 1996; Imwalle et al., 1998; Lucy et al., 2001).

\section{Endocrinology of the Estrous Cycle}

The estrous cycle. The bovine estrous cycle relies upon a continuous series of physiological and endocrine-associated changes involving various organs from neurons in the hypothalamus to cumulus cells in the ovary. These changes result in a recurring pattern of estrus ranging from 17 to $24 \mathrm{~d}$ in length with an average of 21 days depending on the specific female (Table 1.1; Plasse et al., 1970; Senger, 2012). Changes in ovarian structures are produced by endocrine effects which result in two distinct phases of the estrous cycle: the luteal and follicular phases. The luteal phase is characterized by the presence of a CL and comprises 80 percent of the entire cycle length, which begins at CL formation and continues until CL regression. The remainder of the estrous cycle is known as the follicular phase and occurs from CL regression until ovulation.

\section{The Follicular Phase: Endocrine and Ovarian Dynamics of Estrus}

Estrus. Defined as the period of sexual receptivity, the cow exhibits estrus for 12 to $21 \mathrm{~h}$ (Wiltbank et al., 1967). Behavioral estrus is associated with the interaction of a number of hormones which collectively culminate in ovulation and associated biological responses that assist sperm in their trek to the site of fertilization. Estradiol $17 \beta\left(E_{2}\right)$ is a steroid hormone produced by growing and dominant follicles on the ovary. Estradiol is responsible for expression of estrus and prepares the female reproductive tract for mating and sperm transport (Hawk, 1983). The preovulatory LH surge begins with the rise in $\mathrm{E}_{2}$ from preovulatory follicles (Schallenberger et al., 1984), and a threshold level of $E_{2}$ is 
required to initiate positive feedback on the hypothalamus. Once this threshold concentration is reached, the hypothalamic surge center is activated, resulting in the release of large amounts of LH from the anterior pituitary as a consequence of GnRH release (Moenter et al., 1991; Cupp et al., 1995). Often mistaken as a single large release of $\mathrm{LH}$, the preovulatory LH surge is more correctly identified by frequent, high amplitude pulses of LH (Rahe et al., 1980). The surge comes to an end, even in the presence of residual GnRH secretion, when the pituitary becomes desensitized and/or LH reserves are depleted (Moenter et al., 1991). The preovulatory LH surge is necessary for final maturation of the dominant follicle and resulting ovulation.

The Luteal Phase: Metestrus and Diestrus

Metestrus. Ovulation of the dominant follicle occurs $24-32 \mathrm{~h}$ after the onset of estrus (Wiltbank et al., 1967), at which point LH concentrations decline (Garverick et al., 1971; Cupp et al., 1995). Residual cells of the ovulated follicle then undergo a remodeling process known as luteinization. These structural and functional changes result in the formation of a corpus luteum (CL) which produces the hormone progesterone (Garverick and Smith, 1986; Garverick et al., 1992). Cellular remodeling is assisted by luteinizing hormone, as follicular theca and granulosa cells are transformed into small and large luteal cells, respectively (Romereim et al., 2017). Large luteal cells contribute to the greatest amount ( 80 percent) of progesterone $\left(\mathrm{P}_{4}\right)$ produced by the $\mathrm{CL}$, whereas small luteal cells produce the remaining 20 percent (Garverick and Smith, 1986; Garverick et al., 1988). During this time, development of a vascularized network within the CL is essential for progesterone secretion and later becomes important in future 
processes of the estrous cycle (Smith et al., 1994). Formation of the CL during metestrus marks the beginning of the luteal phase.

Diestrus. The bulk of the luteal phase occurs during diestrus. During this time, progesterone is the dominant reproductive hormone with regard to relative concentrations and is responsible for secretion of other hormones, inhibition of behavioral estrus, and maintenance of pregnancy (Garverick et al., 1992; Smith et al., 1994; Wiltbank, 1994; Driancourt, 2001). Concentrations of $\mathrm{P}_{4}$ begin to increase by d 4 of the estrous cycle, increase to maximal concentrations on $\mathrm{d} 7$ to 12 and remain constant until luteolysis on $\mathrm{d}$ 18 or 19 of the cycle (Donaldson and Hansel, 1965; Hansel and Convey, 1983). Progesterone concentrations decline following luteolysis and remain low until the formation of a new CL in the subsequent metestrus (Wettemann et al., 1972; Echternkamp and Hansel, 1973). Progesterone acts on the hypothalamus to maintain low frequency pulsatile release of $\mathrm{GnRH}$, inhibiting the development of preovulatory follicles and the resulting increase in $\mathrm{E}_{2}$ (Hansel and Convey, 1983). Progesterone inhibits the expression of estrus, prevents uterine contractions, and stimulates uterine endometrial glands to support the plausible conceptus (Hafez, 1980).

The Follicular Phase: Proestrus and the late luteal phase

Proestrus. During the luteal phase of the estrous cycle, elevated concentrations of $\mathrm{P}_{4}$ impede estradiol's ability to enhance expression of uterine endometrial oxytocin receptors; however, $\mathrm{P}_{4}$ eventually downregulates its own receptor in the late luteal phase, removing the inhibitory effect on oxytocin receptors. Estradiol then induces the formation of endometrial oxytocin receptors and stimulates the release of oxytocin from the pituitary, producing low levels of prostaglandin $\mathrm{F}_{2 \alpha}$ (PG; McCracken et al., 1995). Luteal 
oxytocin is released as a result of low levels of PG, resulting in the amplification of PG release from the uterine endometrium (McCracken et al., 1996). Prostaglandin $F_{2 \alpha}$ from the uterus exerts its effects by way of a vascular countercurrent exchange on the CL as it travels from the uterus via the uterine vein where molecules are passed to the ovarian artery, transported to the ovary, and act to lyse the CL (McCracken et al., 1996; Lee et al., 2010). Luteolysis occurs as a result of reduced blood flow to the CL, diminishing the supply of nutrients, luteotropic support, and substrates for steroidogenesis (Pharriss et al., 1970; Lee et al., 2010).

As the $\mathrm{CL}$ is lysed, circulating concentrations of $\mathrm{P}_{4}$ decrease rapidly over a two $\mathrm{d}$ period, resulting in luteolysis and marking the end of the luteal phase around $\mathrm{d} 18$ of the estrous cycle (Hansel and Convey, 1983). The negative feedback of $\mathrm{P}_{4}$ on the hypothalamic surge center is thereby removed, resulting in high frequency pulses of GnRH from the hypothalamus, signaling the anterior pituitary to release LH and FSH (Hansel and Convey, 1983; Schallenberger et al., 1984; Spicer and Echternkamp, 1986). These two gonadotropic hormones are implicated in the "two-cell, two-gonadotropin model" (Fortune and Quirk, 1988).

To illustrate this model, the two gonadotropes (LH and FSH) act on two cells within the ovary, the follicular theca and granulosa cells, respectively. The binding of LH to its receptors on the surface of theca cells initiates a cascade of events that ultimately lead to production of testosterone within the theca cell (Fortune et al., 1988; Allen et al., 2016). Testosterone diffuses across the thecal basement membrane into a layer of granulosa cells. The binding of FSH to its receptors on the granulosa cell provides a series of events that allows testosterone to be converted to $E_{2}$ by way of the enzyme 
aromatase (Hansel and Convey, 1983; Rouiller et al., 1998). Positive feedback of $E_{2}$ from growing ovarian follicles acts on the hypothalamus and anterior pituitary, stimulating gonadotropin release (Schallenberger et al., 1984; Walter and Schallenberger, 1984; Spicer and Echternkamp, 1986; Stumpf et al., 1989). Estradiol reaches maximum concentration $3 \mathrm{~d}$ following completion of luteolysis and the subsequent decrease in $\mathrm{P}_{4}$ (Savio et al., 1990; Garverick et al., 1992; Cupp et al., 1995). Together, $E_{2}$ and the gonadotrophs promote continued development and maintenance of preovulatory follicles.

\section{Ovarian Dynamics}

Folliculogenesis. As ovarian structures change in response to endocrine signals, new follicles must develop in order to precipitate a continuous estrous cycle. Folliculogenesis involves the formation of mature follicles originating from a pool of primordial follicles. At birth, a set number of primordial follicles, which developed in utero, are present on the ovaries. These primordial follicles contribute continuously to the formation and development of dominant follicles in the process of follicular wave dynamics (Hansel and Convey, 1983). Follicular waves include three distinct stages: recruitment, selection, and dominance. Cows exhibit 2 to 3 waves per estrous cycle, where the final follicular wave before estrus produces the ovulatory follicle (Sirois and Fortune, 1988).

Recruitment. Gonadotropin stimulation is essential to the maturation of follicles. A cohort of follicles, typically comprised of 1 to 6 small follicles 4 to $5 \mathrm{~mm}$ in diameter, develops from a reserve of primordial follicles. While the activation of primordial follicles is not yet fully understood, current research shows that the protein kinase mTOR and the PI3K signaling pathway are responsible in part for follicular activation (Zengh et 
al., 2012). In mouse ovaries treated with these activators, nearly complete activation and eventual depletion of primordial follicles was observed (Kim, 2012; Sun et al., 2015). The mechanism by which only certain follicles are selected for each cohort is not well known.

Selection. Once a cohort of follicles has been established, a single follicle per wave is selected to become dominant. This process occurs 36 to $48 \mathrm{~h}$ following initiation of a follicular wave (Bao et al., 1997) when the largest follicle within the cohort reaches approximately $8.5 \mathrm{~mm}$ in diameter (Ginther et al., 1997). This large follicle secretes increasing amounts of $E_{2}$ along with the hormone inhibin. Inhibin works at the level of the anterior pituitary, providing negative feedback on the secretion of FSH. Declining FSH works to prevent follicular development of other follicles within the cohort, shifting the dependency of the large follicle from FSH to LH. The first emergence of a follicular wave consistently occurs on d 0 (Mapletoft et al., 2002; Aerts et al., 2008). Emergence of the second wave occurs on d 9 or 10 for two-wave cycles or d 8 or 9 for three-wave cycles. A third wave materializes on d 15 or 16 in three-wave cycles.

Dominance. The large follicle that is selected from the cohort and develops is referred to as the dominant follicle. Remaining small follicles within the cohort become atretic, and production of inhibin from the dominant follicle prevents emergence of a new follicular wave (Hodgen, 1982; Ginther et al., 1996). Depending upon stage of the estrous cycle, the 10-15 mm follicle will either undergo atresia or ovulate (Webb et al., 1992). Dominance occurs in two-wave cows on d 6 and 15 and d 7, 14, and 21 in three-wave cows (Pierson and Ginther, 1984; Savio et al., 1990; Driancourt, 2001; Lucy et al., 2001). 
Once dominance is achieved, endocrine dependency of the dominant follicle transitions from FSH to LH. Luteinizing hormone receptors in the theca and granulosa cell layers increase expression, making the dominant follicle dependent on LH (Bao and Garverick, 1998; Webb et al., 1999). Pulse frequency of LH determines the fate of the dominant follicle, leading to atresia or ovulation. In order to achieve ovulation, the follicle must establish an adequate number of LH receptors. Sufficient numbers of receptors for ovulatory capacity are typically achieved when the follicle reaches a minimum diameter of $10 \mathrm{~mm}$ (Sartori et al., 2001). Pulses of LH are controlled by negative feedback of $\mathrm{P}_{4}$ and positive feedback of $\mathrm{E}_{2}$. Action of $\mathrm{LH}$ on the follicle stimulates the production of androgen precursors from the thecal cells. These precursors are responsible for controlling the health and maintenance of the dominant follicle (Garverick and Smith, 1986; Garverick et al., 1988; 1992). The phase of the estrous cycle during which dominance is achieved dictates the fate of the dominant follicle. Those follicles that reach dominance during the luteal phase of the estrous cycle maintain dominance for 3 to $6 \mathrm{~d}$ before undergoing atresia (Ginther et al., 1989; Knopf et al., 1989). Large follicles that reach dominance late during the luteal phase and coincident with regression of the corpus luteum progress to ovulation (Kastelic et al., 1990).

\section{USE OF PROGESTINS IN ESTRUS SYNCHRONIZATION SYSTEMS}

It is well established that $\mathrm{P}_{4}$ is responsible for inhibiting ovulation and maturation of preovulatory ovarian follicles (Nellor and Cole, 1956; Hansel et al., 1961; Lamond, 1964). Ulberg et al. (1951) first noted the effect $\mathrm{P}_{4}$ injections had on ovarian dynamics of 
heifers, which opened the door to the development of methods to control the bovine estrous cycle. Progesterone inhibits ovulation and follicular maturation via negative feedback on the hypothalamic release of GnRH and subsequent release of $\mathrm{LH}$ from the anterior pituitary (Hansel and Convey, 1983; Jainudeen and Hafez, 1987). The negative feedback effect of progesterone inhibits the preovulatory LH surge which is required for final maturation and ovulation of a dominant follicle (Schallenberger et al., 1984; Garverick and Smith, 1986; Ginther et al., 2000).

Methods that were initially developed to synchronize estrus involved the administration of exogenous progestins, sometimes in combination with estrogens and PG to control CL lifespan. At this time, regulation of the estrous cycle was believed to be controlled by the CL (Thimonier et al., 1975). Years later, however, the use of transrectal ultrasonography to examine ovarian follicular dynamics throughout the estrous cycle revealed that effective means of estrus synchronization required the control of luteal lifespan and manipulation of follicular waves (Savio et al., 1990).

Induction of puberty with progestins. Early attainment of puberty in beef cattle is critical, given that age at puberty is the most important production trait contributing to lifetime productivity. Treatment of pre- and peri-pubertal heifers with progestins was shown to be effective in inducing puberty (Gonzalez-Padilla et al., 1975; Patterson et al., 1990) by preparing the uterus for pregnancy and establishing patterns of gonadotropin secretion that mimic those of cycling heifers (Smith et al., 2007). Exposure to a progestin for a period of 7 to 10 days can be effective in inducing cyclicity in pre- or peripubertal heifers (Anderson et al., 1996; Imwalle et al., 1998) and becomes more effective the 
closer a heifer is to natural attainment of puberty (Short et al., 1976; Tanaka et al., 1995; Hall et al., 1997).

Circulating concentrations of progesterone increase as heifers attain puberty (Berardinelli et al., 1979). The first ovulation a heifer experiences is generally followed by a short luteal phase (Gonzalez-Padilla et al., 1975) and results in a transient increase in $\mathrm{P}_{4}$. Exposure to elevated concentrations of $\mathrm{P}_{4}$ is required to establish normal estrous cyclicity in heifers, and among cows following parturition (Short et al., 1974; Rawlings et al., 1980). Treatment with progestins is associated with an increase in diameter of the largest follicle (Imwalle et al., 1996; Hall et al., 1997) and increased follicular growth, resulting in amplified $\mathrm{E}_{2}$ production by ovarian follicles (Hendricks et al., 1973; Wettemann and Hafs, 1973; Sheffel et al., 1982; Garcia-Winder et al., 1986). Treatment with a progestin results in increased frequency of LH pulses, especially following withdrawal of the progestin (Smith and Day, 1990; Anderson and Day, 1996; Imwalle et al., 1996; Hall et al., 1997). Additionally, $E_{2}$ receptors are downregulated in the hypothalamus, removing negative feedback on LH secretion, and allowing for final maturation and ovulation of a dominant follicle (Anderson et al., 1996; Anderson and Day, 1996).

Presently, there are two exogenous progestins used in estrus synchronization systems: Melengestrol Acetate (MGA) and Controlled Internal Drug Release (CIDR) inserts.

Melengestrol Acetate. Melengestrol acetate is an orally active synthetic progestin (6-methyl-17-alpha-acetoxy-16-methylene-preg-4, 6-diene-3, 20-dione; Figure 1.1) developed in 1962 as a means of controlling behavioral estrus. Melengestrol acetate 
became popular in the feedlot industry as it improves feed efficiency and rate of gain in heifers by allowing follicular development, but preventing estrus expression and ovulation (Zimbelman and Smith, 1966). MGA is delivered in a grain carrier of varying type and quantity, but the progestin itself must be consumed at a rate of $0.5 \mathrm{mg} / \mathrm{hd}^{-1} / \mathrm{d}^{-1}$ in a single feeding. Current best management practices recommend feeding at approximately the same time daily, with adequate bunk space to ensure proper intake (Patterson et al., 2003). Proper feeding management is essential for successful administration of MGA.

Melengestrol acetate replaced the orally active progestin analogue, medroxyprogesterone acetate (MAP; 6-alpha-methyl-17-alpha-acetoxy-pregn-4-ene-3, 20-dione; Figure 1.1), which was less effective in suppressing estrus and ovulation compared to MGA (Zimbelman et al., 1970). Melengestrol acetate has been used successfully for years in estrus synchronization protocols to suppress estrus, prevent the preovulatory LH surge, inhibit ovulation, (Zimbelman and Smith, 1966; Zimbleman et al., 1970; Imwalle et al., 2002) and induce estrous cyclicity in pre- and peripubertal heifers (Patterson et al., 1990; Imwalle et al., 1998).

During MGA treatment, the development of non-ovulatory persistent dominant follicles (Anderson and Day, 1994; Custer et al., 1994; Yelich et al., 1997) and pulsatile release of LH were detected, even in the face of sufficient $\mathrm{P}_{4}$ levels to inhibit estrus. When fed at the recommended level, MGA is not effective at blocking pulsatile LH release; larger doses (1.5 to $5.0 \mathrm{mg}$ ) of MGA can be administered to prevent pulsatile LH release (Kojima et al., 1995; Hageleit et al., 2000); however, feeding at such high levels is not required because the preovulatory LH surge and ovulation are inhibited when 
MGA is administered at a dosage of $0.5 \mathrm{mg}$ per animal per day. Melengestrol acetate is effective at low levels because of an 11.1-fold higher binding affinity for the progesterone receptor than progesterone (Perry et al., 2005). Furthermore, when administered at 1000-fold higher dose than the recommended rate, MGA was shown to bind the estrogen receptor (Perry et al., 2005), suggesting that the mechanisms controlling the LH surge are more sensitive to MGA compared to those controlling pulsatile LH release (Imwalle et al., 2002).

Controlled Internal Drug Release. The intravaginal progesterone-releasing device referred to as the CIDR (controlled internal drug release) is effective in preventing ovulation and expression of estrus and is approved for use in both heifers and cows in the United States. The T-shaped nylon skeleton is coated with silicon containing $1.38 \mathrm{~g}$ of $\mathrm{P}_{4}$ (Figure 1.1) for CIDRs marketed in the US and $1.9 \mathrm{~g}$ of $\mathrm{P}_{4}$ in other countries, including Canada and Brazil. Progesterone is released uniformly across a $15 \mathrm{~d}$ treatment period (Macmillan and Peterson, 1993). Blood concentrations of $\mathrm{P}_{4}$ are maintained at concentrations greater than $2.0 \mathrm{ng} / \mathrm{mL}$ during treatment and are dependent upon stage of the estrous cycle when CIDRs are administered (Macmillan and Thatcher, 1991). Some studies reported $\mathrm{P}_{4}$ concentrations of $1.2 \mathrm{ng} / \mathrm{ml}$ (Hatler et al., 2008) when CIDRs were administered in the absence of a CL.

When CIDRs are compared to treatment with MGA, differences and slight advantages with regard to management exist. The greatest advantage is the consistency of $\mathrm{P}_{4}$ exposure throughout the CIDR insertion period. Circulating $\mathrm{P}_{4}$ increases rapidly to near peak concentrations approximately $1 \mathrm{~h}$ after CIDR insertion and decline rapidly over a 12-24 h period upon CIDR removal (Perry et al., 2004; Lamb and Larson, 2006). 
Macmillan et al. (1991) used a 1.9 g CIDR over a $15 \mathrm{~d}$ period, and noted $\mathrm{P}_{4}$ concentrations peaked at $8.7 \mathrm{ng} / \mathrm{mL}$ after $6 \mathrm{~h}$ and maintained an average concentration of $5.7 \mathrm{ng} / \mathrm{mL}$ in ovariectomized heifers throughout the treatment period. Hatler et al. (2008) reported circulating concentrations of progesterone during CIDR treatment as low as 0.3 and $0.45 \mathrm{ng} / \mathrm{ml}$ prevented ovulation in up to 48 percent of lactating dairy cows and serum concentrations of at least $0.7 \mathrm{ng} / \mathrm{ml}$ were shown to be sufficient in preventing ovulation in 100 percent of cows. Retention rates reported in heifers treated for 4 to $15 \mathrm{~d}$ ranged from 96-99 percent (Macmillan et al., 1991, 1988; Lucy et al., 2001).

Mallory et al. (2010) noted differences in the variance for interval to estrus and resulting synchrony of estrus in beef heifers following long-term treatment with MGA or CIDR. The authors reported mean expression of estrus following CIDR removal occurred $4 \mathrm{~d}$ earlier than in MGA-treated heifers. Furthermore, distribution of estrus following progestin removal differed between treatments, as CIDR-treated heifers exhibited estrus 1 to $2 \mathrm{~d}$ after insert removal as compared to MGA-treated heifers where estrus expression ranged from 2 to $8 \mathrm{~d}$ following withdrawal of MGA from the feed (Mallory et al., 2010). Pregnancy rate to AI did not differ between MGA- and CIDR-treated heifers in multiple studies (Tauck et al., 2007; Mallory et al., 2010).

Differences in synchrony of estrus between MGA and CIDR treated heifers following treatment withdrawal can be explained by the rate at which these two progestins are cleared from the animal's body. Following CIDR removal, $\mathrm{P}_{4}$ concentrations decline rapidly over a 12 to $24 \mathrm{~h}$ period (Perry et al., 2004). In contrast, fecal concentrations of MGA are 1.4 times higher at $24 \mathrm{~h}$ than at $12 \mathrm{~h}$ post-feeding (Schiffer et al., 2001). This suggests that MGA remains active for a longer period of time 
after withdrawal from feed compared to the rapid clearance of progesterone following CIDR removal. This is most likely due to passage rate of MGA through the digestive tract; MGA cannot be immediately removed from the body in contrast to the rapid removal of a CIDR.

\section{DEVELOPMENT OF LONG-TERM PROGESTIN-BASED METHODS TO SYNCHRONIZE ESTRUS IN BEEF HEIFERS}

Development of the MGA-PG protocol. In 1966, Zimbelman and Smith noted that MGA successfully suppressed estrus and ovulation when administered orally on a daily basis. A feeding period of 10 to $18 \mathrm{~d}$ yielded a similar proportion of MGA-treated heifers exhibiting estrus over a 6 d period following withdrawal of MGA compared to a control group of heifers observed over a $20 \mathrm{~d}$ period. A reduction in first service conception rate was observed when insemination was performed at the first estrus following withdrawal of MGA from the feed (Zimbleman et al., 1970).

Prostaglandin $\mathrm{F}_{2 \alpha}$ and its analogues were combined with progestins to better control the estrous cycle in cattle and improve results from estrus synchronization (Lauderdale, 1972; Louis et al., 1972; Rowson et al., 1972). Short term feeding of MGA for 5 to $7 \mathrm{~d}$ combined with PG administration at MGA withdrawal was developed by Beal and Good (1986) and Patterson et al. (1989). These authors noted a reduction in pregnancy rates for heifers that began treatment in the late luteal stage of the estrous cycle. Numerous studies suggested that decreased fertility resulted from extended 
interovulatory intervals and the formation of persistent follicles (Beal and Good, 1986; Beal et al., 1988;; Patterson et al., 1989).

The MGA-PG protocol now recommended and used extensively by the industry consists of a 14-d feeding period of MGA followed by administration of PG $19 \mathrm{~d}$ after removal of MGA from the feed (Figure 1.2). While a 19-d interval provides optimal results, 17- to 19-d intervals from MGA withdrawal to PG administration provide acceptable results (Brown et al., 1988; Nix et al., 1998; Deutscher, 2000; Lamb et al., 2000). Authors of these studies speculated that improvements in fertility using a 19-d interval may be related to preovulatory follicle size at PG administration which may be a result of differences in follicular dynamics in relation to stage of a follicular wave at the time PG is administered (Martin et al., 2014). In comparison with other treatments, Patterson et al. (1995) observed an improvement in estrous response and increased conception and pregnancy rates of beef cows during the synchronized period compared with PG administration alone. Several studies over the years utilized the progestin norgestomet in combination with estradiol valerate in the Syncro-Mate B protocol and reported high estrous response rates following treatment, but highly variable first service pregnancy rates (Odde, 1990). Nonetheless, MGA-PG produced greater synchronized conception and pregnancy rates when compared to Syncro-Mate B (Brown et al., 1988).

Development of MGA Select. The MGA Select protocol was developed in an effort to improve synchrony of estrus following administration of the MGA-PG protocol. The MGA Select protocol involves a $14 \mathrm{~d}$ feeding period of MGA with GnRH administered 12 d after MGA withdrawal on d 26 and PG administration on d 33 of treatment (Figure 1.2). Wood et al. (2001) hypothesized that addition of GnRH to the 
MGA-PG protocol would increase synchrony of estrus and ovulation of beef heifers assigned to an MGA Select protocol. Heifers that were administered GnRH on d 26 ovulated in response to the injection and initiated a new follicular wave $2 \mathrm{~d}$ later. This resulted in an improvement in the synchronized development of follicular waves following treatment with MGA and prior to the administration of PG (Wood et al., 2001). Estrous cycling heifers exhibited improved synchrony of estrus following treatment with the MGA Select protocol compared to prepubertal heifers (Wood-Follis et al., 2004).

Development of CIDR Select. An experiment was designed by Kojima et al. (2004) to compare pre-synchronization with MGA versus CIDR prior to the administration of GnRH and PG. Heifers received a CIDR insert for $14 \mathrm{~d}$ or were placed on a $14 \mathrm{~d}$ feeding regimen of MGA. Gonadotropin releasing hormone was administered on d 23 or 26 following treatment with CIDR or MGA, respectively (Figure 1.2). No differences were observed between treatment groups on the basis of estrous response following PG; however, pre-synchronization with the CIDR improved synchrony of estrus and conception and pregnancy rates compared with MGA Select-treated heifers. Improvements observed among CIDR-treated heifers likely stem from a reduced interval to estrus (Macmillian and Peterson, 1993) and enhanced synchronization of follicular waves following CIDR removal.

Development of CIDR-PG. Leitman et al. (2008) hypothesized that presychronization with a CIDR for $14 \mathrm{~d}$ prior to GnRH and PG would result in improved synchrony of estrus compared with 7-d CIDR-based or GnRH-PG estrus synchronization protocols. Leitman et al. (2008) compared one long-term CIDR treatment (CIDR Select), two short-term CIDR treatments, both 7-d in length, and GnRH-PG treatment. The 
authors found that long-term CIDR treatment was more effective in inducing an ovulatory response among mixed groups of estrous cycling and prepubertal heifers compared to GnRH-PG or CIDR treatment alone for $7 \mathrm{~d}$ (Leitman et al., 2008).

Leitman et al. (2008) found that nine d following CIDR removal, 88 percent of heifers were reported to be on $\mathrm{d} 7$ or 8 of the estrous cycle which supported a study reported by Schafer et al. (2006). A number of studies revealed that response to $\mathrm{GnRH}$ is most influenced by day of the estrous cycle when GnRH is administered (Martinez et al., 2000; Moreira et al., 2000; Atkins et al., 2008). The greatest ovulatory response to GnRH is realized from follicles on d 5 of the estrous cycle, followed in order by d 15, 10, 18, and 2 (Atkins et al., 2008).

Leitman et al. (2009a) later questioned whether the addition of GnRH to the CIDR-PG protocol was necessary to improve synchrony of estrus following PG (Figure 1.2; Leitman et al., 2009b). Heifers assigned to a CIDR-PG protocol exhibited greater synchrony of estrus compared to heifers assigned to CIDR Select, and AI pregnancy rate was greater for heifers assigned to CIDR-PG than heifers assigned to CIDR Select (Leitman et al., 2009b). While both protocols are effective in synchronizing estrus regardless of pubertal status, the addition of GnRH is not required following long-term CIDR treatment.

CIDR vs MGA as a progestin source. Tauck et al. (2007) and Mallory et al. (2010) compared pre-sychronization with MGA and CIDR prior to the administration of PG. Treatments were compared on the basis of synchrony of estrus, estrous response, and pregnancy rate. Both studies reported an increased estrous response and reduced interval to estrus after PG resulting from CIDR-PG treatment (Tauck et al., 2007; Mallory et al., 
2010); however, there appeared to be no difference between treatments in conception rate to AI, AI pregnancy rate, or pregnancy rate at the end of a breeding period. As such, producers can be confident in utilizing either MGA or CIDR as effective methods of presynchronization.

CIDR-PG vs MGA-PG for Fixed-Time Artificial Insemination. Fixed-time artificial insemination concentrates time and labor for beef producers and provides the opportunity to utilize AI without the need to detect estrus (Patterson et al., 2017). Vraspir et al. (2013) designed a study to describe differences between CIDR-PG and MGA-PG treatments followed by FTAI (Figure 1.3). The authors reported similar pregnancy rates to FTAI between CIDR- and MGA-treated heifers (61 vs 62 percent, respectively). Heifers that failed to become pregnant to the initial FTAI were detected for estrus and inseminated 12 to $18 \mathrm{~h}$ after estrus onset. Similar numbers of CIDR- and MGA-treated heifers returned to estrus ( 26 vs 27 percent, respectively), but a greater pregnancy rate to the second AI service was reported in heifers previously treated with MGA than CIDR (66 vs 56 percent, respectively; Vraspir et al., 2013). Collectively, these studies (Tauck et al., 2007; Mallory et al., 2010; Vraspir et al., 2013) demonstrated that FTAI yielded pregnancy rates that were similar to those resulting from artificial insemination performed on the basis of detected estrus utilizing long-term MGA or CIDR based protocols. 


\section{USE OF PREBREEDING EXAMS TO TIME ESTRUS SYNCHRONIZATION PROGRAMS}

Prebreeding examinations that include reproductive tract scores (RTS) provide the opportunity to assess reproductive development and determination of possible abnormal situations that may limit a heifer's reproductive potential (Patterson et al., 1999; Lamb, 2013; Patterson et al., 2013). Thomas et al. (2017) recently reported that many of the differences in pregnancy outcomes among Brahman-influenced heifers are explained by differences in pubertal status of heifers determined by RTS.

Anderson et al. (1991) developed the RTS scoring system to assist beef producers in selecting replacement heifers and more appropriately time estrus synchronization programs (Table 1.2). The reproductive tract scoring (RTS) system assesses pubertal status of heifers by transrectal palpation of the uterus and ovaries. Heifers are evaluated on a scale of one to five, where a RTS of one and two are considered to be "prepubertal" and are likely greater than 30 days from attaining puberty. Peripubertal heifers are assigned a RTS of three and are likely within 30 days of attaining puberty. Estrous cycling, or pubertal females are assigned scores of four or five and are considered to be in the follicular or luteal phases of the estrous cycle, respectively.

Upon palpation, a heifer that is assigned a RTS of one, presents an infantile reproductive tract with small, toneless uterine horns $(<20 \mathrm{~mm}$ in diameter $)$ and small ovaries devoid of palpable follicles. A heifer assigned a score of two will have slightly larger uterine horns ( 20 to $25 \mathrm{~mm}$ in diameter) and ovaries with follicles in the range of 8 $\mathrm{mm}$ in size. Heifers assigned an RTS of three are noted as having increased uterine 
diameter (25 to $30 \mathrm{~mm}$ ) and follicle size ( 8 to $10 \mathrm{~mm}$ ). Heifers assigned a score of 4 are considered to be estrous cycling, and are distinguished on the basis of coiled, turgid uterine horns (30 $\mathrm{mm}$ in diameter) and the presence of a palpable preovulatory size follicle (> $10 \mathrm{~mm}$ in diameter). Heifers with a palpable CL are assigned a RTS of five and present uterine diameters similar to those with RTS of four. Figure 1.4 combines the associated endocrine and ovarian changes that occur as a heifer approaches puberty in addition to the corresponding RTS that would be assigned at respective points in development (Patterson et al., 2002).

Reproductive tract scoring was reported to be a repeatable and accurate means of determining pubertal status in heifers (sensitivity $=82 \%$, specificity $=69 \%$; Rosenkrans and Hardin, 2003). Reproductive tract scoring may be used effectively as a predictor of heifer fertility, and correlates well with pregnancy rate to FTAI, 50-d pregnancy rates, and calf weaning weight (Pence and BreDahl, 1998; Pence et al., 2007; Holm et al., 2009). The RTS system can be used effectively to assist producers in selecting young females for lifetime cow production, even before the start of the first breeding season.

\section{NATURAL SERVICE BREEDING STRATEGIES}

Despite continued progress toward improving estrus synchronization and AI technologies, the most recent USDA NAHMS (2009) survey cites natural service as the most common breeding strategy in the US, representing 79 and 94 percent of heifers and cows serviced, respectively. Very few heifers and cows are serviced only by AI (3.9 and 
1.1 percent, respectively), so the importance of natural service to breeding programs nationwide is significant, and arguably underrepresented with regard to current research.

Induction of puberty with bull introduction. Research of a "bull effect" on inducing puberty in heifers conducted over the last 30 years is limited and has yielded mixed results. Roberson et al. (1987) reported that there was no significant influence of the presence of mature bulls on the age and weight at puberty of peripubertal beef heifers. In a later study, however, Roberson et al. (1991) showed a 70 day exposure to bulls significantly reduced age at which a functional corpus luteum developed. Furthermore, a study performed in South America reported a greater number of cyclic heifers and subsequently higher pregnancy rates when Bos indicus females were exposed to deviated mature bulls prior to AI (Quadros and Lobato, 2004). This was confirmed by a number of other studies which observed decreased age at puberty in both Bos indicus and Bos taurus females (Olivera et al., 2009; Fiol et al., 2010).

The ambiguous results provided from studies involving bull exposure and its effect on puberty attainment in beef heifers pale in comparison to the known effects of presence of the male in other livestock species. A great deal of research was conducted in swine production systems with consistent results reported in the literature (Williams et al., 2005; Filha et al., 2009; Patterson et al., 2002b). It was shown repeatedly that exposure to boars, either via direct or fenceline contact, had a significant influence on the attainment of puberty in peripubertal gilts. These data suggest that more studies are needed to develop strategies that utilize bull exposure to advance sexual development in later maturing breeds of beef heifers. 
Bull-to-Female Ratio. The current recommendation for bull-to-female ratios (BFR) in beef mating systems is a 1:20 to 1:30 ratio for mature bulls and a 1:15 to 1:20 ratio for yearling bulls (Ellis, 2008). These ratios are in line with current BFR reported by producers which claim 1:17 and 1:25 average BFR for yearling and mature bulls, respectively (USDA NAHMS, 2009). A number of studies examined a variety of BFR and suggest that the main driver of reproductive performance is primarily based on reproductive status, sexual and social behavior, and environmental constraints (Rupp et al., 1977; Pexton et al., 1990; Ellis, 2008). Rupp et al. (1977) compared single- and multisire BFR at 1:25, 1:44, and 1:60, noting that fertility, libido and mating ability of the individual sires were more important factors than ratio itself. These authors suggested a BFR of 1:60 was adequate, provided bulls were mature and highly fertile, with adequate scrotal circumference (Rupp et al., 1977). The Society for Theriogenology sets threshold measurements for adequate scrotal circumference for various age classes of young bulls (Table 1.3; Chenoweth et al., 2010). Additionally, single-sire mating can eliminate bull competition and conflicts, which detract from effective breeding (Ellis, 2008).

Natural Service with Estrus-Synchronized Females. Bulls can be introduced following administration of an estrus synchronization protocol to produce a greater number of early calving cows. Research has demonstrated that natural service is an effective alternative to AI in estrus synchronization systems (Farin et al., 1982, 1989; Pexton et al., 1989). Nevertheless, estrus synchronization places unique pressure on bulls when large numbers of females express estrus within a relatively short period of time.

Considerations for natural service breeding during a synchronized period include several factors influenced by both males and females. When FTAI is performed, the goal 
of estrus synchronization is to maximize the number of females that express estrus within a narrow window of time. The opposite is true with regard to estrus synchronization followed by natural service. In this case, a protocol that produces a more extended synchronized period (Ellis, 2008) would be preferred in an effort to spread bull power out over several additional days. Prostaglandin $F_{2 \alpha}$ is utilized in nearly all estrus synchronization protocols currently recommended and used in the U.S. The addition of PG often leads to a concentrated period of estrous expression, however administration of PG is typically contraindicated in natural service programs (Healy et al., 1993; Stegner et al., 2002). One strategy to distribute estrus more widely during a synchronized period would be to introduce bulls after the initial synchronized period, thereby reducing breeding pressure during the subsequent estrus. Additionally, long term progestin-based estrus synchronization protocols can be used in beef heifers without the addition of PG, in which case bulls are introduced $10 \mathrm{~d}$ following removal of CIDR or MGA (Stegner et al., 2002).

BFR is important in synchronized natural service mating systems because of the potential to overwork bulls or deplete semen reserves (Ellis, 2008; Stegner et al., 2002). Healy et al. (1993) reported no difference between BFR of 1:16 and 1:25, but noted that a higher ratio of 1:50 reduced pregnancy rates of estrous synchronized heifers. Bulls may be used for intense 2 to $5 \mathrm{~d}$ breeding periods, but should then be rested for 2 to 3 weeks prior to further breeding (Ellis, 2008). 


\section{CONSIDERATIONS FOR REPRODUCTIVE MANAGEMENT OF BOS INDICUS-INFLUENCED BEEF HEIFERS}

Roughly 40 percent of our nation's beef herd is maintained in relatively hot and humid subtropical environments of the southern and southeastern regions of the US (Cundiff et al., 2012). As such, the influence of Bos indicus genetics plays an important role in the adaptation of cattle to these regions. The Bos indicus species is known for its ability to tolerate high solar energy, high ambient temperatures and relative humidity, parasite and disease challenges, and high fiber forage diets (Koger, 1963; Randel, 2005; Sartori et al., 2010; Yelich and Bridges, 2012). These important production considerations make Bos indicus breeds and their crosses a central component of subtropical beef production systems.

Although the introduction of Bos indicus genetics provide an improvement in environmental adaption in subtropical regions of the US, differences exist between Bos indicus and Bos taurus breeds with regard to attainment of puberty, sensitivity to pharmaceuticals used to synchronize estrus, expression of estrus, and endocrine dynamics.

Puberty. Many heifers produced in the tropics are raised on low quality forages with deficiencies in protein, energy, and/or mineral availability (Sartori et al., 2010). Many of these animals, regardless of biological type, have difficulty reaching puberty until 2 years of age, while contemporaries fed in a temperate climate can reach puberty as early as 9 to 12 months of age (Fajersson et al., 1991). Independent of nutrition, however, Nogueira (2004) proposed an underlying genetic factor accounting for these differences, 
since some females of similar biological type managed under the same conditions become pregnant earlier than others.

Bos taurus heifers generally reach puberty at 10 to 18 months of age (Smith et al., 2007). In stark contrast, purebred Bos indicus heifers in the subtropics typically reach puberty between 16 and 40 months, with a mean of 25 months (Sartori et al., 2010). One of the landmarks of sexual maturity in cattle is the decrease in negative feedback of estradiol on LH release. This occurs coincidentally with the onset of puberty attainment in both Bos taurus and Bos indicus, but LH pulsatility begins earlier in Bos taurus heifers, especially during the initial period of weight gain (Rodrigues et al., 2002). Unfortunately, selection pressure for age at puberty has been much less intensive when compared to Bos taurus breeds (Eler et al., 2002). Age at first conception and heifer pregnancy are highly heritable traits $\left(h^{2}=0.44\right.$ to 0.67 and $h^{2}=0.58$ to 0.66 , respectively; Eler et al., 2006; Pereira et al., 2007), suggesting that improvements in these traits may be realized in Bos indicus influenced heifers if appropriate selection pressure is imposed.

Nutrition plays an important role in early attainment of puberty in late maturing biological types or breeds of cattle, including Bos indicus. Patterson et al. $(1989,1991)$ manipulated energy levels fed to Bos indicus-influenced heifers during the postweaning to prebreeding development phase in order for heifers to attain either 55 or 65 percent of mature body weight prior to the breeding period. Bos indicus-influenced heifers fed to reach 65 percent of mature body weight reached puberty earlier and became pregnant earlier during the breeding season (Patterson et al., 1989a, 1991). The difference between postweaning energy treatment is less pronounced in many of the Bos taurus breeds suggesting that Bos indicus influenced heifers are particularly sensitive to nutritional 
deficiencies prior to breeding. Nutritional management of Bos indicus-influenced heifers designed for them to reach at least 60 percent of mature body weight will ensure a majority of females are cycling prior to initiation of the breeding period (Dale et al., 1959; Patterson et al., 1992).

Ovarian Dynamics. Differences are evident between biological types of cattle with regard to follicular wave dynamics and estrous cycle patterns. A number of studies identified the majority of Bos indicus heifers exhibit three follicular waves, but have observed animals with 2 to 5 waves during a particular cycle (Figueiredo et al., 1997; Alvarez et al., 2000; Mollo et al., 2007). The number of follicular waves influences the interestrous interval, where studies have shown that females with two-wave cycles experience shorter interestrous intervals than three-wave females (Savio et al., 1988, 1990; Sirois \& Fortune 1988; Alvarez et al., 2000; Townson et al., 2002; Sartori et al., 2004). Regardless of the number of follicular waves a heifer experiences, the average interestrus interval for both Bos taurus and Bos indicus females is 21 d (Bó et al., 2003 and Sartori et al., 2004).

Estrous Behavior. Historically, detection of estrous activity was required to facilitate use of artificial insemination, although development of estrus synchronization protocols used for appointment breeding reduces or eliminates the need for estrous detection. Nevertheless, accurate timing of estrus onset and duration of estrus requires more careful evaluation in Bos indicus influenced breeds of cattle compared to Bos taurus breeds (Rae et al., 1999).

A study by Mizuta (2003) compared estrous behavior of Nelore (Bos indicus) and Angus cows (Bos taurus) using Heat-Watch radiotelemetry. Nelore cows stood to be 
mounted for a shorter period of time compared to Angus cows $(12.9 \pm 2.9$ vs $16.3 \pm 4.8$ h, respectively; Mizuta, 2003), and a majority of Nelore cows exhibited estrus during the late evening and at night (Pinheiro et al., 1998). These features, unique to Bos indicus, complicate the efficiency of estrus detection when insemination is based on detected estrus.

Sensitivity to Pharmaceuticals. Bos indicus breeds of heifers are known to maintain higher circulating concentrations of progesterone than Bos taurus females (Carvalho et al., 2008). These females are more sensitive to high circulating concentrations of progesterone and exogenous gonadotropins than Bos taurus females (Randel, 1984; Carvalho et al., 2008). This creates a number of concerns with regard to LH pulsatility, follicular growth, and ovulatory capacity.

When administered at prescribed concentrations, treatment with MGA or CIDR prevents maturation and ovulation of preovulatory ovarian follicles and resulting expression of estrus (Nellor and Cole, 1956; Hansel et al., 1961; Lamond, 1964). Progesterone provides negative feedback on the pulsatile release of GnRH from the hypothalamus, thereby suppressing LH and FSH secretion and decreasing the number of GnRH receptors on the anterior pituitary (Hansel and Convey, 1983). Because Bos indicus females are particularly sensitive to the effects of progesterone, these females are more likely to have suppressed LH and FSH pulsatile secretion. Bos indicus breeds have an inherently low capacity to secrete LH and a much greater sensitivity to exogenous gonadotropins than Bos taurus breeds (Randel, 1984). Because the growing follicle is dependent on both of these gonadotropes during development, a reduction in the 
secretion of LH and FSH can further diminish size of the ovulatory follicle following progestin treatment (Sartori et al., 2010).

Strategies were designed to reduce endogenous $\mathrm{P}_{4}$ production or limit exogenous $\mathrm{P}_{4}$ administration during treatment with a short-term progestin-based estrus synchronization protocol in an effort to improve pregnancy outcomes in Bos indicusinfluenced females exposed for AI (Carvalho et al., 2008; Peres et al., 2009; Mantovani et al., 2010; Cipriano et al., 2011; Williams et al., 2012). Carvalho et al. (2008) noted that the addition of $\mathrm{PG}$ at treatment onset reduced serum $\mathrm{P}_{4}$ concentrations and increased dominant follicle size and ovulation rate of Bos indicus and Bos indicus-influenced heifers. A modified 5-d CO-Synch + CIDR protocol developed by Williams et al. (2012), referred to as "Bee Synch", (Figure 1.5) increased pregnancy rates to FTAI in Brahman influenced cows when PG was administered at CIDR insertion to decrease circulating concentrations of $\mathrm{P}_{4}$ during the treatment period. Similar improvements were not reported in Brahman influenced heifers.

Transrectal Ovarian Palpation. A number of studies noted the challenge in accurately determining CL presence determined via transrectal palpation in Bos indicus influenced heifers, and (Symington and Hale, 1967) suggest that ovarian hormonal activity and morphological changes of the ovary are less pronounced than in Bos taurus cattle. Berardinelli et al. (1979) proposed that small, non-palpable luteal tissue embedded deeply in ovaries of Bos indicus heifers produces a short rise in $\mathrm{P}_{4}$ among prepubertal females. Therefore, accurately identifying Bos indicus females with developed luteal tissue can be difficult by transrectal palpation alone. 
Response to Physiologic Stress. Bos indicus-influenced cattle exhibit increased susceptibility to stress associated events, and stress induced by animal handling and frequent sorting has the potential to result in decreased pregnancy rates among some Bos indicus-influenced heifers (Galina et al., 1996; Dobson and Smith, 2000; Cooke et al., 2009, 2012; Cooke, 2014). A number of studies were designed to examine the effects of stressors on reproductive performance and suggested management schemes to abate them.

Cortisol is produced in response to stress and blood cortisol concentrations are reported to be higher in temperamental cattle compared to cattle that are calm (Cooke et al., 2009a; 2009b; Cooke et al., 2012a; Francisco et al., 2012a). Elevated concentrations of cortisol are associated with a decrease in LH pulsatility by inhibiting pituitary responsiveness to GnRH (Breen and Karsch, 2003). As a result, detrimental effects on follicular growth and maturity may be potentiated by increased stressors around breeding in Bos indicus females.

Recently, research has demonstrated that acclimation to stressors reduced cortisol, increased prepubertal $\mathrm{P}_{4}$, and hastened puberty onset (Cooke et al., 2009, 2012, 2014). Heifers that were acclimated to human handling exhibited improved temperament, reduced cortisol, and attained puberty and became pregnant earlier compared to nonacclimated heifers (Cooke et al., 2009b, 2010b). Acclimation to human interaction seems to be exclusive to heifers, as cows subjected to acclimation did not improve temperament or reproductive performance (Cooke et al., 2009a). Additionally, heritability of temperament was shown to be moderately to highly heritable $\left(\mathrm{h}^{2}=0.4\right.$; O'Bleness et al., 1960). Therefore, improvements in temperament to reduce physiological stress can be 
achieved by culling heifers with poor temperaments and acclimating heifers to human interaction prior to breeding. 


\section{SUMMARY}

Limited information is available to assist beef producers in southern regions of the United States in implementing breeding management strategies that improve reproductive performance of Bos indicus-influenced breeds of beef heifers managed in these environments during their first breeding season. Currently, only one study is reported in the literature from research conducted in the U.S. that evaluated long-term progestin treatment of Bos indicus-influenced beef heifers prior to FTAI (Thomas et al., 2017). Given this consideration, it is essential to gain a better understanding of ways in which to better manage and control puberty induction, estrus, and ovulation in breeding systems involving natural service or artificial insemination focused specifically on these breeds and/or biological types of cattle. To date, no comprehensive studies are reported in the literature that involve consideration of these factors in total. These considerations form the basis for the research presented in this thesis. 
Table 1.1. Characteristics of the bovine estrous cycle.*

\begin{tabular}{lcl}
\hline \hline Stage & Day of the estrous cycle & Characteristics \\
\hline Estrus & 0 & Behavioral estrus (heat) \\
Metestrus & 1 to 4 & Ovulation and CL formation \\
Diestrus & 5 to 16 & $\begin{array}{l}\text { CL growth and maintenance, } \\
\text { Progesterone secretion } \\
\text { Luteolysis and rapid follicular } \\
\text { growth }\end{array}$ \\
\hline
\end{tabular}

* Plasse et al., 1970; Senger, 2012. 


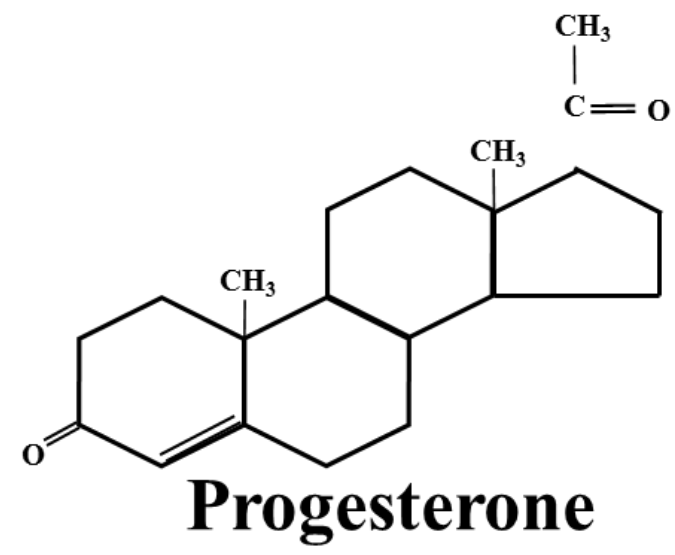

Pregn-4-ene-3, 20-dione

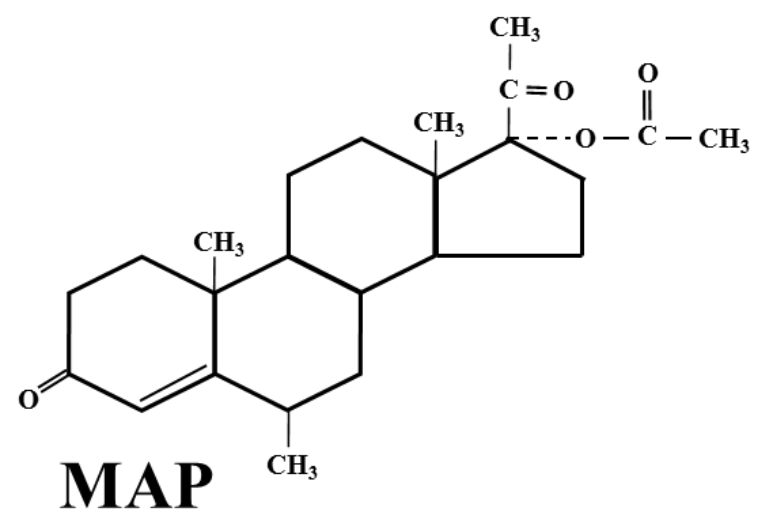

(medroxyprogesterone acetate)

6-alpha-methyl-17-alpha-acetoxy-pregn-4-ene-3, 20-dione

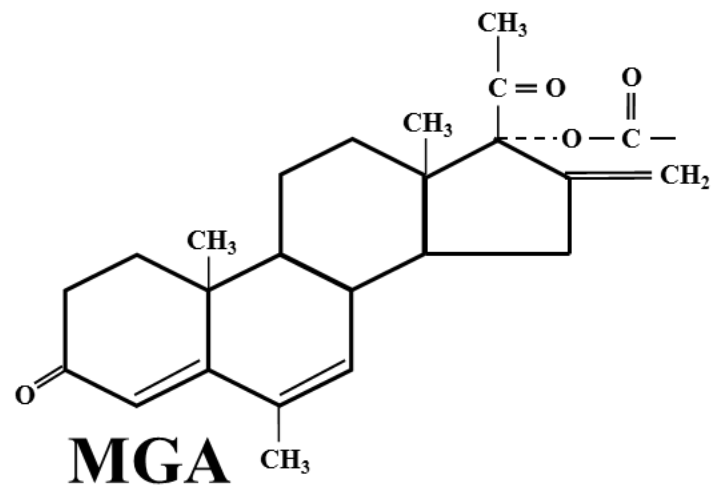

(melengestrol acetate)

6-methyl-17-alpha-acetoxy-16-methylene-pregn-4, 6-diene-3, 20-dione

Figure 1.1. Chemical structures of progesterone $\left(\mathrm{P}_{4}\right)$, medroxyprogesterone acetate (MAP), and melengestrol acetate (MGA). 
MGA Select

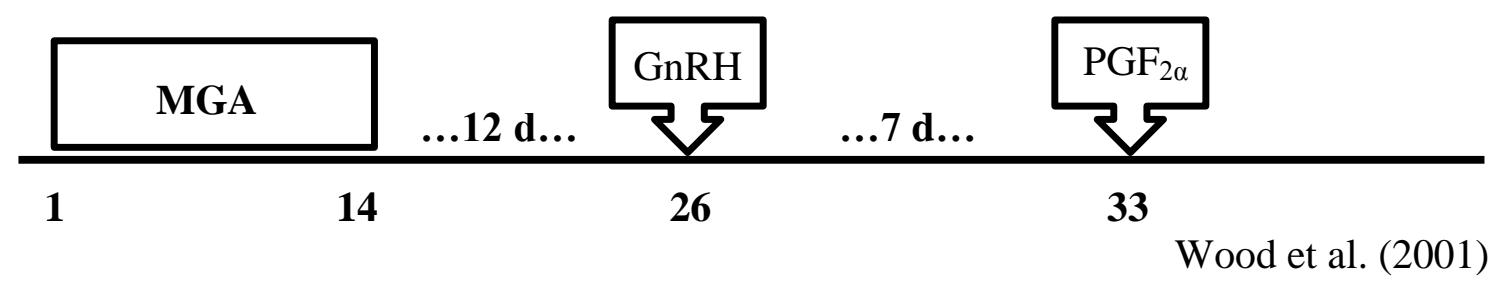

\section{CIDR Select}
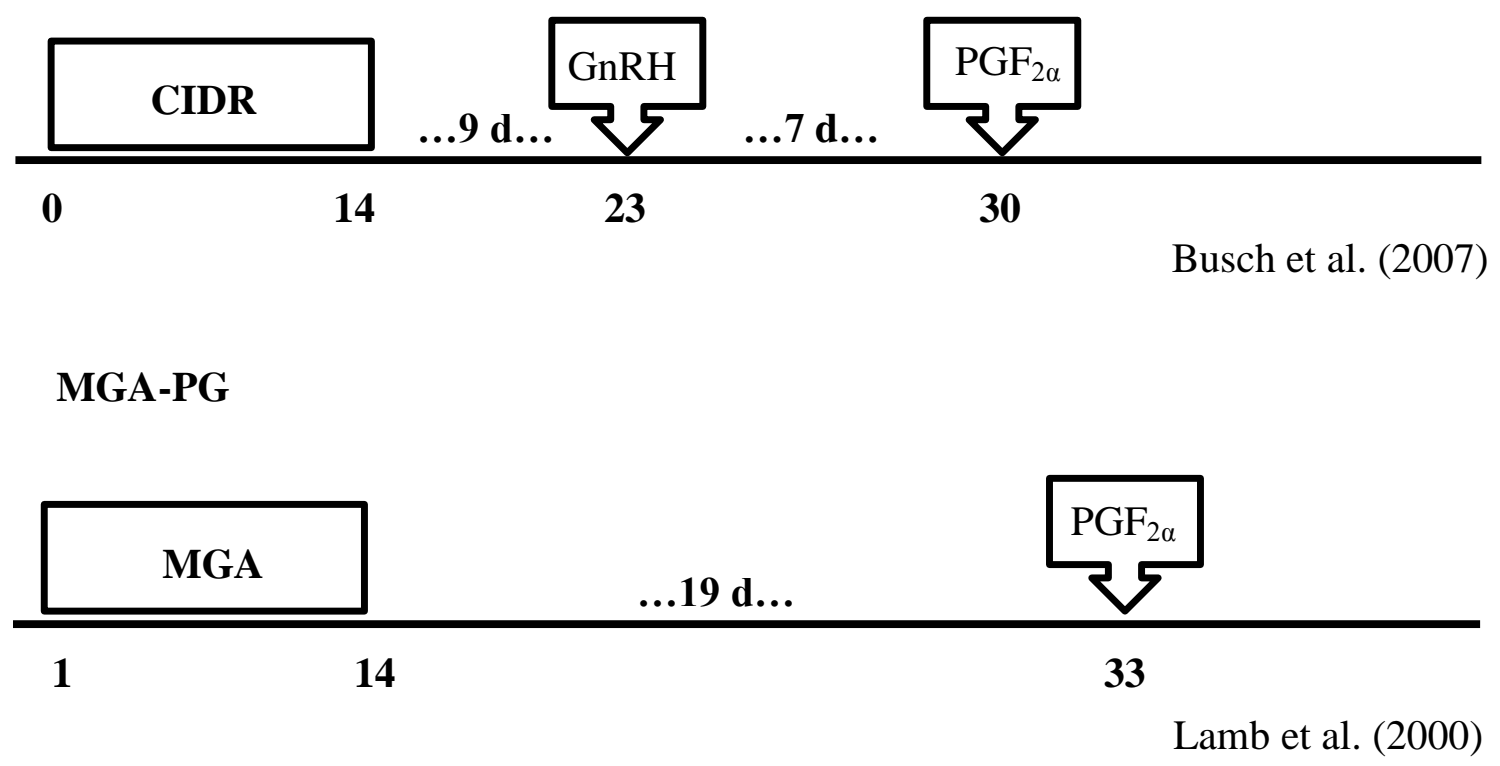

\section{CIDR-PG}

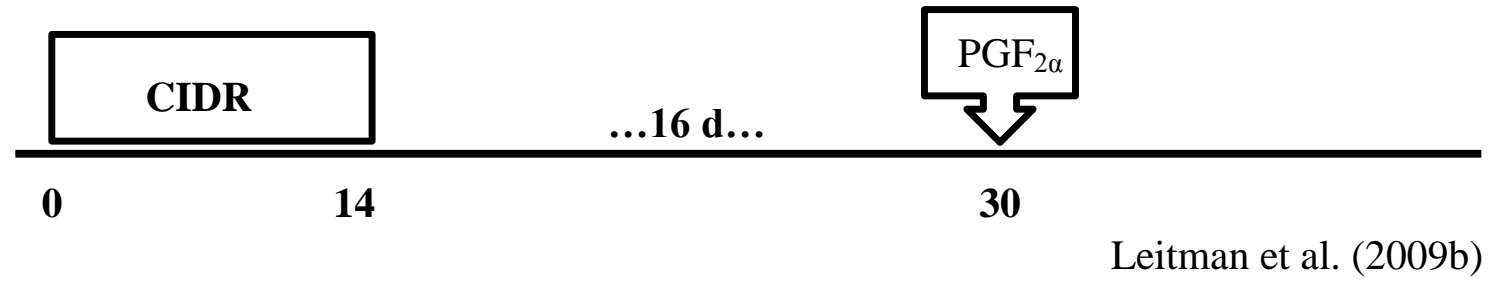

Treatment Days

Figure 1.2. Treatment schedules for MGA Select, CIDR Select, MGA-PG and CIDR-PG. 

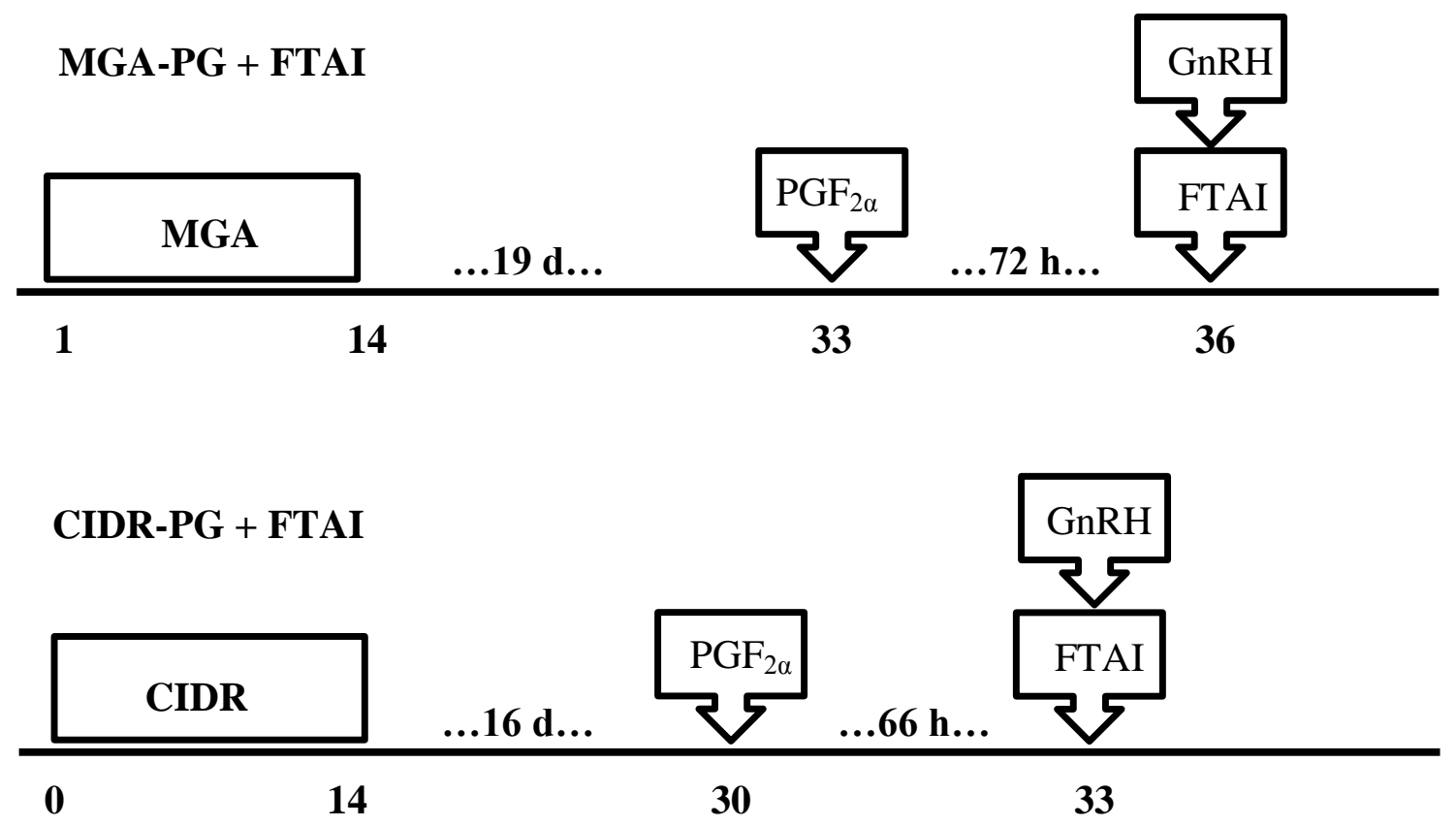

Figure 1.3. Treatment schedules for MGA-PG and CIDR-PG utilizing a FTAI approach (Vraspir et al., 2013). 
Table 1.2. Characteristics associated with the reproductive tract scoring system.*

\begin{tabular}{|c|c|c|c|c|}
\hline Pubertal Group & RTS & Cycling status & Uterine horns & Ovaries \\
\hline \multirow[b]{2}{*}{ Prepubertal } & 1 & Infantile & no tone & $\begin{array}{l}\text { No palpable } \\
\text { follicles }\end{array}$ \\
\hline & 2 & $\begin{array}{l}\text { Non-cycling } \\
>30 \mathrm{~d} \text { to } \\
\text { puberty }\end{array}$ & no tone & $\begin{array}{l}8 \mathrm{~mm} \\
\text { follicles }\end{array}$ \\
\hline Peripubertal & 3 & $\begin{array}{c}\text { Non-cycling } \\
<30 \mathrm{~d} \text { to } \\
\text { puberty }\end{array}$ & slight tone & $\begin{array}{l}\text { 8-10 mm } \\
\text { follicles }\end{array}$ \\
\hline \multirow{2}{*}{ Pubertal } & 4 & $\begin{array}{l}\text { Estrous } \\
\text { cycling; } \\
\text { Follicular } \\
\text { phase }\end{array}$ & coiled & $\begin{array}{l}>10 \mathrm{~mm} \\
\text { follicles }\end{array}$ \\
\hline & 5 & $\begin{array}{c}\text { Estrous } \\
\text { cycling; } \\
\text { Luteal phase }\end{array}$ & distended & $\begin{array}{l}\qquad>10 \mathrm{~mm} \\
\text { follicles, corpus } \\
\text { luteum present }\end{array}$ \\
\hline
\end{tabular}

*Anderson et al., 1991. 


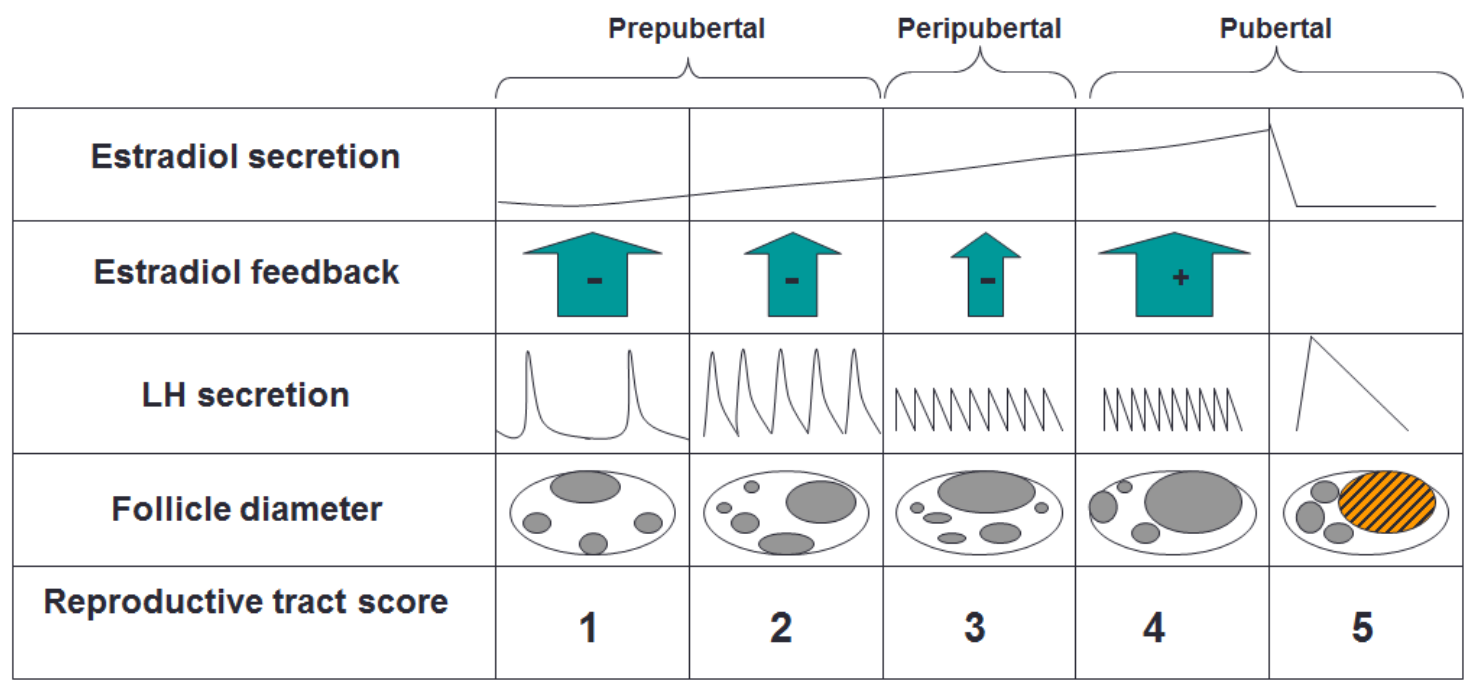

Figure 1.4. A conceptual model for endocrine and ovarian changes associated with onset of puberty in heifers (Day and Anderson, 1998). 
Table 1.3. Scrotal circumference by age in bulls.*

\begin{tabular}{cc}
\hline Age & Scrotal Circumference \\
$\leq 15 \mathrm{mo}$. & $30 \mathrm{~cm}$ \\
$>15 \mathrm{mo} . \leq 18 \mathrm{mo}$. & $31 \mathrm{~cm}$ \\
$>18$ mo. $\leq 21 \mathrm{mo}$. & $32 \mathrm{~cm}$ \\
$>21$ mo. $\leq 24 \mathrm{mo}$. & $33 \mathrm{~cm}$ \\
$>24$ mo. & $34 \mathrm{~cm}$
\end{tabular}

*Society for Theriogenology guidelines established 1993;

Chenoweth et al., 2010. 


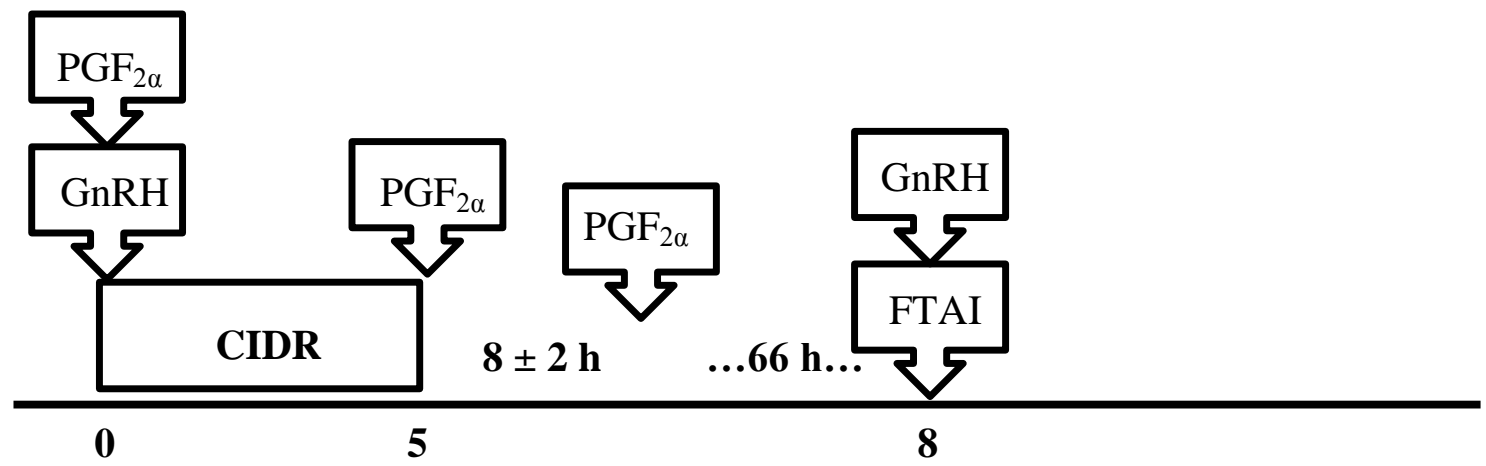

Figure 1.5. Treatment schedule for "BEE Synch" or PG 5-d CO-SYNCH + CIDR utilizing a FTAI approach (Williams et al., 2012). 


\title{
CHAPTER 2
}

\section{COMPARISON OF LONG-TERM PROGESTIN-BASED PROTOCOLS TO SYNCHRONIZE ESTRUS PRIOR TO FIXED-TIME ARTIFICIAL INSEMINATION OR NATURAL SERVICE IN BOS INDICUS-INFLUENCED BEEF HEIFERS}

\begin{abstract}
An experiment was designed to evaluate reproductive performance of Bos indicus-influenced beef heifers $(\mathrm{n}=1,456)$. Weights and reproductive tract scores (RTS; Scale 1-5) were obtained for heifers prior to assignment of one of five treatments: Nonsynchronized + natural service $(\mathrm{NS})$; melengestrol acetate + natural service $(\mathrm{MGA}+\mathrm{NS}$; $\left.0.5 \mathrm{mg} \cdot \operatorname{animal}^{-1} \cdot \mathrm{d}^{-1}\right) ; 14-\mathrm{d}$ controlled internal drug release + natural service $(\mathrm{CIDR}+\mathrm{NS}$; 1.38g progesterone); 14-d MGA-PG + fixed-time AI (FTAI); and 14-d CIDR-PG + FTAI. Heifers in the three NS treatments were exposed to fertile bulls for $65 \mathrm{~d}$, beginning $10 \mathrm{~d}$ after progestin removal for CIDR + NS and MGA + NS treatments. Heifers in FTAI treatments were administered $\mathrm{PGF}_{2 \alpha}(\mathrm{PG} ; 25 \mathrm{mg}$, IM) 16 or $19 \mathrm{~d}$ following CIDR or MGA removal. Fixed-time AI was performed 66 and $72 \mathrm{~h}$ after PG for CIDR-PG and

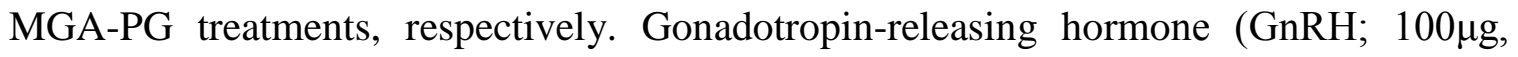
i.m.) was administered at FTAI. Estrus detection aids were applied at PG for heifers in FTAI treatments and evaluated at AI. Heifers in FTAI treatments were exposed to fertile bulls $12 \mathrm{~d}$ following FTAI. Blood samples were collected and ovarian ultrasounds performed at PG administration and FTAI to compare serum concentrations of estradiol
\end{abstract}


and progesterone and to evaluate follicular dynamics among a subset of heifers assigned to FTAI treatments. Pregnancy status was determined at the end of a $65-\mathrm{d}$ breeding period. Data were analyzed using PROC FREQ and GLIMMIX procedures of SAS. Mean concentrations of estradiol at AI differed between MGA- versus CIDR-treated heifers $(\mathrm{P}=0.04 ; 8.2$ versus $6.6 \mathrm{pg} / \mathrm{ml})$, however estrous response after PG (52\% versus $53 \%)$ and pregnancy rates after FTAI (40\%) did not differ between MGA- and CIDR-PG treatments, respectively. Across all treatments, pregnancy rates were compared on 21, 30 and $60 \mathrm{~d}$ of the breeding period based on pubertal status (prepubertal RTS $=1$ and 2 ; peripubertal $\mathrm{RTS}=3$; pubertal $\mathrm{RTS}=4$ and 5). Pregnancy rates differed at each time point based on pretreatment pubertal status $(\mathrm{P} \leq 0.02)$ and weight $(\mathrm{P} \leq 0.05)$. No differences were apparent with regard to progestin type at any time point, although higher pregnancy rates $(\mathrm{P} \leq 0.004)$ were observed among NS treatments than FTAI followed by NS exposure at Days 30 and 60. These data can be used as a basis for recommending improvements in reproductive management of Bos indicus-influenced heifers.

Key Words. Estrus synchronization, Bos indicus, beef heifer, natural service

\section{INTRODUCTION}

Bos indicus breeds of beef cattle are known for their ability to thrive in subtropical environments, and percentage Bos indicus breed composition accounts for a large proportion of the cattle population in the southern United States and worldwide (Sartori et al., 2010; Cundiff et al., 2012). However, with the influence of Bos indicus 
genetics come inherent concerns relative to reproductive efficiency in comparison to Bos taurus contemporaries. These concerns include later attainment of puberty, heightened response to physiological stress, and differing response of Bos indicus-influenced heifers to certain reproductive treatments (Cooke et al., 2009a, 2009b, 2010a, 2010b; Sartori et al., 2010; Vasconcelos et al., 2013).

South American researchers developed several protocols for use in synchronizing estrus in purebred Bos indicus breeds of beef cattle. However, these protocols generally employ estradiol products that are not currently approved for use by the United States Food and Drug Administration. In the United States, adoption of AI has been limited in regions with a high prevalence of Bos indicus-influenced genetics, likely due to a lack of estrus synchronization approaches that are effective in these breeds or breed crosses. For Bos taurus heifers, long-term progestin-based estrus synchronization protocols using melengestrol acetate (MGA) or Controlled Internal Drug Release (CIDR) inserts are well-characterized (Brown et al., 1988; Lamb et al., 2000; Leitman et al., 2008; Mallory et al., 2010) and have been widely adopted across the United States. In Bos indicusinfluenced heifers, however, long-term progestin-based estrus synchronization protocols have been evaluated less extensively by comparison, with use of the CIDR-PG protocol in Bos indicus-influenced heifers investigated only recently (Thomas et al., 2017).

Treatment with exogenous progestins accelerates attainment of puberty and improves pregnancy rates among pre- and peripubertal heifers (Gonzalez-Padilla et al., 1975; Patterson et al., 1990). Exposure to progesterone increases LH pulsatility and is associated with an increase in the diameter of the largest follicle present on the ovary (Hansel and Convey, 1983). Although long-term progestin treatment often results in the 
formation of a persistent follicle with reduced fertility (Sirios and Fortune, 1990; Anderson and Day, 1996; Yelich et al., 1997), the reduction in fertility following longterm progestin treatment is not a concern due to the design of long-term progestin protocols, as heifers are not exposed for breeding until the subsequent estrus.

Additionally, because pregnancy rates were shown to be higher in a subsequent estrus following a heifer's pubertal estrus (Byerley et al, 1987), long-term progestin-based protocols may offer advantages over short-term protocols in that estrous cyclicity is induced among pre- and peri-pubertal heifers earlier in the treatment schedule.

This experiment was designed to evaluate the efficacy of long-term progestinbased treatments for Bos indicus-influenced beef heifers and to characterize effects relative to pubertal status, progestin type, and breeding service type. The 14-d CIDR and 14-d MGA based estrus synchronization protocols were compared in conjunction with natural service (NS) or fixed-time artificial insemination (FTAI), with results compared to a non-synchronized NS treatment. We hypothesized that use of long-term progestin treatments would result in a greater number of heifers becoming pregnant early in the breeding season as compared to non-synchronized NS treated heifers, and that pretreatment pubertal status would play a critical role in breeding success following FTAI.

\section{MATERIALS AND METHODS}

All experimental procedures were performed under guidelines established by the University of Missouri-Columbia Animal Care and Use Committee. 
2.1 Animals. Bos indicus-influenced beef heifers utilized in this experiment were 1/8 to 3/8 Brahman (Bos indicus) with varying proportions of Angus, Red Poll and/or South Devon (Bos taurus). Heifers $(\mathrm{n}=1456)$ ranged in age from 12 to 15 months, although no individual birthdate information was available. Heifers were managed on pasture in five treatment groups with approximately equal numbers of heifers per pasture. All heifers received a corn silage-based partial mixed ration (PMR) and had equal access to ryegrass pasture throughout the treatment period. Individual reproductive tract scores (RTS; scale 1-5; Anderson et al., 1991; Rosenkrans and Hardin, 2003; Holm et al., 2009) and weights were obtained for all heifers prior to treatment initiation.

2.2 Experimental Treatments. Heifers remained within their group of origin as presented at RTS and one of five treatments (Fig. 1) was randomly assigned to each pen of heifers: 1) NS only 2) MGA + NS 3) CIDR + NS 4) MGA-PG + FTAI and 5) CIDRPG + FTAI. Heifers assigned to the NS only $(n=299)$ treatment did not receive estrus synchronization treatment and were exposed to experienced, fertile 2-yr-old bulls at the rate of one bull per 25 heifers on Day 0 . The 14-d MGA $(0.5 \mathrm{mg} \cdot a n i m a)^{-1} \cdot \mathrm{d}^{-1}$ melengestrol acetate; $\mathrm{n}=295)+\mathrm{NS}$ treatment consisted of a $14 \mathrm{~d}$ feeding regimen of MGA in a $4 \mathrm{~kg}$ pelleted corn gluten carrier fed prior to feeding of the PMR. Heifers were exposed to fertile bulls on Day 0,10 d following cessation of MGA treatment. A second treatment involving estrus synchronization and natural service was imposed using a 1.38 g progesterone intravaginal insert (CIDR; Zoetis, Madison, NJ) that remained inserted for a 14 d period (14-d CIDR + NS; $n=289$ ). Heifers were exposed to fertile bulls on Day 0, $10 \mathrm{~d}$ following CIDR removal. The final two treatments included the CIDR-PG and 
MGA-PG protocols followed by FTAI. Heifers in the CIDR-PG treatment $(n=278)$ received a CIDR insert for $14 \mathrm{~d}$ and prostaglandin $\mathrm{F}_{2 \alpha}(\mathrm{PG} ; 25 \mathrm{mg}$ im; Lutalyse Sterile Solution, Zoetis, Madison, NJ) was administered $16 \mathrm{~d}$ after CIDR removal. FTAI was performed $66 \mathrm{~h}$ following PG administration. For heifers assigned to the MGA-PG treatment $(n=295)$, MGA was fed as described previously and PG was administered 19 d following removal of MGA from the diet. On Day 0, FTAI was performed $72 \mathrm{~h}$ after PG administration. Gonadotropin releasing hormone (GnRH; $100 \mu \mathrm{g}$ im; Cystorelin, Merial, Athens, GA) was administered concurrent with FTAI in both FTAI treatment groups. Heifers assigned to the three treatments that did not receive MGA were fed the same $4 \mathrm{~kg}$ pelleted corn gluten supplement and PMR.

2.3 Artificial Insemination. Insemination was performed by two experienced technicians using conventional frozen-thawed semen from a single AI sire. Technicians were balanced across both FTAI treatments and were preassigned to individual heifers based on RTS and weight. Twelve d following FTAI, heifers in both FTAI treatments were exposed to fertile bulls at a ratio of one bull per 25 heifers.

2.4 Estrus Detection. Estrus detection aides (Estrotect ${ }^{\mathrm{TM}}$, Rockway Inc., Spring Valley, WI) were applied at PG to heifers in FTAI treatment groups. Estrus detection aides were evaluated at FTAI to determine estrous response following PG, with estrus defined as $\geq 50 \%$ of the scratch-off coating removed from the Estrotect ${ }^{\mathrm{TM}}$. 
2.5 Blood Collection and RIA. Among a subset of heifers in the two FTAI treatments $(\mathrm{CIDR}-\mathrm{PG} \mathrm{n}=48$; MGA-PG $\mathrm{n}=47)$, blood samples were collected at PG and FTAI via jugular venipuncture to determine progesterone $\left(\mathrm{P}_{4}\right)$ and estradiol-17 $\left(\mathrm{E}_{2}\right)$ concentrations. Blood samples were allowed to clot and stored at $4{ }^{\circ} \mathrm{C}$ for 24 hours. Serum was collected by centrifugation and stored at $-20{ }^{\circ} \mathrm{C}$. Serum concentrations of $\mathrm{P}_{4}$ were determined via a validated radioimmunoassay (RIA; Pohler et al., 2016). The intra- and inter-assay coefficient of variation was less than $3 \%$.

Blood samples collected at PG and FTAI were assayed in triplicate determinations for estradiol, using the liquid-phase double-antibody RIA procedures described by Rozell and Keisler (1990) with the following modifications: All assay buffers consisted of $0.1 \%$ gelatin, $0.01-\mathrm{M}$ EDTA, $0.9 \% \mathrm{NaCl}, 0.01-\mathrm{M} \mathrm{PO}_{4}, 0.01 \%$ sodium azide, $0.05 \%$ Tween-20, $\mathrm{pH}=7.1$ (PABET). As a standard measure of assay quality control and performance, pooled bovine sera was assayed in triplicate at 25-, 40-, 60-, 100-, 175-, 200-, and 300- $\mu \mathrm{L}$ volumes, which performed in parallel to the standard curves. The estradiol assay utilized $3-{ }^{125}$ Iodo-Estradiol-17B (MP Biomedicals \#07138226) and rabbit anti-estradiol antisera (MP Biomedicals \#07138216). A preprecipitated sheep anti-rabbit second antibody was used for precipitation. The intraand inter-assay coefficient of variation was less than 5\%.

2.6 Ovarian Ultrasonography. Presence of corpora lutea and diameter of the largest follicle present on the ovary (largest follicle diameter [LFD]) were measured at PG and FTAI for a subset of heifers in both FTAI treatments (CIDR-PG $n=21$; MGAPG $n=22$ ) via transrectal ultrasonography (SonoSite EDGE equipped with a L52 10.0- 
to 5.0-MHz linear array transducer; SonoSite Inc., Bothell, WA, USA). Heifers in the subset were randomly selected to represent similar proportions of RTS and weight from both FTAI treatments.

2.7 Pregnancy Diagnosis. Initial pregnancy diagnosis was performed by transrectal ultrasonography (SonoSite EDGE equipped with a L52 10.0-5.0 MHz lineararray transducer; SonoSite Inc., Bothell, WA) when first-service pregnancies ranged from 70-75 d of gestation. Pregnancies resulting from FTAI were distinguished from natural service pregnancies on the basis of fetal size, as heifers were not exposed to bulls until 12 d after insemination was performed (Curran et al., 1986; Poock and Payne, 2013). Heifers without positive sign of pregnancy at the initial examination were reexamined $28 \mathrm{~d}$ later, when later-conceived pregnancies ranged from 45-55 d of gestation.

2.8 Statistical Analysis. Treatment differences for RTS and weight were analyzed using the TTEST procedure of SAS (SAS Inst. Inc., Cary, NC). Differences between FTAI treatments relative to estrous response and AI pregnancy rate, and pregnancy rate at 21,30 , and $60 \mathrm{~d}$ of the breeding season were analyzed using the GLIMMIX procedure of SAS (SAS Inst. Inc., Cary, NC) with treatment, pubertal status (prepubertal RTS = 1 and 2; peripubertal $\mathrm{RTS}=3$; pubertal $\mathrm{RTS}=4$ and 5), weight, and the treatment $\mathrm{x}$ pubertal status interaction included in the model. Steroid concentrations and follicle diameters were analyzed using SAS (PROC GLIMMIX; SAS Inst. Inc., Cary, NC) with compressed variables of treatment, pubertal status, estrous response, and FTAI pregnancy outcome in the model. 


\section{RESULTS}

Mean weights and RTS are listed for each treatment in Table 1. Treatment groups differed with respect to both weight and RTS. Treatment groups ranged in weight from 298 to $313 \mathrm{~kg}$. Heifers in both synchronized natural service treatments were heavier $(\mathrm{P} \leq$ 0.003), on average, than those in the other three treatments. Differences also existed among treatments relative to RTS $(\mathrm{P} \leq 0.007)$, where mean RTS ranged from $2.9 \pm 0.1$ to $3.3 \pm 0.1$ across treatments. To account for these differences, weight and pubertal status were included in the statistical model.

3.1 Pregnancy rates. Pregnancy rates at 21, 30, and $60 \mathrm{~d}$ of the breeding season are listed for each treatment in Table 2. Overall, pretreatment pubertal status had a significant influence $(\mathrm{P} \leq 0.0006)$ on pregnancy rate at 21,30 , and $60 \mathrm{~d}$ of the breeding season, where more heifers that were pubertal prior to initiation of treatments became pregnant than heifers that were prepubertal. On Day 21, pregnancy rate was again affected by pubertal status $(\mathrm{P}=0.0001)$ and the interaction of pubertal status by service type $(\mathrm{P}=0.03$; Table 3). By Day 21, pubertal heifers assigned to FTAI treatments tended to achieve higher pregnancy rates compared to NS $(\mathrm{P}=0.07)$, whereas prepubertal heifers achieved higher pregnancy rates when exposed for NS rather than FTAI $(\mathrm{P}=$ $0.07)$.

Pregnancy rate on Day 30 was influenced by pubertal status $(\mathrm{P}=0.0002)$, service type $(P=0.002)$, the interaction of progestin source by service type $(P=0.05)$, and the interaction of pubertal status by service type $(P=0.04)$. A greater $(P=0.002)$ number of 
heifers became pregnant by Day 30 of the breeding season in treatments involving NS preceded by either MGA or CIDR $(66 \%$; 384/584) compared to treatments in which FTAI was performed prior to the introduction of bulls following FTAI (58\%; 331/573). The progestin by service type interaction is based on higher pregnancy rates being achieved by heifers in the CIDR + NS treatment. While there was no difference between service type among pubertal heifers, the pubertal status by service type interaction stems from higher pregnancy rates observed among prepubertal heifers receiving NS (63\%; 128/202) rather than to FTAI followed by NS ( $\mathrm{P}=0.0004 ; 45 \% ; 82 / 183)$. Very few prepubertal heifers that were assigned to FTAI treatments became pregnant between Days 21 and 30. By Day 60, more heifers that were peripubertal or pubertal prior to treatment became pregnant than those that were prepubertal $(\mathrm{P} \leq 0.003)$. Additionally, more heifers became pregnant by Day 60 in NS treatments $(P=0.004)$ than in treatments in which FTAI was performed prior to NS. This was again due to a greater number of pre- and peripubertal heifers becoming pregnant following natural service than to FTAI followed by natural service $(\mathrm{P} \leq 0.05)$, even though pubertal heifers performed similarly with regard to service type.

In FTAI treatment groups, pregnancy rates resulting from FTAI (Table 4) were influenced by pubertal status and estrous response $(\mathrm{P} \leq 0.04)$, and interactions between pubertal status and estrous response, and weight and treatment $(\mathrm{P} \leq 0.04)$. Timed AI pregnancy rates did not differ based on technician. Pubertal heifers achieved higher pregnancy rates to FTAI than prepubertal heifers $(\mathrm{P}=0.01)$, with intermediate results observed among peripubertal heifers. A greater proportion of heifers that expressed estrus prior to FTAI became pregnant than those that failed to express estrus by appointment 
breeding ( $\mathrm{P}<0.0001 ; 172 / 302,57 \%$ vs 56/269, 21\%). The influence of pubertal status on estrous response was more apparent among non-estrous heifers at FTAI, as pregnancy rates of non-estrous heifers were highest among pubertal heifers $(38 \%)$ than peri- $(17 \%)$ and prepubertal heifers $(\mathrm{P} \leq 0.02 ; 8 \%$; Table 4$)$.

Melengestrol acetate and CIDR performed similarly and overall pregnancy rates did not differ at any time point between MGA- or CIDR-treated heifers (Table 3). Pregnancy rates did not differ within service type with regard to progestin, suggesting that both sources are effective means of pre-synchronizing estrus prior to natural service or FTAI.

3.2 Estrous response. Estrous response rates at FTAI are shown in Table 4. The MGA-PG + FTAI and CIDR-PG + FTAI treatments performed similarly $(\mathrm{P}=0.8)$ with $52 \%$ and $53 \%$ of the heifers exhibiting estrus by FTAI, respectively. While numeric differences exist within pubertal status groups with regard to treatment, there was no effect of treatment or pubertal status on estrous response at FTAI. Weight had a significant influence $(\mathrm{P}=0.02)$ on estrous response at FTAI where heavier heifers exhibited estrus at a higher frequency than lightweight heifers.

\subsection{Endocrinology and Follicular Dynamics. Mean serum $\mathrm{E}_{2}$ and $\mathrm{P}_{4}$} concentrations for a subset of heifers in each of the FTAI treatments are shown in Table 5. Heifers that exhibited estrus by FTAI had higher serum concentrations of progesterone $(\mathrm{P}=0.006 ; 8.6$ versus $4.5 \mathrm{ng} / \mathrm{ml})$ and larger dominant follicle diameters (LFD; 9.2 versus $7.5 \mathrm{~mm} ; \mathrm{P}=0.01)$ at $\mathrm{PG}$ than those that failed to express estrus. At FTAI, LFD was 
influenced by pretreatment pubertal status $(\mathrm{P}=0.02)$, where pubertal heifers exhibited larger LFD than pre- and peripubertal heifers. Heifers assigned to the MGA-PG + FTAI treatment had higher serum concentrations of $\mathrm{P}_{4}$ at $\mathrm{PG}(8.1$ versus $5.0 \mathrm{ng} / \mathrm{ml} ; \mathrm{P}=0.04)$ than CIDR-PG + FTAI treated heifers. Serum concentrations of $\mathrm{E}_{2}$ at FTAI were higher $(\mathrm{P}=0.04)$ among MGA- versus CIDR-treated heifers; however, LFD at FTAI among estrous heifers tended to be larger among CIDR- than MGA-treated heifers $(\mathrm{P}=0.08 ; 11$ \pm 0.5 versus $9.3 \pm 0.8$ ). Heifers that expressed estrus by FTAI had larger follicle diameters at both PG and FTAI than non-estrous heifers $(\mathrm{P} \leq 0.01$; Table 6$)$.

\section{DISCUSSION}

These data highlight the importance of puberty attainment among heifers prior to the start of the breeding season, especially when implementing FTAI programs. The interaction between pubertal status (prepubertal RTS $=1$ and 2; peripubertal RTS = 3; pubertal RTS $=4$ and 5) and service type at 21 and $30 \mathrm{~d}$ of the breeding season emphasizes the importance of and need for management practices that result in adequate reproductive development of heifers, especially among breeds of cattle that are later maturing.

Reproductive tract scores are performed to assess reproductive status of heifers prior to breeding and can be the foundation for improving reproductive efficiency of subsequent generations of replacement females. A common recommendation for management of Bos taurus heifers is that $\geq 50 \%$ of heifers receive a RTS of 4 or 5 at the time estrus synchronization is applied (Smith et al., 2011). In the present study, only 33\% 
(487/1456) of heifers were assigned a RTS of 4 or 5 . Moreover, the most commonly assigned RTS among heifers in this trial was an RTS of 3 (32\%; 467/1456). Heifers classified as RTS 3 are generally considered to be less than $30 \mathrm{~d}$ from attainment of puberty. Low pregnancy rates to FTAI are generally observed in prepubertal heifers, as evidenced by data (Patterson et al., 2017) from the Missouri Show-Me Select ${ }^{\circledR}$ Replacement Heifer Program. Many of the heifers that were assigned a reproductive tract score of 1 or 2 in the Missouri dataset were synchronized using the 14-d CIDR-PG + FTAI protocol used in this experiment and achieved pregnancy rates following FTAI of $8 \%(8 / 97)$ and $32 \%(182 / 572)$, respectively. Similar results were reported from the Missouri program following treatment with the 14-d MGA-PG protocol used in conjunction with FTAI. Estrous cycling heifers achieved significantly higher pregnancy rates $(47 \%, 265 / 564)$ to FTAI compared to heifers that were non-cycling prior to treatment initiation $(35 \%, 81 / 230$; Locke et al., 2016). The low number of RTS 1 and 2 heifers reported from the Missouri program is in large measure a function of the fact that beef producers now realize the reduced reproductive performance of prepubertal heifers and in many cases elect to cull these heifers prior to the breeding season. This strategy is optimal, as it places greater selection pressure on puberty attainment. An alternative management strategy worth considering to optimize pregnancy rates of mixed groups of estrous cycling and pre- or peripubertal heifers would be to assign RTS 4 and 5 heifers to FTAI and use estrous synchronization followed by natural service for the pre-and peripubertal heifers.

The RTS system is a useful tool in assessing the reproductive status of Bos taurus heifers prior to the first breeding season and subsequently time estrus synchronization 
programs. The RTS system is a repeatable and accurate means of determining pubertal status in heifers (sensitivity $=82 \%$, specificity $=69 \%$; Rosenkrans and Hardin, 2003), and relies on accurate description of ovarian structures and uterine horn dimensions determined via transrectal palpation of the uterus and ovaries. Determination of RTS in this study was performed by experienced technicians and utilized the same metrics for assignment of RTS that have long been tested and validated in Bos taurus beef heifers. It is worth noting however, that differences are reported in the literature between Bos taurus and Bos indicus-influenced breeds of cattle as they pertain to ovarian morphology and detectable presence of luteal tissue. Ovarian steroid secretion patterns and morphological changes of the ovary are considered to be less pronounced in Bos indicus breeds (Sygmington and Hale, 1967), and small, non-palpable luteal tissue can be deeply embedded in ovaries of Bos indicus heifers (Berardinelli et al. 1979). Because of these less prominent ovarian structures determined at the time RTS is performed, pubertal status of Bos indicus heifers may be misjudged in the absence of obvious large follicles or corpora lutea. Therefore, accurately describing pubertal status in Bos indicusinfluenced beef heifers may be complicated based on these different yet distinct ovarian characteristics. In the present study, estrous response at FTAI was influenced by weight and not by pubertal status. The fact that weight was of more predictive value on pregnancy rate than pubertal status may suggest that the sensitivity and specificity of RTS classification of Bos indicus-influenced heifers is lower than that previously described for Bos taurus heifers.

The effects of limited energy supplementation of Bos indicus-influenced beef heifers during the postweaning phase are more apparent in Bos indicus-influenced heifers 
than Bos taurus heifers, especially with regard to age at puberty onset and pregnancy rates at the end of a $45 \mathrm{~d}$ breeding period (Patterson et al., 1991). While heifers in this study received ad libitum access to pasture and a balanced PMR, many Bos indicusinfluenced heifers lack adequate nutritional supplementation during the postweaning to prebreeding phase development phase (Sartori et al., 2010). The mean weight of heifers presented in this research $(306 \mathrm{~kg})$ is generally lighter than target weights established for earlier maturing Bos taurus heifers (Hall and Glaze, 2017) and ranged in weight from 217 to $436 \mathrm{~kg}$. Prior to the beginning of the breeding season, the average weight of these heifers was approximately 56 percent of mature body weight assuming a $545 \mathrm{~kg}$ mature weight. The long-standing recommendation for mature body weight prior to breeding is 65 percent (Patterson et al., 1992). Recently, some researchers have argued that this target is excessive, requiring unnecessary supplementation and higher feed costs to achieve the higher prebreeding weight (Funston, 2004; Larson et al., 2009; Roberts et al., 2009). Developing heifers to lower target weights would further complicate management of heifers to attain puberty, especially among younger heifers and later maturing breeds. Arguably, improvements in reproductive performance of heifers in this study may have been realized if fed to the upper range of recommended target weights to maximize growth during the postweaning phase. Strategies that increase both nutritional management and selection pressure for earlier attainment of puberty would likely result in increased pregnancy rates following FTAI and greater numbers of heifers becoming pregnant early in the breeding season to natural service.

In this study, the addition of progestins appeared to be useful for inducing puberty in pre- and peripubertal heifers (Table 2) as evidenced by higher pregnancy rates 
observed among CIDR + NS and MGA + NS treatments compared to NS only by d 21 . Additionally, the use of progestins was an effective method to presynchronize cycling heifers, as a greater number of cycling heifers became pregnant within the first $21 \mathrm{~d}$ of the breeding season when treated with either CIDR or MGA and AI than NS only, supporting the use of estrus synchronization and FTAI to increase the number of heifers that conceive early in the breeding season.

When FTAI is performed, the goal of estrus synchronization is to maximize the number of females that express estrus within a narrow window of time. This same consideration does not necessarily apply in situations involving estrus synchronization followed by natural service. In these cases, protocols that produce a more extended synchronized period would be preferred in an effort to spread bull power out over several additional days (Ellis, 2008). Although PG is utilized in nearly all protocols designed to synchronize estrus that are currently recommended, the addition of PG often leads to a concentrated period of estrous expression, so administration of PG is typically contraindicated in synchronized natural service programs (Healy et al., 1993; Stegner et al., 2002).

An important consideration related to interpretation of results from this study pertains to synchrony of estrus on the return estrus following FTAI among those heifers that failed to conceive to the FTAI service. Estrous expression among these heifers would have remained highly synchronized and the bull-to-female ratio (BFR) of 1:25 may not have been adequate to service the large number of heifers that expressed estrus during the short window of time. Busch et al. (2007) reported that heifers failing to become pregnant to FTAI following treatment with a long-term CIDR-based treatment returned to estrus 
over a four to five day period. Based on the number of heifers that conceived to FTAI, it is conceivable that a maximum average of 34 heifers per day may have exhibited estrus throughout the 4 to 5 day period during which a repeat estrus occurred. Given the behavior of multi-sire natural service groups, dominant bulls may perform nearly all the breeding, depleting semen quantity and quality; however, research examining BFR following estrus synchronization reported no difference between ratios of 1:16 and 1:25 (Healy et al., 1993), suggesting that the BFR used in this study should have been adequate.

Unexpectedly, pregnancy rates among heifers in the NS control treatment were not different from those observed in the FTAI treatments (Table 2). These differences however were not apparent among the three NS treatments. The question arises as to whether introduction of bulls into the NS treatments influenced attainment of puberty, and if so, to what extent. Effects of bull exposure with respect to attainment of puberty were evaluated over the last 30 years, but experiments have yielded mixed results. Previous studies that support the effects of bull introduction relative to puberty induction were based on exposure periods of 35 to $70 \mathrm{~d}$ (Roberson et al., 1991; Quadros and Lobato, 2004; Fiol et al., 2010). Given these mixed data regarding the effects of bull exposure on puberty induction coupled with the fact that bulls were exposed to NS treatments only $12 \mathrm{~d}$ longer than FTAI treatments, this relatively short amount of time is unlikely to have resulted in improvements in reproductive performance. Nonetheless, analysis of this effect should be examined more thoroughly in Bos indicus breeds and their crosses. 
Higher pregnancy rates to FTAI (Table 4) were observed among heifers that exhibited estrus (57\%) prior to FTAI than non-estrous heifers $(21 \%)$. Ultimately, reduced breeding performance of the FTAI treatments stems from suboptimal pregnancy rates to FTAI. Therefore, strategies that would potentially increase pregnancy rates to FTAI could alleviate any potential concerns related to bull power in the natural service phase of the breeding season. For these reasons, use of a split-time (STAI; Thomas et al., 2014a, 2014b; Bishop et al., 2016, 2017) rather than a FTAI approach may enhance estrous response and pregnancy rates to timed AI. Split-time AI has not been evaluated in Bos indicus-influenced breeds of beef heifers but could potentially produce a number of benefits due to the generally low rates of estrous response and inherently reduced LH production among Bos indicus-influenced females. If non-estrous heifers are permitted to further generate LH stores prior to the GnRH-induced LH surge, improved follicular growth and maturity may result. For this reason, use of GnRH at FTAI may be limiting the success of non-estrous females in particular, as evidenced by the extremely low pregnancy rates presented in Table 4, by prematurely inducing the preovulatory LH surge. Use of ST rather than FTAI also reduces reliance on GnRH to induce ovulation (Bishop et al., 2017). GnRH was reported to produce inconsistent results among Bos taurus heifers (Macmillan et al., 1991; Pursley et al., 1997), and response to exogenous GnRH has been noted to diminish with increasing percentages of Bos indicus breeds (Portillo et al., 2008). Examination of a STAI approach has not been studied in Bos indicus-influenced heifers, but merits further investigation to better understand the role it might play in optimizing preovulatory LH production, follicular growth, and ovulation. 
Additional causes for reduced pregnancy rates among non-estrous heifers lie within the behavioral responses to human interaction of this biological type.

Bos indicus breeds of cattle are unique from Bos taurus in their characteristic response to physiological stressors, and, as a result, exhibit increased levels of cortisol in situations involving human interaction and animal handling (Cooke et al., 2009a, 2009b, 2010a, 2010b). Cortisol reduces response to GnRH (Breen and Karsch, 2003) and subsequent LH and FSH release to support changes in follicular dynamics, oocyte maturation, and ovulation (Randel, 2005). Non-estrous heifers in this study may have been particularly sensitive to physiological stressors, thereby increasing circulating cortisol and decreasing estrous response and reproductive performance. While implementation of STAI may enhance endogenous GnRH and LH release, increased handling associated with this approach may be detrimental because of the potential for stress-induced release of cortisol. Administration of protocols designed to synchronize estrus, especially those involving multiple handing events (e.g. four handling events in the 14-d CIDR-PG protocol), increase human-animal interaction and create the potential for stress-related effects on reproduction. Alternatively, repeated handling was reported to decrease cortisol and accelerate attainment of puberty in Bos taurus and Bos indicusinfluenced heifers that were subjected to thrice weekly handling over a four-week period (Cooke et al., 2009, 2012). In the present study, heifers in the NS only and MGA + NS treatments were handled once in the prebreeding phase to assess individual RTS; those heifers assigned to CIDR-PG + FTAI were handled a total of five times from RTS to FTAI over approximately a four-week period. While determination of physiological stress and cortisol were not measured in this study, these effects should be carefully 
considered when handling heifers involving Bos indicus influenced breeds or biological types.

Differences between endocrine and follicular dynamics of Bos indicus and Bos taurus heifers are reported in the literature and results from this study raise a number of questions that warrant further investigation pertaining to these differences. Follicle diameters observed in the subset of heifers (Table 6) that were sampled were smaller than those reported for Bos taurus heifers of similar ages (Bishop et al., 2017; Holm et al., 2016); measurements were, however, similar to those reported for purebred Bos indicus heifers (Monteiro et al., 2013). CIDR-treated heifers that exhibited estrus prior to FTAI had greater mean LFD at both PG and FTAI, and heifers that became pregnant to FTAI tended to have increased concentrations of $E_{2}$ at the time inseminations were performed. Interestingly, MGA-treated heifers had higher concentrations of $\mathrm{P}_{4}$ at $\mathrm{PG}$ and $\mathrm{E}_{2}$ at $\mathrm{AI}$ than CIDR-treated heifers (Table 5), which differs from studies involving Bos taurus breeds subjected to the same protocols, in which case steroid concentrations at these time points were reportedly higher in CIDR-treated heifers (Mallory et al., 2010). These data also raise questions regarding differences in response among Bos indicus-influenced breeds of heifers based on their response to the two progestins used in this study. Similar proportions of heifers in both treatments exhibited estrus despite differences between mean LFD and $\mathrm{E}_{2}$ at $\mathrm{AI}$, in which case CIDR-treated heifers had larger follicles but lower circulating concentrations of $\mathrm{E}_{2}$ at $\mathrm{AI}$. Treatment with MGA was followed by higher serum concentrations of $\mathrm{P}_{4}$ at $\mathrm{PG}$, which may have contributed to decreased follicle diameters among MGA- versus CIDR-treated heifers at PG. Differences in estradiol 
production may be a product of differences between how the two progestins affect LH pulsatility and resulting follicular development.

Bos indicus females are uniquely sensitive to progesterone as it affects $\mathrm{LH}$ pulsatility, so minimizing the suppressive effect of $\mathrm{P}_{4}$ on LH and FSH release may improve both follicle size and $\mathrm{E}_{2}$ production. One of the questions that arises from this study is the way in which to use progestins to suppress estrus and ovulation while maximizing follicular growth and maturation throughout treatment. This would be perhaps best accomplished with use of MGA, as the dosage can easily be manipulated. Research that led to the $0.5 \mathrm{mg} \cdot \mathrm{animal}^{-1} \cdot \mathrm{d}^{-1}$ concentration of MGA (Zimbleman and Smith, 1966) was developed using Bos taurus females, and no research has examined the optimal dosage that suppresses ovulation and maximizes follicular activity in Bos indicus-influenced beef heifers. Previous studies have shown that a $0.5 \mathrm{mg}$ concentration is effective in Bos indicus-influenced heifers (Patterson et al., 1990), but no further research has been conducted to evaluate differences in follicular dynamics or steroid hormone production. Support for decreased concentration of progestins for estrus synchronization of Bos indicus comes from Brazilian studies in which multiple-use CIDR inserts increased follicular diameter and resulted in increased pregnancy rates (Claro et al., 2010). Because of their heightened sensitivity to progesterone, investigation of varying concentrations of progesterone or MGA required to inhibit estrus and ovulation among Bos indicus breeds and their composites may be useful to improve results following treatment. This will require carefully designed studies involving frequent blood sampling and ovarian ultrasonography to fully assess and characterize potential differences. 
This experiment is the largest comprehensive field trial conducted in the United States and reported in the literature involving Bos indicus-influenced beef heifers utilizing estrus synchronization prior to natural service or FTAI. These results reinforce previously reported studies conducted with Bos taurus breeds, but at the same time raise a number of questions that have yet to be answered for heifers of this biological type. Careful oversight of nutritional and reproductive management of Bos indicus-influenced beef heifers are essential considerations in managing heifers among these breeds or biological types given their propensity for attainment of puberty at older ages and heavier weights. Strategies that increase selection pressure and nutritional management for attainment of puberty will likely result in improved reproductive efficiency among these heifers and should be a priority of beef producers and researchers alike. Encouraging utilization of pre-breeding exams to assess reproductive maturity and the ultimate success of a development program will assist beef producers in making informed decisions regarding which females to cull and the appropriate time at which to initiate treatments designed to synchronize estrus. Further, incorporating new strategies to facilitate use of artificial insemination among Bos indicus breeds and their crosses (i.e. STAI) may result in higher pregnancy rates to AI. These data clearly show that long-term progestin-based protocols can be used effectively to synchronize estrus prior to natural service or FTAI in Bos indicus-influenced beef heifers and offer the added benefit of inducing puberty in pre- or peripubertal heifers prior to treatment initiation. However, these practices alone fail to compensate for inadequacies in selection and management of these heifers prior to breeding. Given these considerations, management of Bos indicus-influenced beef heifers in the United States should involve the collective efforts of beef producers, veterinarians, 
and research scientists to further investigate methods to improve reproductive efficiency and genetic merit of these herds.

\section{ACKNOWLEDGEMENTS}

The Missouri Agricultural Experiment Station (Columbia, MO) contributed. The authors gratefully acknowledge the Florida Cattle Enhancement Board for financial support for this project; Select Sires Inc. for providing personnel support; Zoetis (Madison, NJ) for providing the Lutalyse sterile solution and EAZI-Breed CIDR cattle inserts; Merial (Athens, GA) for providing the Cystorelin; Estrotect Inc. (Spring Valley, WI) for providing estrus detection aids; White Farms heifer development (Chiefland, FL) and Deseret Ranches (St. Cloud, FL) for their support of this project. 

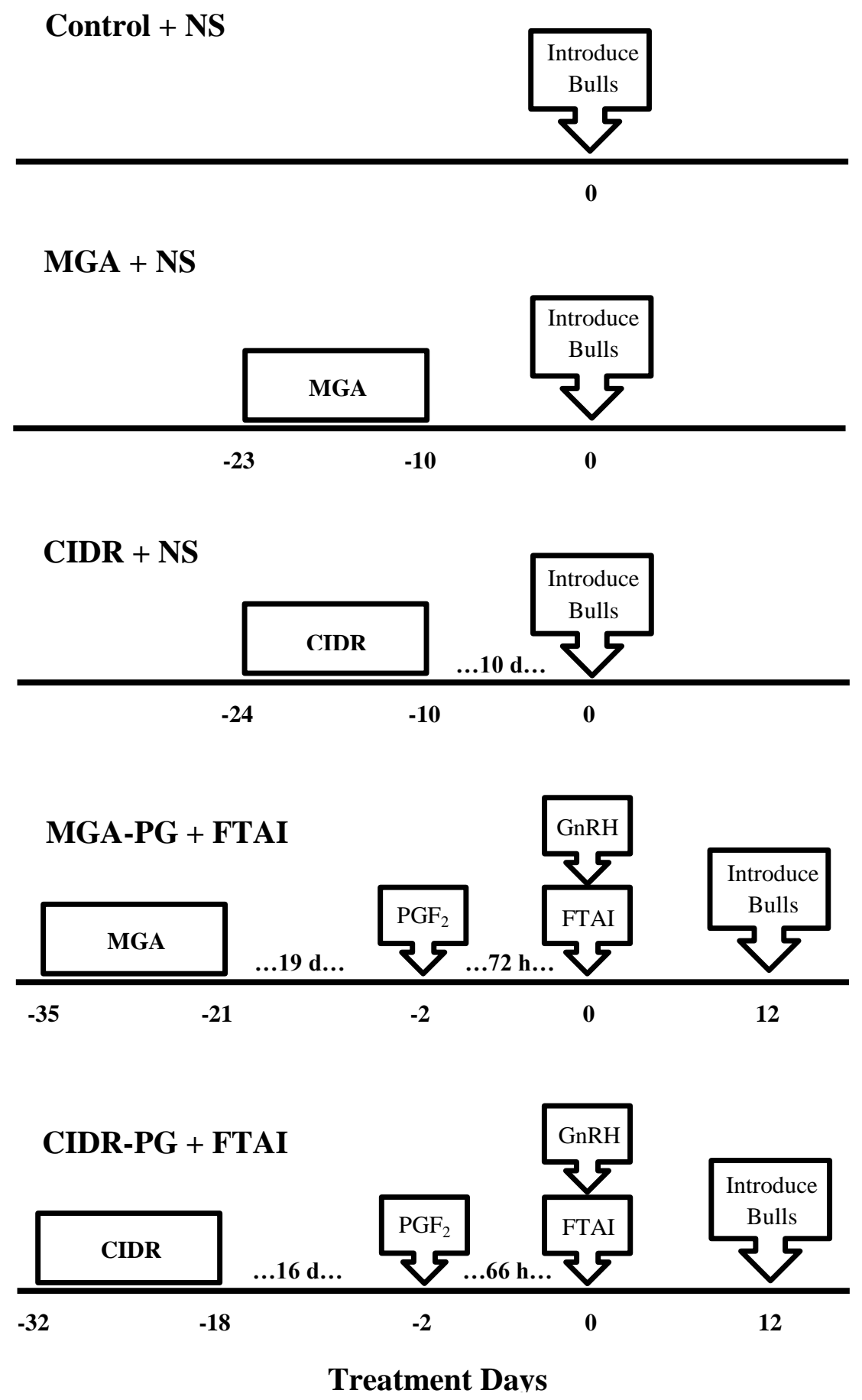

Figure 2.1. Treatment schedules for NS, MGA + NS, CIDR + NS, MGA-PG + FTAI, and CIDR-PG + FTAI. 
Table 2.1. Number of heifers, mean weight (Wt), and reproductive tract score (RTS) by treatment.

\begin{tabular}{cccl}
\hline \hline Treatment & $\mathrm{N}$ & Wt. Kg \pm SE & RTS \pm SE \\
\hline NS & 299 & $298 \pm 2^{\mathrm{ac}}$ & $3.0 \pm 0.1^{\mathrm{b}}$ \\
MGA + NS & 295 & $312 \pm 1^{\mathrm{b}}$ & $3.3 \pm 0.1^{\mathrm{ac}}$ \\
CIDR + NS & 289 & $313 \pm 2^{\mathrm{b}}$ & $2.9 \pm 0.1^{\mathrm{b}}$ \\
MGA-PG + AI & 295 & $305 \pm 2^{\mathrm{ad}}$ & $3.0 \pm 0.1^{\mathrm{ab}}$ \\
CIDR-PG + AI & 278 & $302 \pm 2^{\mathrm{a}}$ & $3.2 \pm 0.1^{\mathrm{a}}$ \\
\hline abcd Values within column with different superscripts differ $(\mathrm{P} \leq$ \\
0.05).
\end{tabular}


Table 2.2. Pregnancy rates of heifers within treatment based on pubertal status and day(s) of the breeding season.

\begin{tabular}{|c|c|c|c|c|c|c|c|c|c|c|c|c|c|}
\hline \multirow{2}{*}{$\begin{array}{l}\text { Pubertal } \\
\text { status }\end{array}$} & \multirow{2}{*}{$\begin{array}{c}\text { Breeding } \\
\text { period }\end{array}$} & \multicolumn{2}{|c|}{ Control + NS } & \multicolumn{2}{|c|}{$\mathrm{MGA}+\mathrm{NS}$} & \multicolumn{2}{|c|}{$\mathrm{CIDR}+\mathrm{NS}$} & \multicolumn{2}{|c|}{$\begin{array}{c}\text { MGA-PG + } \\
\text { FTAI }\end{array}$} & \multicolumn{2}{|c|}{$\begin{array}{c}\text { CIDR-PG + } \\
\text { FTAI }\end{array}$} & \multicolumn{2}{|l|}{ Total } \\
\hline & & $\mathrm{N}$ & $\%$ & $\mathrm{~N}$ & $\%$ & $\mathrm{~N}$ & $\%$ & $\mathrm{~N}$ & $\%$ & $\mathrm{~N}$ & $\%$ & $\mathrm{~N}$ & $\%$ \\
\hline \multirow{3}{*}{ Prepubertal } & Day 21 & $45 / 117$ & $38^{\mathrm{a}}$ & $42 / 81$ & $52^{\wedge}$ & $60 / 121$ & $50 *$ & $48 / 102$ & $47^{\mathrm{a}}$ & $29 / 81$ & $36^{\mathrm{a} \wedge *}$ & $224 / 502$ & $45^{\mathrm{a}}$ \\
\hline & Day 30 & $64 / 117$ & $55^{\mathrm{c} 13}$ & $50 / 81$ & $62^{13}$ & $78 / 121$ & $64^{1}$ & $52 / 102$ & $51^{\mathrm{c} 23}$ & $30 / 81$ & $37^{\mathrm{c} 2}$ & $274 / 502$ & $55^{\mathrm{d}}$ \\
\hline & Day 60 & $92 / 117$ & $79^{1 \wedge}$ & $69 / 81$ & $85^{1}$ & $89 / 121$ & $74^{12}$ & $73 / 102$ & $72^{2 \wedge}$ & $54 / 81$ & $67^{\mathrm{f} 2}$ & $377 / 502$ & $75^{g}$ \\
\hline \multirow{3}{*}{ Peripubertal } & Day 21 & $44 / 91$ & $48^{\mathrm{ab}}$ & $51 / 97$ & 53 & $51 / 89$ & 57 & $53 / 98$ & $54^{\mathrm{ab}}$ & $45 / 92$ & $49^{\mathrm{ab}}$ & $244 / 467$ & $52^{\mathrm{b}}$ \\
\hline & Day 30 & $55 / 91$ & $60^{\mathrm{cd}}$ & $61 / 97$ & 63 & $63 / 89$ & $71^{\wedge}$ & $58 / 98$ & $59^{\mathrm{cd}}$ & $50 / 92$ & $54^{\mathrm{d} \wedge}$ & $287 / 467$ & $61^{\mathrm{e}}$ \\
\hline & Day 60 & $73 / 91$ & 80 & $83 / 97$ & 86 & $79 / 89$ & $89^{\wedge}$ & $81 / 98$ & 83 & $72 / 92$ & $78^{\mathrm{fg} \wedge}$ & $388 / 467$ & $83^{\text {gh }}$ \\
\hline \multirow{3}{*}{ Pubertal } & Day 21 & $57 / 91$ & $63^{b}$ & $64 / 117$ & $55^{1}$ & $47 / 79$ & 59 & $61 / 95$ & $64^{\mathrm{b}}$ & $71 / 105$ & $68^{2 b}$ & $300 / 487$ & $62^{c}$ \\
\hline & Day 30 & $67 / 91$ & $74^{\mathrm{d}}$ & $74 / 117$ & 63 & $58 / 79$ & 73 & $64 / 95$ & $67^{d}$ & $73 / 105$ & $70^{\mathrm{e}}$ & $336 / 487$ & $69^{f}$ \\
\hline & Day 60 & $81 / 91$ & 89 & $94 / 117$ & 80 & $71 / 79$ & 90 & $79 / 95$ & 83 & $91 / 105$ & $87^{\mathrm{g}}$ & $416 / 487$ & $85^{\mathrm{h}}$ \\
\hline Total & & $246 / 299$ & 82 & $246 / 295$ & 83 & $239 / 289$ & $83^{* \wedge}$ & $233 / 295$ & $79 *$ & $217 / 278$ & $78^{\wedge}$ & $1181 / 1456$ & 81 \\
\hline
\end{tabular}

Pregnancy rates at each time point within column with different superscripts differ $(\mathrm{P} \leq 0.05)$.

${ }^{12}$ Pregnancy rates at each time point within row with different superscripts differ $(\mathrm{P} \leq 0.04)$.

$\wedge *$ Denotes tendency within row $(\mathrm{P} \leq 0.08)$. 
Table 2.3. Pregnancy rates of heifers based on progestin and service type.

\begin{tabular}{|c|c|c|c|c|c|c|c|c|c|}
\hline \multirow{3}{*}{ Pubertal status } & \multirow{3}{*}{$\begin{array}{c}\text { Breeding } \\
\text { period }\end{array}$} & \multicolumn{4}{|c|}{ Progestin type } & \multicolumn{4}{|c|}{$\underline{\text { Service type }}$} \\
\hline & & \multicolumn{2}{|c|}{ CIDR } & \multicolumn{2}{|c|}{ MGA } & \multicolumn{2}{|c|}{ AI } & \multicolumn{2}{|c|}{ NS } \\
\hline & & $\mathrm{N}$ & $\%$ & $\mathrm{~N}$ & $\%$ & $\mathrm{~N}$ & $\%$ & $\mathrm{~N}$ & $\%$ \\
\hline \multirow{3}{*}{ Prepubertal } & Day 21 & $89 / 202$ & $44^{a}$ & $90 / 183$ & $49^{a}$ & $77 / 183$ & $42^{\mathrm{a} 1}$ & $102 / 202$ & $50^{2}$ \\
\hline & Day 30 & $108 / 202$ & $53^{\mathrm{a}}$ & $102 / 183$ & $56^{\mathrm{a}}$ & $82 / 183$ & $45^{\mathrm{a}}$ & $128 / 202$ & 63 \\
\hline & Day 60 & $143 / 202$ & $71^{\mathrm{a}}$ & $142 / 183$ & 78 & $127 / 183$ & $69^{a}$ & $158 / 202$ & 78 \\
\hline \multirow{3}{*}{ Peripubertal } & Day 21 & $96 / 181$ & $53^{\mathrm{b}}$ & $104 / 195$ & $53^{\mathrm{a}}$ & $98 / 190$ & $52^{\mathrm{b}}$ & $102 / 186$ & 55 \\
\hline & Day 30 & $113 / 181$ & $62^{\mathrm{b}}$ & $119 / 195$ & $61^{\mathrm{ab}}$ & $108 / 190$ & $57^{\mathrm{b}}$ & $128 / 186$ & 69 \\
\hline & Day 60 & $151 / 181$ & $83^{\mathrm{b}}$ & $164 / 195$ & 84 & $153 / 190$ & $81^{\mathrm{b}}$ & $162 / 186$ & 87 \\
\hline \multirow{3}{*}{ Pubertal } & Day 21 & $118 / 184$ & $64^{\mathrm{c}}$ & $125 / 212$ & $59^{\mathrm{b}}$ & $132 / 200$ & $66^{\mathrm{c} 1}$ & $111 / 196$ & $57^{2}$ \\
\hline & Day 30 & $131 / 184$ & $71^{\mathrm{b}}$ & $138 / 212$ & $65^{\mathrm{b}}$ & $137 / 200$ & $69^{c}$ & $132 / 196$ & 67 \\
\hline & Day 60 & $162 / 184$ & $88^{\mathrm{b}}$ & $173 / 212$ & 82 & $170 / 200$ & $85^{\mathrm{b}}$ & $165 / 196$ & 84 \\
\hline Total & & $461 / 567$ & 81 & $483 / 590$ & 82 & $447 / 573$ & $78^{1}$ & $494 / 584$ & $85^{2}$ \\
\hline
\end{tabular}

\footnotetext{
${ }^{\mathrm{abc}}$ Values within column at each breeding period with different superscripts differ $(\mathrm{P} \leq 0.05)$.
}

${ }^{12}$ Values within row with different superscripts differ $(\mathrm{P} \leq 0.004)$. 
Table 2.4 Estrous response after PG and pregnancy rates after FTAI among heifers assigned to FTAI treatments based on treatment and pretreatment pubertal status.

\begin{tabular}{|c|c|c|c|c|c|c|c|c|c|}
\hline \multirow[t]{2}{*}{$\begin{array}{l}\text { Pubertal } \\
\text { Status }\end{array}$} & \multirow[t]{2}{*}{$\begin{array}{l}\text { FTAI } \\
\text { treatment }\end{array}$} & \multicolumn{2}{|c|}{$\begin{array}{c}\text { Estrous response } \\
\text { at FTAI }\end{array}$} & \multicolumn{2}{|c|}{ Pregnancy rate } & \multicolumn{2}{|c|}{$\begin{array}{l}\text { Pregnancy rate } \\
\text { estrous }\end{array}$} & \multicolumn{2}{|c|}{$\begin{array}{c}\text { Pregnancy rate } \\
\text { non-estrous }\end{array}$} \\
\hline & & $\mathrm{N}$ & $\%$ & $\mathrm{~N}$ & $\%$ & $\mathrm{~N}$ & $\%$ & $\mathrm{~N}$ & $\%$ \\
\hline \multirow{2}{*}{ Prepubertal } & CIDR-PG & $45 / 81$ & 56 & $22 / 81$ & $27^{\mathrm{a}}$ & $19 / 45$ & $42^{1}$ & $3 / 36$ & $8^{\mathrm{a} 2}$ \\
\hline & MGA-PG & $46 / 101$ & 46 & $34 / 101$ & 34 & $30 / 46$ & $65^{1}$ & $4 / 55$ & $7^{\mathrm{a} 2}$ \\
\hline \multirow{2}{*}{ Peripubertal } & CIDR-PG & $45 / 91$ & 49 & $35 / 91$ & $38^{\mathrm{ab}}$ & $27 / 45$ & $60^{1}$ & $8 / 46$ & $17^{\mathrm{ab} 2}$ \\
\hline & MGA-PG & $51 / 98$ & 52 & $39 / 98$ & 40 & $31 / 51$ & $61^{1}$ & $8 / 47$ & $17^{\mathrm{ab} 2}$ \\
\hline \multirow{2}{*}{ Pubertal } & CIDR-PG & $58 / 105$ & 55 & $54 / 105$ & $51^{\mathrm{b}}$ & $34 / 58$ & 59 & $20 / 47$ & $42^{\mathrm{b}}$ \\
\hline & MGA-PG & $57 / 95$ & 60 & $44 / 95$ & 46 & $31 / 57$ & $54^{1}$ & $13 / 38$ & $34^{\mathrm{b} 2}$ \\
\hline \multirow[t]{2}{*}{ Total } & CIDR-PG & $148 / 277$ & 53 & $111 / 277$ & 40 & $80 / 148$ & $54^{1}$ & $31 / 129$ & $24^{2}$ \\
\hline & MGA-PG & $154 / 294$ & 52 & $117 / 294$ & 40 & $92 / 154$ & $59^{1}$ & $25 / 140$ & $18^{2}$ \\
\hline
\end{tabular}

${ }^{\mathrm{ab}}$ Values within column with different superscripts differ $(\mathrm{P} \leq 0.05)$.

${ }^{12}$ Values within row with different superscripts differ $(\mathrm{P} \leq 0.05)$. 
Table 2.5. Steroid concentrations of heifers assigned to FTAI treatments based on estrous response and pregnancy status.

\begin{tabular}{|c|c|c|c|c|c|c|}
\hline Pubertal status & FTAI treatment & $\mathrm{N}$ & $\%$ & $\begin{array}{c}\mathrm{P} 4 \text { at PG } \\
(\mathrm{ng} / \mathrm{ml}) \pm \mathrm{SE}\end{array}$ & $\begin{array}{c}\text { E2 at PG } \\
(\mathrm{pg} / \mathrm{ml}) \pm \mathrm{SE}\end{array}$ & $\begin{array}{c}\mathrm{E} 2 \text { at AI } \\
(\mathrm{pg} / \mathrm{ml}) \pm \mathrm{SE}\end{array}$ \\
\hline \multirow{10}{*}{ Prepubertal } & CIDR-PG & 18 & 38 & $5.7 \pm 2.5$ & $10.0 \pm 1.1$ & $7.3 \pm 1.6$ \\
\hline & Estrous & $9 / 18$ & 50 & $9.2 \pm 4.6$ & $13.3 \pm 2.1^{\mathrm{a}}$ & $9.1 \pm 2.8$ \\
\hline & Non-estrous & $9 / 18$ & 50 & $3.7 \pm 1.7$ & $6.4 \pm 0.7^{\mathrm{b}}$ & $5.6 \pm 0.9^{\mathrm{a}}$ \\
\hline & Pregnant & $2 / 18$ & 11 & $9.2 \pm 4.6$ & $13.3 \pm 2.1^{\mathrm{x}}$ & $9.1 \pm 2.8$ \\
\hline & Non-pregnant & $16 / 18$ & 89 & $3.7 \pm 1.7$ & $6.4 \pm 0.7^{y}$ & $5.8 \pm 0.9^{\wedge}$ \\
\hline & MGA-PG & 18 & 38 & $6.7 \pm 2.0$ & $5.6 \pm 0.9$ & $10.6 \pm 1.3$ \\
\hline & Estrous & $5 / 18$ & 28 & $9.2 \pm 3.8$ & $5.1 \pm 1.7$ & $12.4 \pm 2.3$ \\
\hline & Non-estrous & $13 / 18$ & 72 & $5.9 \pm 1.7$ & $6.0 \pm 0.7$ & $8.4 \pm 1.0^{\mathrm{b}}$ \\
\hline & Pregnant & $3 / 18$ & 17 & $9.2 \pm 3.8$ & $5.1 \pm 1.7$ & $12.4 \pm 2.3$ \\
\hline & Non-pregnant & $15 / 18$ & 83 & $5.9 \pm 1.7$ & $6.0 \pm 0.7$ & $8.4 \pm 1.0^{\wedge}$ \\
\hline \multirow{10}{*}{ Peripubertal } & CIDR-PG & 16 & 33 & $5.1 \pm 1.6$ & $6.2 \pm 0.8$ & $6.9 \pm 1.1$ \\
\hline & Estrous & $9 / 16$ & 56 & $7.8 \pm 2.5$ & $6.0 \pm 1.1$ & $8.0 \pm 1.5$ \\
\hline & Non-estrous & $7 / 16$ & 44 & $2.3 \pm 2.2$ & $6.5 \pm 1.0$ & $6.2 \pm 1.3$ \\
\hline & Pregnant & $7 / 16$ & 44 & $7.8 \pm 2.5$ & $6.0 \pm 1.1$ & $8.0 \pm 1.5$ \\
\hline & Non-pregnant & $9 / 16$ & 56 & $2.3 \pm 2.2^{\mathrm{x}}$ & $6.5 \pm 1.0$ & $6.2 \pm 1.3$ \\
\hline & MGA-PG & 13 & 28 & $5.2 \pm 2.1$ & $6.5 \pm 1.0$ & $7.1 \pm 1.4$ \\
\hline & Estrous & $5 / 13$ & 38 & $4.1 \pm 3.3$ & $7.5 \pm 1.7$ & $8.2 \pm 2.3$ \\
\hline & Non-estrous & $8 / 13$ & 62 & $8.9 \pm 2.1$ & $6.1 \pm 0.9$ & $6.2 \pm 1.2$ \\
\hline & Pregnant & $3 / 13$ & 23 & $4.1 \pm 3.8$ & $7.5 \pm 1.7$ & $8.2 \pm 2.3$ \\
\hline & Non-pregnant & $10 / 13$ & 77 & $8.9 \pm 2.1^{y}$ & $6.1 \pm 0.9$ & $6.2 \pm 1.2$ \\
\hline \multirow{10}{*}{ Pubertal } & CIDR-PG & 14 & 29 & $5.9 \pm 2.2$ & $6.7 \pm 1.1$ & $6.3 \pm 1.4$ \\
\hline & Estrous & $11 / 14$ & 79 & $7.5 \pm 2.0$ & $6.4 \pm 0.9$ & $6.6 \pm 1.2$ \\
\hline & Non-estrous & $3 / 14$ & 21 & $5.0 \pm 3.8$ & $6.1 \pm 1.7$ & $7.3 \pm 2.3$ \\
\hline & Pregnant & $11 / 14$ & 79 & $7.5 \pm 2.0$ & $6.4 \pm 0.9$ & $6.6 \pm 1.2$ \\
\hline & Non-pregnant & $3 / 14$ & 21 & $5.0 \pm 3.8$ & $6.1 \pm 1.7$ & $7.3 \pm 2.3$ \\
\hline & MGA-PG & 16 & 34 & $6.8 \pm 1.9$ & $6.8 \pm 0.8$ & $8.5 \pm 1.1$ \\
\hline & Estrous & $11 / 16$ & 69 & $9.9 \pm 2.0$ & $5.9 \pm 0.9$ & $8.8 \pm 1.2$ \\
\hline & Non-estrous & $5 / 16$ & 31 & $4.1 \pm 3.3$ & $7.7 \pm 1.3$ & $7.9 \pm 1.8$ \\
\hline & Pregnant & $11 / 16$ & 69 & $9.9 \pm 2.0$ & $5.9 \pm 0.9$ & $8.8 \pm 1.2$ \\
\hline & Non-pregnant & $5 / 16$ & 31 & $4.1 \pm 3.3$ & $7.7 \pm 1.3$ & $7.9 \pm 1.8$ \\
\hline \multirow{10}{*}{ Total } & CIDR-PG & 48 & -- & $5.3 \pm 1.0$ & $6.6 \pm 0.4$ & $6.6 \pm 0.6^{x}$ \\
\hline & Estrous & $29 / 48$ & 60 & $6.7 \pm 1.2^{\mathrm{a}^{\wedge}}$ & $6.6 \pm 0.6$ & $7.3 \pm 0.7$ \\
\hline & Non-estrous & $19 / 48$ & 40 & $2.8 \pm 1.5^{\mathrm{b}}$ & $6.7 \pm 0.7$ & $5.5 \pm 0.9^{\mathrm{a}}$ \\
\hline & Pregnant & $20 / 48$ & 42 & $7.5 \pm 2.2^{\mathrm{ax}}$ & $7.8 \pm 1.1$ & $6.5 \pm 0.9$ \\
\hline & Non-pregnant & $28 / 48$ & 58 & $3.6 \pm 1.2^{\mathrm{bx}}$ & $6.4 \pm 0.6$ & $6.2 \pm 0.8$ \\
\hline & MGA-PG & 47 & -- & $7.4 \pm 1.0$ & $6.2 \pm 0.4$ & $8.2 \pm 0.6^{\mathrm{y}}$ \\
\hline & Estrous & $21 / 47$ & 45 & $11.5 \pm 1.5^{\mathrm{a}^{\wedge}}$ & $6.4 \pm 0.7$ & $8.4 \pm 0.8$ \\
\hline & Non-estrous & $26 / 47$ & 55 & $5.2 \pm 1.2^{\mathrm{b}}$ & $6.1 \pm 0.6$ & $8.0 \pm 0.8^{\mathrm{b}}$ \\
\hline & Pregnant & $17 / 47$ & 36 & $10.2 \pm 2.3^{\mathrm{y}}$ & $6.2 \pm 1.1$ & $10.1 \pm 1.5^{\mathrm{a}}$ \\
\hline & Non-pregnant & $30 / 47$ & 64 & $10.1 \pm 1.4^{\mathrm{y}}$ & $6.7 \pm 0.7$ & $7.2 \pm 0.9^{\mathrm{b}}$ \\
\hline
\end{tabular}

\footnotetext{
${ }^{a b}$ Values within column with different superscripts differ $(\mathrm{P} \leq 0.05)$.

${ }^{x y}$ Values within column with different superscripts differ $(P \leq 0.05)$.

${ }^{\wedge}$ Denotes tendency $(\mathrm{P}=0.07)$.
} 
Table 2.6. Diameter of the largest follicle (LFD) and estradiol concentration $\left(\mathrm{E}_{2}\right)$ at FTAI based on treatment and estrous response.

\begin{tabular}{|c|c|c|c|}
\hline \multicolumn{4}{|c|}{ Treatment } \\
\hline Item & CIDR-PG + FTAI & $\underline{\text { MGA-PG + FTAI }}$ & $\underline{\mathrm{P} \text {-value }}$ \\
\hline $\mathrm{N}$ & 20 & 23 & \\
\hline $\mathrm{LFD}$ at $\mathrm{PG}(\mathrm{mm}) \pm \mathrm{SE}$ & $8.6 \pm 0.4$ & $7.8 \pm 0.4$ & 0.2 \\
\hline Estrous & $9.6 \pm 0.6^{\mathrm{a}}$ & $8.2 \pm 0.7$ & 0.2 \\
\hline Non-estrous & $7.4 \pm 0.6^{\mathrm{b}}$ & $7.6 \pm 0.5$ & 0.7 \\
\hline $\mathrm{E}_{2}$ at $\mathrm{PG}(\mathrm{pg} / \mathrm{ml}) \pm \mathrm{SE}$ & $7.6 \pm 0.7^{1}$ & $5.8 \pm 0.7^{2}$ & 0.09 \\
\hline Estrous & $7.6 \pm 1.0$ & $5.9 \pm 1.4$ & 0.3 \\
\hline Non-estrous & $7.5 \pm 1.2$ & $5.8 \pm 0.9$ & 0.2 \\
\hline $\mathrm{LFD}$ at FTAI $(\mathrm{mm}) \pm \mathrm{SE}$ & $10.1 \pm 0.4$ & $9.7 \pm 0.4$ & 0.6 \\
\hline Estrous & $11.2 \pm 0.5^{\mathrm{a}}$ & $10.3 \pm 0.7$ & 0.3 \\
\hline Non-estrous & $8.9 \pm 0.6^{\mathrm{b}}$ & $9.2 \pm 0.5$ & 0.8 \\
\hline $\mathrm{E}_{2}$ at FTAI $(\mathrm{pg} / \mathrm{ml}) \pm \mathrm{SE}$ & $10.3 \pm 0.8$ & $9.5 \pm 0.8$ & 0.2 \\
\hline Estrous & $8.7 \pm 1.0^{\mathrm{a}}$ & $8.3 \pm 1.4$ & 0.8 \\
\hline Non-estrous & $5.3 \pm 1.1^{\mathrm{b} 1}$ & $7.9 \pm 0.9^{2}$ & 0.08 \\
\hline
\end{tabular}

${ }^{\mathrm{ab}}$ Values within column with different superscripts differ $(\mathrm{P} \leq 0.03)$.

${ }^{12}$ Denotes tendency $(\mathrm{P} \leq 0.09)$. 
Aerts, J.M.J., and P.E.J. Bols. 2008. Ovarian Follicular Dynamics. A review with emphasis on the bovine species. Part II: Antral development, exogenous influence and future prospects. Reprod. Domest. Anim. 45(1):180-7.

Allen, J.J., S.L. Herrick, and J.E. Fortune. 2016. Regulation of steroidogenesis in fetal bovine ovaries: Differential effects of LH and FSH. J. Mol. Endocrinol. 57(4):275-86.

Alvarez P., L.J. Spicer, C.C. Chase Jr, M.E. Payton, T.D. Hamilton, R.E. Stewart, A.C. Hammond, T.A. Olson, and R.P. Wetteman. 2000. Ovarian and endocrine characteristics during the estrous cycle in Angus, Brahman and Senepol cows in a subtropical environment. J. Anim. Sci. 78:1291-302.

Anderson K.J., D.G. LeFever, J.S. Brinks, and K.G Odde. 1991. The use of reproductive tract scoring in beef heifers. Agri-Practice 12:106-11.

Anderson, J. 1944. The periodicity and duration of oestrus in Zebu and grade cattle. J. Agric. Sci. $34: 57$.

Anderson, K.J., D.G. LeFever, J.S. Brinks, and K.G. Odde. 1991. The use of reproductive tract scoring as a predictor of fertility and production outcomes in beef heifers. Agri-Practice. 12:106-11.

Anderson, L.H. and M.L. Day. 1994. Acute progesterone administration regresses persistent dominant follicles and improves fertility of cattle in which estrus was synchronized with melengestrol acetate. J. Anim. Sci. 72:2955-2961.

Anderson, L.H., and M.H. Day. 1996. Site-specific reductions in the number of hypothalamic estradiol receptor-containing neurons during progestin-induced puberty in heifers. Biol. Reprod. 54(Suppl. 1):178.

Anderson, L.H., C.M. McDowell, and M.L. Day. 1996. Progestin-induced puberty and secretion of luteinizing hormone in heifers. Biol. Reprod. 54:1025-1031.

Atkins, J.A., D.C. Busch, H.F. Bader, D.H. Keisler, D.J. Patterson, M.C. Lucy, and M.F. Smith. 2008. Gonadotropin-releasing hormone-induced ovulation and luteinizing hormone release in beef heifers: Effect of day of the cycle. J. Anim. Sci. 86:83-93.

Bao, B. and H.A. Garverick. 1998. Expression of steroidogenic enzyme and gonadotropin receptor genes in bovine follicles during ovarian follicular waves: A review. J. Anim. Sci. 73(7):1903-21.

Bao, B., H.A. Garverick, G.W. Smith, M.F. Smith, B.E. Salfen, and R.S. Youngquist. 1997. Changes in messenger ribonucleic acid encoding luteinizing hormone receptor, cytochrome P450-side chain cleavage, and aromatase are associated with recruitment and selection of bovine ovarian follicles. Biol. Reprod. 56:1158-1168.

Beal, W.E. and G.A. Good. 1986. Synchronization of estrus in postpartum beef cows with melengestrol acetate and prostaglandin $F_{2 \alpha}$. J. Anim. Sci. 63:343-347. 
Beal, W.E., J.R. Chenault, M.L. Day, and L.R. Corah. 1988. Variation in conception rates following synchronization of estrus with melengestrol acetate and prostaglandin $F_{2 \alpha} . J$. Anim. Sci. 66:599-602.

Berardinelli, J.G., R.A. Dailey, R.L. Butcher, and E.K. Inskeep. 1979. Source of progesterone prior to puberty in beef heifers. J. Anim. Sci. 49:1276-1280.

Bishop B.E., J.M. Thomas, J.M. Abel, S.E. Poock, M.R. Ellersieck, M.F. Smith, and D.J. Patterson. 2017. Split-time artificial insemination in beef cattle: II. Comparing pregnancy rates among non-estrous heifers based on administration of $\mathrm{GnRH}$ at AI. Theriogenology. $87: 229-234$.

Bishop B.E., J.M. Thomas, J.M. Abel, S.E. Poock, M.R. Ellersieck, M.F. Smith, and D.J. Patterson. 2016. Split-time artificial insemination in beef cattle: I. Using estrous response to determine the optimal time(s) at which to administer $\mathrm{GnRH}$ in beef heifers and postpartum cows. Theriogenology. 86:1102-10.

Bó G.A., P.S Baruselli, and M.F. Martinez. 2003 Pattern and manipulation of follicular development in Bos indicus cattle. Anim. Reprod. Sci. 78:307-326.

Breen, K.M. and F.J. Karsch. 2003. Does cortisol inhibit pulsatile luteinizing hormone secretion at the hypothalamic or pituitary level? Endocrinology. 145(2):692-698.

Brown, L.N., K.G. Odde, M.E. King, D.G. LeFever, and C.J. Neubauer. 1988. Comparison of melengestrol acetate-prostaglandin $\mathrm{F}_{2 \alpha}$ to Syncro-Mate B for estrus synchronization in beef heifers. J. Anim. Sci. 30:1-12.

Burris, J.M. and B.M. Priode. 1958. Effect of calving date on subsequent calving performance. J. Anim. Sci. 17(3):527-533.

Busch, D.C., D.J. Wilson, D.J. Schafer, N.R. Leitman, J.K. Haden, M.R. Ellersieck, M.F. Smith, and D.J. Patterson. 2007. Comparision of progestin-based estrus synchronization protocols before fixed-time artificial insemination on pregnancy rate in beef heifers. J. Anim. Sci. 85:1933-1939.

Byerley, D.J., R.B. Staigmiller, J.G. Berardinelli, and R.E. Short. 1987. Pregnancy rates of beef heifers bred either puberal or third estrus. J. Anim. Sci. 65(3):645-50.

Carvalho, J.B., N.O. Carvalho, E.L. Reis, M. Nichi, A.H. Souze, and P.S. Baruselli. 2008. Effect of early luteolysis in progesterone-based timed AI protocols in Bos indicus, Bos indicus $\mathrm{X}$ Bos taurus, and Bos taurus heifers. Theriogenology. 69:167-175.

Chenoweth, P.J. 1994. Aspects of reproduction in female Bos indicus cattle: A review. Aust. Vet. J. 71:422-426.

Chenoweth, P.J., F.M. Hopkins, J.C. Spitzer, and R.E. Larsen. 2010. Guidelines for using the bull breeding soundness evaluation form. Theriogenology. 2(1):43-50. 
Cipriano R.S., B.A. Carvalho, N.R. Marangoni, and G.P. Nogueira. 2011. LH and FSH concentration and follicular development in Nellore heifers submitted to fixed-time artificial insemination protocols with different progesterone concentrations. Anim. Reprod. Sci. 127:16-22.

Claro, I., O.G. Filho, R.F. Peres, F.H. Aono, M.L. Day, and J.L. Vasconcelos. 2010. Reproductive performance of prepubertal Bos indicus heifers after progesterone-based treatments. Theriogenology. 74(6)903-11.

Cooke, R. F. and D. W. Bohnert. 2010b. Effects of acclimation to handling on performance, reproductive, and physiological responses of replacement beef heifers. BEEF045 In: 2010 Oregon Beef Council Report. p. 6-9.

Cooke, R. F., C. Mueller, T. DelCurto, and D. W. Bohnert. 2010a. Effects of temperament on reproductive and physiological responses of beef cows. BEEF046 In: 2010 Oregon Beef Council Report. p. 10-13.

Cooke, R. F., J. D. Arthington, B. R. Austin, and J. V. Yelich. 2009b. Effects of acclimation to handling on performance, reproductive, and physiological responses of Brahman crossbred heifers. J. Anim. Sci. 87:3403-3412.

Cooke, R. F., J. D. Arthington, D. B. Araujo, and G. C. Lamb. 2009a. Effects of acclimation to human interaction on performance, temperament, physiological responses, and pregnancy rates of Brahman-crossbred cows. J. Anim. Sci. 87:4125-4132.

Cooke, R.F., D.W. Bohnert, C.I. Cappellozza, C.J. Mueller, and T. Delcurto. 2012. Effects of temperament and acclimation to handling on reproductive performance of Bos taurus beef females. J. Anim. Sci. 90(10):3547-55.

Cooke, R. F. 2014. Temperament and acclimation to human handling influence growth, health, and reproductive responses in Bos taurus and B. indicus cattle. J. Anim. Sci. 92:53255333.

Cundiff, L.V., R.M. Thallman, and L.A. Kuehn. 2012. Impact of Bos indicus genetics on the global beef industry. In: Proc. Beef Improvement Federation. April 18. Houston, TX.

Cupp, A.S., T.T. Stumpf, F.N. Kojima, L.A. Werth, M.W. Wolfe, M.S. Roberson, R.J. Kittok, and J.E. Kinder. 1995. Secretion of gonadotrophins change during the luteal phase of the bovine oestrous cycle in the absence of corresponding changes in progesterone or $17 \beta$ oestradiol. Anim. Reprod. Sci. 37:109-119.

Curran S., R.A. Pierson, and O.J. Ginther. 1986. Ultrasonographic appearance of the bovine conceptus from days 20 through 60. J Am Vet Med Assoc. 189:1295-1302.

Custer, E.E., W.E. Beal, S.J. Wilson, A.W. Meadows, J.G. Berardinelli, and R. Adair. 1994. Effect of melengestrol acetate (MGA) or progesterone-releasing intravaginal device (PRID) on follicular development, concentrations of estradiol-17 $\beta$ and progesterone, and luteinizing hormone release during an artificially lengthened bovine estrous cycle. J. Anim. Sci. 72:1282-1289. 
Dale, H.E., A.L. Ragsdale and C.S. Cheng. 1959. Effect of constant environmental temperatures, 50 degrees and 80 degrees $\mathrm{F}$ on appearance of puberty in beef heifers. J. Anim. Sci. 19:1363.

Day, M.L. and L.H. Anderson. 1998. Current concepts on the control of puberty in cattle. J. Anim. Sci. 76 (Suppl. 3): 1-15.

Day, M.L. K. Imakawa, M. Garcia-Winder, D.D. Zalesky, B.D. Schanbacher, R.J. Kittok, and J.E. Kinder. 1984. Endocrine mechanisms of puberty in heifers: estradiol negative feedback regulation of luteinizing hormone secretion. Biol. Reprod. 32(2):332-341.

Day, M.L., K. Imakawa, P.L. Wolf, R.J. Kittock, and J.E. Kinder. 1987. Endocrine mechanisms of puberty in heifers: Estradiol negative feedback regulation of luteinizing hormone secretion. Biol. Reprod. 31:332-341.

Deutscher, G.H. 2000. Extending interval from seventeen to nineteen days in the melengestrol acetate-prostaglandin estrous synchronization program for heifers. Prof. Anim. Sci. 16:164-168.

Dobson H. and R.F. Smith. 2000. What is stress, and how does it affects reproduction? Anim. Reprod. Sci. 60-61:743-52.

Donaldson, L.E. and W. Hansel. 1965. Prolongation of life span of the bovine corpus luteum by single injections of bovine luteinizing hormone. J. Dairy Sci. 48(7):903-4.

Driancourt, M.A. 2001. Regulation of ovarian follicular dynamics in farm animals. Implications for manipulation of reproduction. Theriogenology. 55:1211-1239.

Dziuk, P. J., and R. A. Bellows. 1983. Management of reproduction in beef cattle, sheep and pigs. J. Anim. Sci. 57(Suppl.2): 355.

Echternkamp, S.E. and W. Hansel. 1973. Concurrent changes in bovine plasma hormone levels prior to and during the first postpartum estrous cycle. J. Anim. Sci. 37:1362-1370.

Eler, J.P., J.B. Ferraz, J.C. Balieiro, E.C. Mattos and G.B. Mourão. 2006. Genetic correlation between heifer pregnancy and scrotal circumference measured at 15 and 18 months of age in Nellore cattle. Genet. Mol. Res. 5:569-580.

Eler J.P., J.A. Silva Jr, J.B.S. Feraz, F. Dias, H.N. Oliveira, J.L. Evans and B.L. Golden. 2002. Genetic evaluation of the probability of pregnancy at 14 months for Nelore heifers. J. of Anim. Sci. 80:951-954.

Ellis, R.W. Natural service mating with bulls: Management guidelines. 2008. In: Proc. Applied Reproductive Strategies in Beef Cattle. Dec 2-3. Fort Collins, CO.

Fajersson P., H.V. Barradas, H. Romanponce, and R.M. Cook. 1991. The effects of dietary protein on age and weight at the onset of puberty in Brown Swiss and Zebu heifers in the tropics. Theriogenology. 35:845-855. 
Farin, P.W., P.J. Chenoweth, E.R. Mateos, and J.E. Pexton. 1982. Beef bulls mated to estrus synchronized heifers: single vs. multi-sire breeding groups Theriogenology. 17:365-372.

Farin, P.W., P.J. Chenoweth, and D.F. Tomky. 1989. Breeding soundness, libido, and performance of beef bulls mated to estrus- synchronized heifers Theriogenology. 32:717725.

Figueiredo, R.A., C.M. Barros, O.L. Pinheiro, and J.M.P. Sole. 1997. Ovarian follicular dynamics in Nelore breed (Bos indicus) cattle. Theriogenology. 47:1489-1505.

Filha, W., M. Bernardi, I. Wentz, and F. Bortolozzo. 2009. Growth rate and age at boar exposure as factors influencing gilt puberty, Livest. Sci. 120:51-57.

Fiol, C., G. Quintans, and R. Ungerfeld. 2010. Response to biostimulation in peri-puberal beef heifers: influence of male-female proximity and heifer's initial body weight. Theriogenology. 74(4):569-75.

Fortune, J.E., and S.M. Quirk. 1988. Regulation of steroidogenesis in bovine preovulatory follicles. J. Anim. Sci. 66:1.

Fortune, J.E., J. Sirois, and S.M. Quirk. 1988. The growth and differentiation of ovarian follicles during the bovine estrous cycle. Theriogenology. 29:95-109.

Francisco, C.L., R.F. Cooke, R.S. Marques, R.R. Mills, D.W. Bohnert. 2012. Effects of temperament and acclimation to handling on feedlot performance of Bos taurus feeder cattle originated from a rangeland-based cow-calf system. J. Anim. Sci. 90(13):5067-77.

Funston, R. N. 2004. Fat supplementation and reproduction in beef females. J. Anim. Sci. 82(E. Suppl.):E154-161.

Galina C.S., A. Orihuela, and I. Rubio. 1996. Behavioural trends affecting oestrus detection in Zebu cattle. Anim. Reprod. Sci. 42:465-70.

Garcia-Winder, M., P.E. Lewis, D.R. Deaver, V.G. Smith, G.S. Lewis, and E.K. Inskeep. 1986. Endocrine profiles associated with life span of induced corpora lutea in postpartum beef cows. J. Anim. Sci. 62:1353-1362.

Garverick H.A., J.R. Parfet, C.N. Lee, J.P Copelin, R.S.Youngquist, and M.F. Smith. 1988. Relationship of pre- and post-ovulatory gonadotropin concentrations to subnormal luteal function in postpartum beef cattle. J. Anim. Sci. 66:104-11.

Garverick, H. A., R. E. Erb, G. D. Niswender, and C. J. Callahan. 1971. Reproductive steroids in the bovine. III. Changes during the estrous cycle. J. Anim. Sci. 32:946.

Garverick, H.A. and M.F. Smith. 1986. Mechanism associated with subnormal luteal function. J. Anim. Sci. 62 (Suppl. 2):92-105.

Garverick, H.A., W.G. Zollers Jr., and M.F. Smith. 1992. Mechanisms associated with corpus luteum lifespan in animals having normal or subnormal luteal function. Anim. Reprod. Sci. 28:111-124. 
Ginther O.J., K. Kot, L.J. Kulick, and M.C. Wiltbank. 1997. Emergence and deviation of follicles during the development of follicular waves in cattle. Theriogenology. 48:75-87.

Ginther O.J., D.R. Bergfelt, L.J. Kulick, and K. Kot. 2000. Selection of the dominant follicle in cattle: role of two-way functional coupling between follicle-stimulating hormone and the follicles. Biol. Reprod. 62(4):920-7.

Ginther, O.J., J.P. Kastelic, and L. Knopf. 1989. Comparison and characteristics of follicular waves during the development of follicular waves in cattle. Theriogenology. 48:75-87.

Ginther, O.J., M.C. Wiltbank, P.M. Frike, J.R. Gibbons, and K. Kot. 1996. Selection of the dominant follicle in cattle. Biol. Reprod. 55:1187-94.

Gonzalez-Padilla E., J.N. Wiltbank, and G.D. Niswender. 1975. Puberty in beef heifers I. The interrelation between pituitary, hypothalamic and ovarian hormones. J. Anim. Sci. 40:1091.

Hafez, E.S.E. 1980. Reproduction in farm animals. 4th ed. London: Lea and Febiger.

Hageleit, M., A. Daxenberger, W.D. Kraetzl, A. Kettler, and H.H.D. Meyer. 2000. Dosedependent effects of melengestrol acetate (MGA) on plasma levels of estradiol, progesterone, and luteinizing hormone in cycling heifers and influences on estrogen residues in edible tissues. Acta. Pathol. Microbiol. Immunol. Scand. 108:847-854.

Hall, J.B., R.B. Staigmiller, R.E. Short, R.A. Bellows, M.D. MacNeil, and S.E. Bellows. 1997. Effect of age and pattern of gain on induction of puberty with a progestin in beef heifers. J. Anim. Sci. 75:1606-1611.

Hall, J.B. and J.B. Glaze. 2017. Heifer nutritional developmental strategies. In: Proc. Applied Reproductive Strategies in Beef Cattle. Aug 29-30. Manhattan, KS.

Hansel, W. and E.M. Convey. 1983. Physiology of the estrous cycle. J. of Anim. Sci. 57 (Suppl. 2) 404-424.

Hansel, W., P.V. Malven, and D.L. Black. 1961. Estrous cycle regulation in the bovine. J. Anim. Sci. 20:621-625.

Hatler, T.B., S.H. Hayes, D.L. Ray, P.S. Reames, and W.J. Silvia. 2008. Effect of subluteal concentrations of progesterone on luteinizing hormone and ovulation in lactating dairy cows. Vet J. 177(3):360-368.

Hawk, H.W. 1983. Sperm survival and transport in the female reproductive tract. J. Dairy Sci. 66(12):2645-60.

Healy, V.M., G.W. Boyd, P.H. Gutierrez, R.G. Mortimer, and J.R. Piotrowski. 1993. Investigating optimal bull:heifer ratios required for estrus-synchronized heifers. J. Anim. Sci. 71:291-297.

Hendricks, D.M., J.R. Hill, and J.F. Dickey. 1973. Plasma ovarian hormone levels and fertility in beef heifers treated with melengestrol acetate (MGA). J. Anim. Sci. 37:1169-1175. 
Hodgen, G.D. 1982. The dominant ovarian follicle. Fertil. Steril. 38:281-300.

Holm D.E., P.N. Thompson, and P.C. Irons. 2009. The value of reproductive tract scoring as a predictor of fertility and production outcomes in beef heifers. J. Anim. Sci. 87:1934-40.

Holm, D.E. M. Nielen, R. Jorritsma, P.C. Irons, and P.N. Thompson. 2016. Ultrasonographic reproductive tract measures and pelvis measures as predictors of pregnancy failure and anestrus in restricted bred beef heifers. Theriogenology. 85(3):495-501.

Imwalle, D.B., D.J. Patterson, and K.K. Schillo. 1996. Effects of melengestrol acetate on pulsatile secretion of luteinizing hormone in beef heifers. J. Anim. Sci. 74(Suppl. 1):235.

Imwalle, D.B., D.J. Patterson, and K.K. Schillo. 1998. Effects of melengestrol acetate on onset of puberty, follicular growth, and patterns of luteinizing hormone secretion in beef heifers. Biol. Reprod 58:1432-1436.

Imwalle, D.B., D.L. Fernandez, and K.K. Schillo. 2002. Melengestrol acetate blocks the preovulatory surge of luteinizing hormone, the expression of behavioral estrus, and ovulation in beef heifers. J. Anim. Sci. 80:1280-1284.

Jainudeen, M.R., and E.S.E. Hafez. 1987. Reproductive cycles: Cattle and water buffalo. In: Reproduction in farm animals. ESE Hafez. Lea and Febiger, Philadelphia, PA. p. 297314.

Kastelic, J.P., L. Knopf, and O.J. Ginther. 1990. Effect of day of prostaglandin F2 $\alpha$ treatment on secretion and development of the ovulatory follicle in heifers. Anim. Reprod. Sci. 23:169-180.

Kim, J.Y. 2012. Control of ovarian primordial follicle activation. Clin. Exp. Reprod. Med. 39:1014.

Kiser, T.E., R.R. Krealing, G.B. Rampacek, B.J. Landmeier, A.B. Caudel, and J.D. Chapman. 1981. J. Anim. Sci. 53:1545-1550.

Knopf, L. J.P. Kastelic, E. Schallenberger, and O.J. Ginther. 1989. Ovarian follicular dynamics in heifers: Test of two-wave hypothesis by ultrasonically monitoring individual follicles. Domest. Anim. Endo. 6:111-119.

Koger, M. 1963. Breeding for the American topics. In: T. J. Cunha, M. Koger, and A. C. Warnick, (Ed.) Crossbreeding Beef Cattle. Series I. Univ. Florida Press, Gainesville. p. 41-46.

Kojima, F. N. 2003. The estrous cycle in cattle: Physiology, endocrinology, and follicular waves. Prof. Anim. Sci. 19:83-95.

Kojima, F.N., J.F. Bader, J.E. Stegner, D.J. Schafer, J.C. Clement, R.L. Eakins, M.F. Smith, and D.J. Patterson. 2004. Substituting EAZI-BREED CIDR inserts (CIDR) for melengestrol acetate (MGA) in the MGA Select protocol in beef heifers. J. Anim. Sci. 82 (Suppl. 1): 225. 
Kojima, F.N., J.R. Chenault, M.E. Wehrman, E.G. Bergfeld, A.S. Cupp, L.A. Werth, V. Marsical, T. Sanchez, R.J. Kittok, and J.E. Kinder. 1995. Melengestrol acetate at greater doses typically used for estrus synchrony in bovine females does not mimic endogenous progesterone in regulation of secretion of luteinizing hormone and $17 \beta$-estradiol. Biol. Reprod. 52:455-463.

Lamb, G.C. 2013. Criteria for selecting replacements at weaning, before breeding and after breeding. Vet. Clin. North Am. Food Anim. Pract. 29(3):567-78.

Lamb, G.C. and J.E. Larson. 2006. Review of estrus synchronization systems: CIDR. In: Proc. Applied Reproductive Strategies in Beef Cattle. Aug 30-31. St. Joseph, MO. p. 105-118.

Lamb, G.C., D.W. Nix, J.S. Stevenson, and L.R. Corah. 2000. Prolonging the MGAprostaglandin- $\mathrm{F}_{2 \alpha}$ interval from 17 to 19 days in an estrus synchronization system for heifers. Theriogenology. 53: 691-698.

Lamond, D.R. 1964. Synchronization of ovarian cycles in sheep and cattle. Anim. Bred. Abstr. 32:269-285.

Larson, D. M., A. S. Cupp, and R. N. Funston. 2009. Extending grazing in heifer development systems decreases costs without compromising production. J. Anim. Sci. 87, E-Suppl. $3: 140$.

Lauderdale, J.W. 1972. Effects of PGF2 $\alpha$ on pregnancy and estrous cycles of cattle. J. Anim. Sci. $35: 246$.

Lee, J., J.A. McCracken, S.K. Banu, R. Rodriguez, T.K. Nithy, and J.A. Arosh. 2010. Transport of Prostaglandin F $2 \alpha$ Pulses from the Uterus to the Ovary at the Time of Luteolysis in Ruminants Is Regulated by Prostaglandin Transporter-Mediated Mechanisms. Endocrinology. 151(7):3326-35.

Leitman, N.R., D.C. Busch, J.F. Bader, D.A. Mallory, D.J. Wilson, M.C. Lucy, M.R. Ellersieck, M.F. Smith, and D.J. Patterson. 2008. Comparison of protocols to synchronize estrus and ovulation in estrous-cycling and prepubertal beef heifers. J. Anim. Sci. 86:1808-1818.

Leitman, N.R., D.C. Busch, D.A. Mallory, D.J. Wilson, M.R. Ellersieck, M.F. Smith, and D.J. Patterson. 2009a. Comparison of long-term CIDR-based protocols to synchronize estrus in beef heifers. Anim. Reprod. Sci. 114:345-355

Leitman, N.R., D.C. Busch, D.A. Mallory, D.J. Wilson, M.R. Ellersieck, M.F. Smith, and D.J. Patterson. 2009b. Comparison of controlled internal drug release insert-based protocols to synchronize estrus in prepubertal and estrous-cycling beef heifers. J. Anim. Sci. 87:39763982.

Lesmeister, J.L., P.J. Burfening, and R.L. Blackwell. 1973. Date of first calving in beef cows and subsequent calf production. J. Anim. Sci. 36:1-6.

Locke J.W.C., J.M. Thomas, B.E. Bishop, J.M. Abel, S.E. Poock, D.S. Brown, J.E. Decker, and D.J. Patterson. 2016. The Show-Me-Select Replacement Heifer Program: Adding value to beef herds in Missouri. J. Anim. Sci. 94(E-Suppl. 5):271. 
Louis, T.M., H.D. Hafs, and D.A. Morrow. 1972. Estrus and ovulation after uterine prostaglandin $\mathrm{F}_{2 \alpha}$ in cows. J. Anim. Sci. 35:247.

Lucy M.C., H.J. Billings, W.R. Butler, L.R. Ehnis, M.J. Fields, D.J. Kesler, J.E. Kinder, R.C. Mattos, R.E. Short, W.W. Thatcher, R.P. Wettemann, J.V. Yelich, and H.D. Hafs. 2001. Efficacy of an intravaginal progesterone insert and an injection of PGF2alpha for synchronizing estrus and shortening the interval to pregnancy in postpartum beef cows, peripubertal beef heifers, and dairy heifers. J. Anim. Sci. 79:982-995.

Macmillan, K.L. and A.J. Peterson. 1993. A new intravaginal progesterone releasing device for cattle (CIDR-B) for oestrus synchronization, increasing pregnancy rates and the treatment of post-partum anoestrus. Anim. Reprod. Sci. 33:1-25.

Macmillan, K.L., V.K. Taufa, D.R. Barnes, and A.M. Day. 1991. Plasma progesterone concentrations in heifers treated with a new intravaginal device. Anim. Reprod. Sci. 26:25-40.

Macmillan, K.L., V.K. Taufa, D.R. Barnes, A.M. Day, and R. Henry. 1988. Detecting oestrus in synchronized heifers using tailpaint and aerosol raddle. Theriogenology 30:1099-1114.

Macmillan, K.L. and W.W. Thatcher, 1991. Effects of an agonist of gonadotropin-releasing hormone on ovarian follicles in cattle. Biol. Reprod. 45: 883-889.

Mallory, D.A., D.J. Wilson, D.C. Busch, M.R. Ellersieck, M.F. Smith, and D.J. Patterson. 2010. Comparison of long-term progestin based estrus synchronization protocols in beef heifers. J. Anim. Sci. 88:3568-3578.

Mantovani A.P., M. Nichi, M.F. Sá Filho, H. Ayres, L.F. Vettorato, G.A. Bó, and P.S. Baruselli . 2010. Follicular growth and plasma progesterone patterns in Bos indicus x Bos taurus heifers submitted to different PGF2 $\alpha$ /progesterone-based synchronization protocols. Anim. Reprod. Sci. 7:91-96.

Mapletoft, R.J., K.B. Steward, and G.P. Adams. 2002. Recent advances in the superovulation in cattle. Reprod. Nutr. Dev. 42(6):601-11.

Martin, L.C., J.S. Brinks, R.M. Bourdon, and L.V. Cundiff. 1992. Genetic effects on beef heifer puberty and subsequent reproduction. J. of Anim. Sci. 70:4006-17.

Martin, N.T., J.M. Thomas, J.M. Nash, D.A. Mallory, M.R. Ellersieck, S.E. Poocks, M.F. Smith, and D.J. Patterson. 2014. Comparison of a 16- versus a 19-day interval between controlled internal drug release removal and prostaglandin F2 $\alpha$ following a 14-day controlled internal drug releasetreatment and fixed-time artificial insemination in postpartum beef cows. J. Anim. Sci. 92:1759-1767.

Martinez, M.F., J.P. Kastelic, G.P. Adams, E. Janzen, D.H. McCartney, and R.J. Mapletoft. 2000. Estrus synchronization and pregnancy rates in beef cattle given CIDR-B, prostaglandin and estradiol, or GnRH. Can. Vet J. 41:786-790.

McCracken, J.A., E.E. Custer, J.C. Lamsa, and A.G. Robinson. 1995. The central oxytocin pulse generator: A pacemaker for luteolysis. Adv. Exp. Med. Biol. 395:133-54. 
McCracken, J.A., E.E. Custer, J.A. Eldering, and A.G. Robinson. 1996. The central oxytocin pulse generator: a pacemaker for the ovarian cycle. Acta. Neurobiol. Exp. (Warz.) 56:819-832.

McLeod, B.J., A.R. Peters, W. Haresign, and G.E. Lamming. 1985. Plasma LH and FSH responses and ovarian activity in prepubertal heifers treated with repeated injections of low doses of GnRH for 72 h. J. Reprod. Fert. 74:589-596.

Mizuta K. 2003. Comparative study of the behavioral aspects of estrus and plasma levels of LH, FSH, progesterone and estradiol preceding ovulation in Nelore (Bos taurus indicus), Angus (Bos taurus taurus) and Nelore x Angus (Bos taurus indicus x Bos taurus taurus). Thesis (Doctorate) - Faculty of Veterinary Medicine and Animal Science, University of São Paulo, São Paulo. p 98.

Moenter S.M., A. Caraty, A. Locatelli, and F.J. Karsch. 1991. Pattern of gonadotropin-releasing hormone $(\mathrm{GnRH})$ secretion leading up to ovulation in the ewe: Existence of a preovulatory GnRH surge. Endocrinology. 129:1175-1182.

Mollo M.R., R. Rumpf, A.C. Martins, M.C.C. Mattos, G. Lopes Jr, L.H.D. Carrijo, and R. Sartori. 2007. Ovarian function in Nelore heifers under low or high feed intake. Acta Sci. Vet. 35: 958.

Monteiro F.M., M.E. Mercandante, C.M. Barros, R.A. Satrapa, J.A. Silca, L.Z. Olivera, N.Z. Saraiva, C.S. Olivera, and J.M. Garcia. 2013. Reproductive tract development and puberty in two lines of Nellore heifers selected for postweaning weight. Theriogenology. 80:10-17.

Moreria, F., R.L. de la Sota, T. Diaz, and W.W. Thatcher. 2000. Effect of day of the estrous cycle at the initiation of a timed artificial insemination protocol on reproductive responses in dairy heifers. J. Anim. Sci. 78:1586-1576.

Nellor, J. E. and H. H. Cole. 1956. The hormonal control of estrus and ovulation in beef heifers. J. Animal Sci. 15:650.

Nix. D.W., G.C. Lamb, V. Traffas, and L.R. Corah. 1998. Increasing the interval to prostaglandin from 17 to 19 days in GA-prostaglandin synchronization system for heifers. In: Proc. Kansas State Univ. Cattlemen's Day Report of Progress. 804: pp. 31-36.

O’Bleness, G.V., L.D. van Vleck, and C.R. Henderson. 1960. Heritabilities of some type appraisal traits and their genetic and phenotypic correlations with production. J. Dairy Sci. 43(10):1490-1498.

Odde, K.G. 1990. A review of synchronization of estrus in postpartum cattle. J. Anim. Sci. 68:817-830.

Oliveira, C.M.G., B.D. Oliveira Filho, M.L. Gambarini, M.A.O. Viu, D.T. Lopes, and A.P.F. Sousa. 2009. Effect of biostimulation and nutritional supplementation on pubertal age and pregnancy rates of Nelore heifers (Bos indicus) in a tropical environment. Anim. Reprod. Sci. 113:38-43. 
Parish, J.A., J.E. Larson, and R.C. Vann. 2010. The estrous cycle of cattle. Mississippi State University Extension Publication P2616. Mississippi State University. http://extension.msstate.edu/sites/default/files/publications/publications/p2616.pdf

Patterson, D.J. and J.E. Decker. 2015. Phenotypic data collection for reproductive tratis in replacement beef heifers. In: Proc. Beef Improvement Federation. June 9-12. Biloxi, MS.

Patterson D.J., J.B. Hall, N.W. Bradley, K.K. Schillo, B.L. Woods, and J.M. Kearnan. 1995. Improved synchrony, conception rate, and fecundity in postpartum suckled beef cows fed melengestrol acetate prior to prostaglandin F2 $\alpha$. J. Anim. Sci. 73:954-959.

Patterson, D.J., J.M. Thomas, J.W.C. Locke, B.E. Bishop, J.M. Abel, E.R. Knickmeyer, and M.F. Smith. 2017b. Control of estrus and ovulation in beef heifers. In: Proc. Applied Reproductive Strategies in Beef Cattle. Aug. 29-30. Manhattan, KS.

Patterson, D. J., L. R. Corah, and J. R. Brethour. 1990. Response of prepubertal Bos taurus and Bos indicus $\mathrm{x}$ Bos taurus heifers to melengestrol acetate with or without gonadotropin releasing hormone. Theriogenology. 33:661-669.

Patterson, D.J., D.S. Brown, J.E. Decker, and S.E. Poock. 2017a. Adding value to replacement beef heifers: A working model. In: Proc. Beef Improvement Federation. May 31-Jun. 3. Athens, GA.

Patterson, D.J., F.N. Kojima, and M.F. Smith. 2003. Methods to synchronize estrous cycles of postpartum beef cows with melengestrol acetate. Prof. Anim. Sci. 19:109-115.

Patterson, D.J., G.H. Kiracofe, J.S. Stevenson, and L.R. Corah. 1989. Control of the bovine estrous cycle with melengestrol acetate prior to prostaglandin F2 $\alpha$. J. Anim. Sci. 73:954959.

Patterson, D.J., L.R. Corah, G.H. Kiracofe, J.S. Stevenson, and L.R. Corah. 1989a. Conception rate in Bos Taurus and Bos indicus crossbred heifers after postewaning energy manipulation and synchronization of estrus with melengestrol acetate and fenprostalene. J. Anim. Sci. 67:1138.

Patterson, D.J., L.R. Corah, J.R. Brethour, M.F. Spire, J.J. Higgins, G.H. Kiracofe, J.S. Stevenson, and D.D. Simms. 1991. Evaluation of reproductive traits in Bos taurus and Bos indicus crossbred heifers: Effects of postweaning energy manipulation. J. Anim. Sci. 69:2349.

Patterson, D.J., R.C. Perry, G.H. Kiracofe, R.A. Bellows, R.B. Staigmiller, and L.R. Corah. 1992. Management considerations in heifer development and puberty. J. Anim. Sci. 70:4018-4035.

Patterson, D.J., S.L. Wood, and R.F. Randle. 2002. Procedures that support reproductive management of replacement heifers. In: Proc. Applied Reproductive Strategies in Beef Cattle. Sept 5-6. Manhattan, KS. p. 204-226.

Patterson, J.L., H.J. Willis, R.N. Kirkwood, and G.R. Foxcroft. 2002b. Impact of boar exposure on puberty attainment and breeding outcomes in gilts. Theriogenology. 57:2015-2025. 
Patterson, D.J., D.S. Brown, W.J. Sexten, J.E. Decker, and S.E. Poock. 2013. Management strategies for adding value to replacement beef heifers: A working model. In: Veterinary Clinics of North America: Food Animal Practice; Management Considerations in Beef Heifer Development and Puberty. pp. 653-666.

Patterson, D.J., S.L. Wood, and R.F. Randle. Procedures that support reproductive management of replacement beef heifers. Proc. Am. Soc. Anim. Sci. 1999. Available at: http://www.asas.org/jas/symposia/proceedings/0902.pdf. Accessed August 3, 2000.

Pence, M, and R BreDahl. 1998. Clinical use of reproductive tract scoring to predict pregnancy outcome. Pages 259-260 in Proc. 31st Annu. Con. AABP, Spokane, WA. Am. Assoc. Bov. Pract., Stillwater, MN.

Pence, M, D Ensley, R Berghaus, J Rossi, T Wilson, and PT Cannon. 2007. Improving reproductive efficiency through the use of reproductive tract scoring in a group of beef replacement heifers. Bov. Pract. 41:35-40.

Pereira E., H.N Oliveira, J.P. Eler, J.A.Silva, and M.H. Van Melis. 2007. Comparison among three approaches for evaluation of sexual precocity in Nellore cattle. Animal. 1:411-418.

Peres R.F.G., I. Claro Jr, O.G. Sá Filho, G.P. Nogueira, and J.L. Vasconcelos. 2009. Strategies to improve fertility in Bos indicus postpubertal heifers and nonlactating cows submitted to fixed-time artificial insemination. Theriogenology. 72:681-9.

Perry, G.A., M.F. Smith, and T.W. Geary. 2004. Ability of intravaginal progesterone inserts and melengestrol acetate to induce estrous cycles in postpartum beef cows. J. Anim. Sci. 82:695-704.

Perry, GA, and R Cushman. 2013. Effect of age at puberty/conception date on cow longevity. In: Veterinary Clinics of North America: Food Animal Practice; Management Considerations in Beef Heifer Development and Puberty. 29:579- 590.

Perry, G.A., W.V. Welshons, R.C. Bott, and M.F. Smith. 2005. Basis of melengestrol acetate action as a progestin. Domest. Anim. Endocrinol. 28:147-161.

Pexton, J.E., P.W. Farin, G.W. Rupp, and P.J. Chenoweth. 1990. Factors affecting mating activity and pregnancy rates with beef bulls mated to estrus synchronized females Theriogenology. 34:1059-1070.

Pexton, J.E., P.W. Farin, R.A. Gerlach,, and J.L. Sullins. 1989. Efficiency of single-sire mating programs with beef bulls mated to estrus synchronized females Theriogenology. 32:705716.

Pharriss B.B., J.C. Cornette, and G.D. Gutknecht. 1970. Vascular control of luteal steroidogenesis. J. Reprod. Fertil. Suppl. 10:97-103.

Pierson, R.A. and O.J. Ginther. 1984. Ultrasonography of the bovine ovary. Theriogenology. 21:495-505. 
Pinheiro O.L., C.M. Barros, R.A. Figueredo, E.R. Valle, R.O. Encarnação, and C.R. Padovani. 1998 Estrous behavior and the estrus-to-ovulation interval in Nelore cattle (Bos indicus) with natural estrus or estrus induced with prostaglandin F2 $\alpha$ or norgestomet and estradiol valerate. Theriogenology. 49:667-681.

Plasse, D., A. C. Warnick, and M. Koger. 1970. Reproductive Behavior of Bos Indicus Females in a Subtropical Environment. IV. Length of Estrous Cycle, duration of Estrus, Time of Ovulation, Fertilization and Embryo Survival in Grade Brahman Heifers1. J. Anim. Sci. 30:63-72.

Pohler, K.G., M. Pereira, F.Lopes, J. Lawrence, D.H. Keisler, M.F. Smith, J.L. Vasconcelos, and J. A. Green. 2016. Circulating concentrations of bovine pregnancy associated glycoproteins and late embryonic mortality in lactating dairy herds. J. Dairy. Sci. 99: 1584-1594.

Poock, S.E. and C.A. Payne. 2013. Incorporating reproductive management of beef heifers into a veterinary practice. Vet Clin Food Anim. 29:667-678.

Portillo, G.E., G.A. Bridges, J.W. de Araujo, M.K. Shaw, F.N. Schrick, W.W. Thatcher, and J.V. Yelich. 2008. Response to GnRH on day 6 of the estrous cycle is diminished as the percentage of Bo indicus breeding increases in Angus, Brangus and Brahman x Angus heifers. Anim. Reprod. Sci. 103:38-51.

Pursley, J.R., M.C. Wiltbank, J.S. Stevenson, J.S. Ottobre, H.A. Garverick, and L.L. Anderson. 1997. Pregnancy rates per artificial insemination for cows and heifers inseminated at a synchronized ovulation or synchronized estrus. J Dairy Sci. 80: 295-300.

Quadros, S.A. and J.F.P. Lobato. Biostimulation and reproductive performance of beef heifers. 2004. Bras. Zootec. 33(3):679-683.

Rae, D.O., P.J. Chenoweth, M.A. Giangreco, P.W. Dixon, and F.L. Bennet. 1999. Assessment of estrus detection by visual observation and electronic detection methods and characterization of factors associated with estrus and pregnancy in beef heifers. Theriogenology. 51:1121-1132.

Rahe, C.H., R.E. Owens, J.L. Fleefer, H.J. Newton, and P.G. Harms. 1980. Pattern of plasma luteinizing hormone in the cyclic cow: Dependence upon the period of the cycle. Endocrinology 107:498-503.

Randel, R.D. 1984. Seasonal effects on female reproductive functions in the bovine Indian breeds). Theriogenology. 21:70-85.

Randel, R.D. 2005. Reproduction of Bos indicus breeds and crosses. In: Proc. Applied Reproductive Strategies in Beef Cattle. Nov 12-13. College Station, TX. p. 104-123.

Rawlings, N.C., L. Weir, B. Todd, J. Manns, and J.H. Hyland. 1980. Some endocrine changes associated with the postpartum period of the suckling beef cow. J. Reprod. Fertil. 60:301308. 
Roberson, M.S., M.W. Wolfe, T.T. Stumpf, L.A. Werth, A.S. Cupp, N. Kojima, P.L. Wolfe, and P.J. Kittok. 1991. Influence of growth rate and exposure to bulls on age at puberty in beef heifers. J. Anim. Sci. 69:2092-2098.

Roberson, M.S., R.P. Ansotegui, J.G. Berardinelli, R.W. Whitman, and M.J. McInerney. 1987. Influence of biostimulation by mature bulls on occurrence of puberty in beef heifers. J. Anim. Sci. 64:1601-1605.

Roberts, A. J., T. W. Geary, E. E. Grings, R. C. Waterman, and M. D. MacNeil. 2009. Reproductive performance of heifers offered ad libitum or restricted access to feed for a one hundred forty-day period after weaning. J. Anim. Sci. 87:3043-3052.

Rodrigues H.D., J.E. Kinder, and L.A. Fitzpatrick. 2002. Estradiol regulation of luteinizing hormone secretion in heifers of two breed types that reach puberty at different ages. Biol. Reprod. 66:603-609.

Romereim S.M., A.F. Summers, W.E. Pohlmeier, P. Zhang, X. Hou, H.A. Talbott, R.A. Cushman, J.R. Wood, J.S. Davis, and A.S. Cupp. 2017. Gene expression profiling of bovine ovarian follicular and luteal cells provides insight into cellular identities and functions. Mol. Cell. Endocrinol. 439:379-94.

Rosenkrans K.S. and D.K. Hardin 2003. Repeatability and accuracy of reproductive tract scoring to determine pubertal status in beef heifers. Theriogenology. 59:1087-92.

Rouiller, P., P. Matton, M. Dufour, M.A. Sirard, and L.A. Guilbault. 1998. Steroid production, cell proliferation, and apoptosis in cultured bovine antral and mural granulosa cells: Development of an in vitro model to study estradiol production. Mol. Reprod. Dev. 50(2):170-7.

Rowson, L.E.A., R. Tervit, and A. Brand. 1972. The use of prostaglandin for synchronization of oestrus in cattle. J. Reprod. Fertil. 29:145.

Rozell, T.G. and D.H. Keisler. 1990. Effects of oestradiol on LH, FSH and prolactin in ovariectomized ewes. J. Reprod. Fertil. 88: 645-653.

Rupp, G.P., L. Ball, M.C. Shoop, P.J. Chenoweth. 1977. Reproductive efficiency of bulls in natural service: Effects of male to female ratio and single- vs multiple-sire breeding groups. J. Am. Vet. Med. Assoc. 171:639-642.

Saldarriaga J.P., D.A. Cooper, J.A. Cartmill, J.F. Zuluaga, R.L. Stanko, and G.L. Williams. 2007. Ovarian, hormonal, and reproductive events associated with synchronization of ovulation and timed appointment breeding of Bos indicus-influenced cattle using intravaginal progesterone, gonadotropin-releasing hormone, and prostaglandin F2 $\alpha$. J. Anim. Sci. 85:151-62.

Sartori R., M.R. Bastos, P.S. Baruselli, L.U. Gimenes, R.L. Ereno, and C.M. Barros. 2010. Physiological differences and implications to reproductive management of Bos taurus and Bos indicus cattle in a tropical environment. Soc. Reprod. Fertil. Suppl. 67:357-75. 
Sartori R., P.M. Fricke, J.C. Ferreira, O.J. Ginther, and M.C. Wiltbank. 2001. Follicular deviation and acquisition of ovulatory capacity in bovine follicles. Biol. Reprod. 65:1403-1409.

Sartori R., J.M. Haughian, R.D. Shaver, G.J.M. Rosa, and M.C. Wiltbank. 2004. Comparison of ovarian function and circulating steroids in estrous cycles of Holstein heifers and lactating cows. J. Dairy Sci. 87:905-920.

Savio J.D., L. Keenan, M.P. Boland, and J.F. Roche. 1988. Pattern of growth of dominant follicles during the oestrous cycle of heifers. J. Reprod. Fertil. 83:663-671.

Savio, J.D., M.P. Boland, N. Hynes, M.R. Mattiacci, and J.F. Roche. 1990. Will the first dominant follicle o the estrous cycle of heifers ovulate following luteolysis on day 7 ? Theriogenology. 33:677-687.

Schafer, D.J., D.C. Busch, M.F. Smith, and D.J. Patterson. 2006. Characterization of follicular dynamics, timing of estrus, and response to GnRH and PG in replacement beef heifers and presynchronization with a 14-day CIDR. J. Anim. Sci. 84 (Suppl. 1): 49.

Schallenberger E., D. Schams, B. Bullermann, and D.L. Walters. 1984. Pulsatile secretion of gonadotrophins, ovarian steroids and ovarian oxytocin during prostaglandin-induced regression of the corpus luteum in the cow. J. Reprod. Fertil. 71(2):493-501.

Schiffer, B, A. Daxenberger, K. Meyer, and H.H.D. Meyer. 2001. The fate of trenbolone acetate and melengestrol acetate after application as growth promoters in cattle: Environmental studies. Environ. Health Perspect. 109:1145-1151.

Schillo, K.K., D.J. Dierschke, and E.R. Hauser. 1983. Estrogen-induced release of luteininzing hormone in prepubertal and postpubertal heifers. Theriogenology. 19:727-738.

Seidel, G.E., L.L. Larson, and R.H. Foote. 1971. Effects of age and gonadotropin treatment on superovulation in the calf. J. Anim. Sci. 33:617-622.

Senger, P.L. 2012. Pathways to Pregnancy and Parturition Third Edition. Current Conceptions, Inc., Pullman, WA.

Sheffel, C.E., B.R. Pratt, W.L. Ferrell, and E.K. Inskeep. 1982. Induced corpra lutea in the postpartum beef cow. II. Effects of treatment with progestogen and gonadotropins. J. Anim. Sci. 54:830-836.

Short, R.E., R.A. Bellows, J.B. Carr, R.B. Staigmiller, and R.D. Randel. 1976. Induced or synchronized puberty in heifers. J. Anim. Sci. 43:1254.

Short, R.E., R.D. Randel, and R.A. Bellows. 1974. Factors affecting reproduction in the postpartum cow. J. Anim. Sci. 39:226.

Sirois J, and J.E. Fortune. 1990. Lengthening the bovine estrous cycle with low levels of exogenous progesterone: A model for studying ovarian follicular dominance. Endocrinology. 127(2):916-25. 
Sirois J. and J.E. Fortune. 1988. Ovarian follicular dynamics during the estrous cycle in heifers monitored by real-time ultrasonography. Biol. Reprod. 39:308-317.

Smith M.F., E.W. McIntush, and G.W. Smith. 1994. Mechanisms associated with corpus luteum development. J. Anim. Sci. 72(7):1857-72.

Smith M.F., G.A. Perry, J.A. Atkins, E.M. Jinks, K.G. Pohler, and D.J. Patterson. 2011. Keys to a successful estrus synchronization and artificial insemination program. In: Proc. Applied Reproductive Strategies in Beef Cattle. Aug. 31-Sept. 1. Joplin, MO. p.105-121.

Smith, M.F., G.A. Perry, J. B. Hall, J.A. Atkins, D.C. Busch, and D.J. Patterson. 2007. Physiological principles underlying synchronization of estrus. In: Proc. Applied Reproductive Strategies in Beef Cattle. September 11-12. Billings, MT. p. 1-26.

Smith, R.K., and M.L. Day. 1990. Mechanism of induction of puberty in beef heifers with melengestrol acetate. In: Ohio Beef Cattle Research and Industry Report. p. 137-142.

Spicer, L.J. and S.E. Echternkamp. 1986. Ovarian follicular growth, function and turnover in cattle: A review. J. Anim. Sci. 62(2):428-51.

Stegner, J.E., F.N. Kojima, S.L. Wood, M.F. Smith, and D.J. Patterson. 2002. Using MGA to shorten the breeding season. University of Missouri Extension Publication MP735. University of Missouri.

Stumpf T.T., M.L Day, M.W. Wolfe, A.C. Clutter, J.A. Stotts, P.L. Wolfe, R.J. Kittok, and J.E. Kinder. 1989. Effect of estradiol on secretion of luteinizing hormone during the follicular phase of the bovine estrous cycle. Biol. Reprod. 41(1):91-7.

Sun X., Y. Su, Y. He, J. Zhang, W. Liu, H. Zhang, Z. Hou, J. Liu, and J. Li. 2015. New strategy for in vitro activation of primordial follicles with mTOR and PI3K stimulators. Cell Cycle. 14(5):721-31.

Symington, R.B. and D.H. Hale. 1967. The stimulation of sexual activity in lactating Zebu cows. Rhodesia, Zambia and Malawi J of Ag Research. 5:13.

Tanaka, Y., D.L. Vincent, K.S. Ledgerwood, and C.W. Weems. 1995. Variable progesterone response and estradiol secretion in prepubertal beef heifers following treatment with Norgestomet implants. Theriogenology. 43:1077.

Tauck S.A., J.R.C. Wilkinson, J.R. Olsen, J.N. Janitell, and J.G. Berardinelli. 2007. Comparison of controlled internal drug release device and melengesterol acetate as progestin sources in an estrous synchronization protocol for beef heifers. Theriogenology. 68:164-167.

Thimonier, J., D. Chupin, and J. Pelot. 1975. Synchronization of estrus in heifers and cyclic cows with progestogens and prostaglandin analogues alone or in combination. Ann. Biol. Anim. Biochem. Biophys. 15:437-499.

Thomas J.M., S.L. Lock, S.E. Poock, M.R. Ellersieck, M.F. Smith, and D.J. Patterson. 2014a. Delayed insemination of non-estrous suckled beef cows improves pregnancy rates when using sex-sorted semen in timed artificial insemination. J. Anim. Sci. 92:1745-50. 
Thomas J.M., S.L. Lock, S.E. Poock, M.R. Ellersieck, M.F. Smith, and D.J. Patterson. 2014b. Delayed insemination of non-estrous heifers and cows when using conventional semen in timed artificial insemination. J. Anim. Sci. 92:4189-97.

Thomas, J.M., J.W.C. Locke, B.E. Bishop, J.M. Abel, M.R. Ellersieck, J.V. Yelich, S.E. Poock, M.F. Smith, and D.J. Patterson. 2017. Evaluation of the 14-d CIDR and 9-d CIDR protocols for synchronization of estrus in Bos indicus-influenced and Bos taurus beef heifers. Theriogenology. 92:190-196.

Townson D.H., P.C.W. Tsang, W.R. Butler, M. Frajblat, L.C. Griel Jr, C.J. Johnson, R.A. Milvae, G.M. Niksic, and J.L. Pate. 2002. Relationship of fertility to ovarian follicular waves before breeding in dairy cows. J. Anim. Sci. 80:1053-1058.

Ulberg, L.C., R.E. Christian, and L.E. Casida. 1951. Ovarian response in heifers to progesterone injections. J. Anim. Sci. 10:725-759.

USDA NAHMS. 2008. Part II. Reference of beef cow-calf management practices in the United States.

https://www.aphis.usda.gov/animal_health/nahms/beefcowcalf/downloads/beef0708/Beef 0708_dr_PartII.pdf. Accessed September 17, 2017.

USDA NAHMS. 2009. Bull management practices on US beef cow-calf operations Info Sheet. February 2009.

https://www.aphis.usda.gov/animal_health/nahms/beefcowcalf/downloads/beef0708/Beef 0708_is_BullMgmt.pdf. Accessed September 30, 2017.

Vasconcelos J.L.M., O.G. Sá Filho, and R.F. Cooke. 2014. Impacts of Reproductive Technologies on Beef Production in South America. In: Lamb G., DiLorenzo N. (eds) Current and Future Reproductive Technologies and World Food Production. Advances in Experimental Medicine and Biology, vol 752. Springer, New York, NY.

Vraspir, R.A., A.R. Summers, D. O'Hare, L.D. Rowden, and R.N. Funston. 2013. Comparison of melengestrol acetate and controlled internal drug-release long-term progestin-based synchronization protocols on fixed-time artificial-insemination pregnancy rate in beef heifers. Prof. Anim. Sci. 26(6):575-579.

Walters, D.L. and E. Schallenberer. 1984. Pulsatile secretion of gonadotrophins, ovarian steroids and ovarian oxytocin during the periovulatory phase of the oestrous cycle in the cow. J. Reprod. Fertil. 71(2):503-12.

Webb, R., B.K. Campbell, H.A. Garverick, and D.G. Armstrong. 1999. Molecular mechanisms regulating follicular recruitment and selection. J. Reprod. Fertil. 54(Suppl.):33-48.

Webb, R.J., J.G. Gong, A.S. Law, and S. M. Rusbridge. 1992. Control of ovarian function in cattle. J. Reprod. Fertil. Suppl. 45:141-56.

Wettemann, R.P. and H.D. Hafs. 1973. Pituitary and gonadal hormones associated with fertile and nonfertile inseminations at synchronized and control estrus. J. Anim. Sci. 36:716721. 
Wettemann, R.P., H.D. Hafs, L.A. Edgerton, and L.V. Swanson. 1972. Estradiol and progesterone in blood serum during the bovine estrous cycle. J. Anim. Sci. 34:1020-1024.

Williams G., R. Stanko, C. Allen, R. Cardoso, L. Prezotto, J. Thorson, and M. Amstalden. 2012. Evidence that prostaglandin administration at the onset of a 5-day CO-Synch + CIDR synchronization protocol markedly improves fixed-time AI pregnancy rates in Bos indicus-influenced cattle. J. Anim. Sci. 89(E-Suppl. 1):264.

Williams, N.H., J. Patterson, and G. Foxcroft. Non-negotiables of gilt development. 2005. Advances in Pork Production. 16: 281.

Wiltbank, J. N. 1970. Increase proportion bred in first $21 \mathrm{~d}$, increase conception rate at $1^{\text {st }}$ service. Research Needs in Beef Cattle Reproduction. J. Anim. Sci. 31:755-762.

Wiltbank, J. N., R. P. Shumway, W. R. Parker, and D. R. Zimmerman. 1967. Duration of estrus, time of ovulation and fertilization rate in beef heifers synchronized with dihydroxyprogesterone acetophenide. J. Anim. Sci. 26:764-767.

Wiltbank, M.C. 1994. Cell types and hormonal mechanisms associated with mid-cycle corpus luteum function. J. Anim. Sci. 72:1873-83.

Wood-Follis, S.L., F.N. Kojima, M.C. Lucy, M.F. Smith, and D.J. Patterson. 2004. Estrus synchronization in beef heifers with progestin-based protocols I. Differences in response based on pubertal status at the initiation of treatment. Theriogenology. 62(8):1518-28.

Wood, S.L., M.C. Lucy, M.F. Smith, and D.J. Patterson. 2001. Improved synchrony of estrus and ovulation with the addition of GnRH to a melengestrol acetate-prostalandin $\mathrm{F}_{2 \alpha}$ synchronization treatment in beef heifers. J. Anim. Sci. 79:2210-2216.

Yelich, J.V. and G.A. Bridges. 2012. Synchronization response: Bos taurus vs. Bos indicus Cattle. In: Proc. Beef Improvement Federation. April 18-21. Houston, TX.

Yelich, J.V., R.D. Giesert, R.A. Schmitt, G.L. Morgan, and J.P. McCann. 1997. Persistence of the dominant follicle during melengestrol acetate administration and its regression by exogenous estrogen treatment in beef cattle. J. Anim. Sci. 75:745-754.

Zheng. W., G. Nagaraju, Z. Liu, and K. Liu. 2012. Functional roles of the phosphatidylinositol 3kinases (PI3Ks) signaling in the mammalian ovary. Mol. Cell. Endocrinol. 356(1-2):2430 .

Zimbleman, R.G., and L.W. Smith. 1966. Control of ovulation in cattle with melengestrol acetate. I. Effect of dosage and route of administration. J Reprod. Fertil. 11:185-191.

Zimbleman, R.G., J.W. Lauderdale, J.H. Sokolowski, and T.G. Schalk. 1970. Safety and pharmacologic evaluations of melengestrol acetate in cattle and other animals: A review. J. Am. Vet. Assoc. 157: 1528-1536. 


\section{VITA}

James William Cameron Locke was born on February 1, 1994 to Jason Locke and Charla Locke. The oldest of four sons, Cameron was raised on a large beef operation and was involved in all aspects of the operation from forage and row crop production to breeding cows and tagging calves. He attended the Stockton R-1 School district from kindergarten through high school, graduating in May of 2012. There he was an active member of extracurricular groups, was president of the Stockton FFA chapter, competed in public speaking, and was a member of a number of top-ten state FFA contest teams. Cameron completed a Bachelor of Science in Animal Sciences degree from the University of Missouri in 2015 and began classes at the MU College of Veterinary Medicine in August of 2015 to earn a Doctorate in Veterinary Medicine. He elected to pursue a Master of Science in Animal Science concurrent with the DVM degree under the guidance of Dr. David Patterson. Cameron's Master of Science degree was awarded in December, 2017. Upon graduation, he will return to the University of Missouri College of Veterinary Medicine, Class of 2020. 